\title{
Synchrotron Radiation Studies of Magnetic Materials and Devices
}

Wen Zhang 
SYNCHROTRON RADIATION STUDIES OF

MAGNETIC MATERIALS AND DEVICES

Wen Zhang 


\section{GRADUATION COMMITTEE}

\section{DEPUTY CHAIRMAN}

prof.dr.ir. G.J.M. Smit

CHAIRMAN \& SECRETARY

prof.dr.ir. A.J. Mouthaan

PROMOTOR

prof.dr.ir. W.G. van der Wiel

CO-PROMOTOR

prof. Y. Xu

ASSISTANT PROMOTOR

dr.ir. M.P. de Jong

\section{MEMBERS}

dr.ir. L. Abelmann

prof.dr.ing. A.J.H.M. Rijnders

prof.dr.ir. H.J.M. Swagten

prof. G. van der Laan
University of Twente, EWI

University of Twente, EWI

University of Twente, EWI

University of York

University of Twente, EWI

University of Twente, EWI

University of Twente, TNW

Eindhoven University of Technology

Diamond Light Source

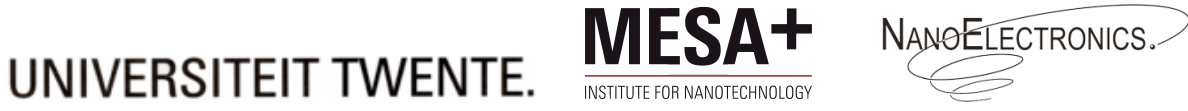

The work described in this thesis was performed at the NanoElectronics Group of MESA+ Institute for Nanotechnology, University of Twente, The Netherlands, and Spintronics and Nanodevice Laboratory, University of York, The United Kingdom. This research was financially supported by the European Research Council (ERC) and the UK Engineering and Physical Sciences Research Council (EPSRC).

\section{Cover design by Wen Zhang}

Copyright (C) 2012 by Wen Zhang, Enschede, the Netherlands.

All rights reserved.

Printed by Wöhrmann Print Service

ISBN: 978-90-365-3357-7

DOI: $10.3990 / 1.9789036533577$ 


\title{
SYNCHROTRON RADIATION STUDIES OF MAGNETIC MATERIALS AND DEVICES
}

\author{
DISSERTATION
}

\author{
to obtain \\ the degree of doctor at the University of Twente, \\ on the authority of the rector magnificus, \\ Prof. dr. H. Brinksma, \\ on account of the decision of the graduation committee, \\ to be publicly defended \\ on Friday 25 May 2012 at 12.45 hrs \\ by
}

Wen Zhang

born on 10 May 1981

in Jiangsu, China 
This dissertation has been approved by

the promotors: $\quad$ prof. dr. ir. W. G. van der Wiel

prof. Y. Xu

the assistent promotor: dr. ir. M. P. de Jong 
Dedicated to my family,

my parents Baoquan and Xun,

my brother Feiran,

and my husband Johnny 



\section{Contents}

1 Introduction 1

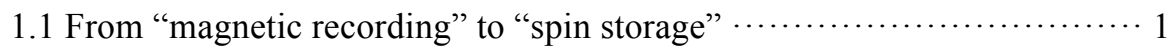

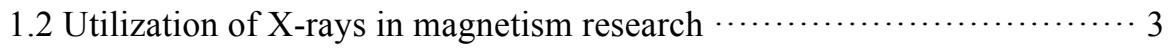

1.2.1 XMCD study on the origin of magnetocrystalline anisotropy $\cdots \cdots \cdots 3$

1.2.2 XPEEM imaging of current-driven magnetic domain wall motion $\cdots 4$

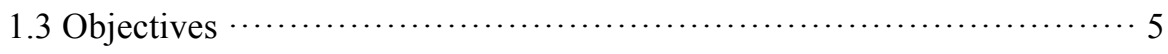

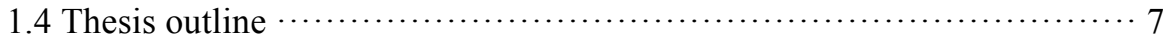

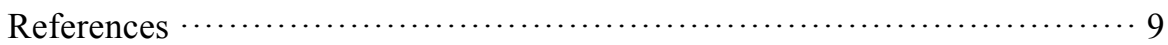

2 Experimental 11

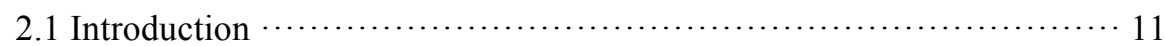

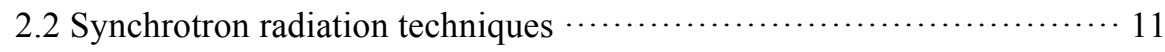

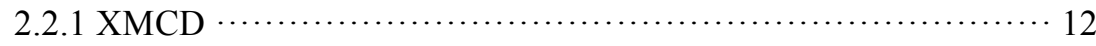

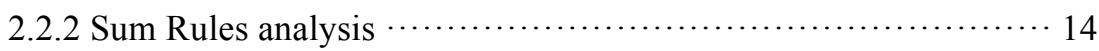




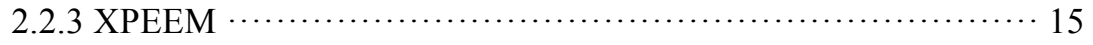

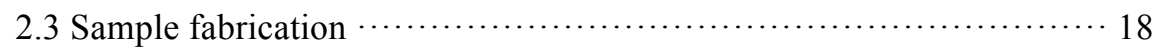

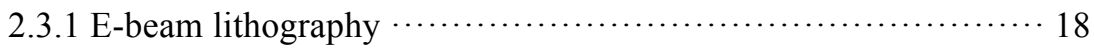

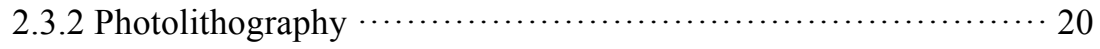

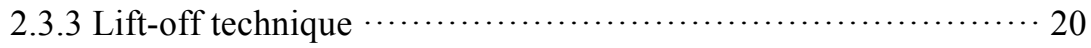

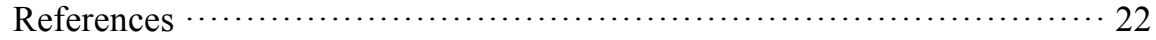

3 The relation between the Co orbital moment and magnetocrystalline anisotropy in $\mathrm{Co}_{80} \mathrm{Pt}_{20}$ :oxide thin films 23

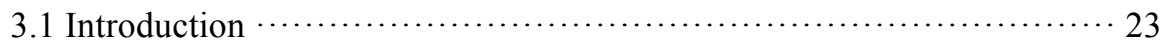

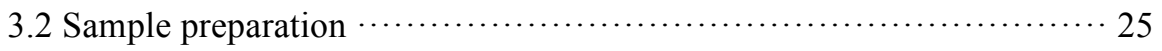

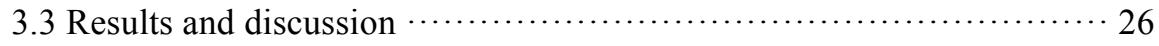

3.3.1 TEM measurement of oxide volume fraction and grain size $\cdots \cdots \cdot 26$

3.3.2 VSM results as a function of oxide volume fraction $\cdots \ldots \ldots \ldots \ldots 27$

3.3.3 XMCD results as a function of magnetic grain size $\cdots \cdots \cdots \cdots \cdots \cdots+28$

3.3.3.1 Magnetic anisotropy energy as a function of

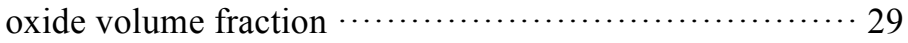

3.3.3.2 Co orbital anisotropy as a function of grain size $\cdots \cdots \cdots+\cdots 31$

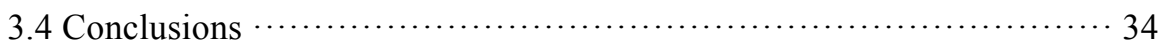

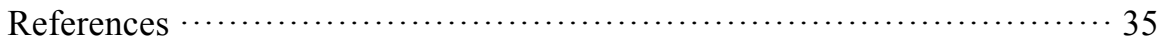

4 Observation of current-driven oscillatory domain wall motion in $\mathrm{Ni}_{80} \mathrm{Fe}_{20} / \mathrm{Co}$ bilayer nanowire

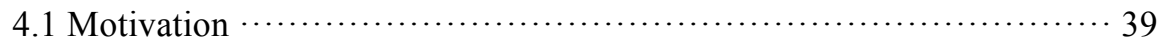

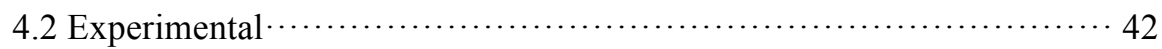




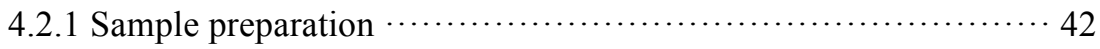

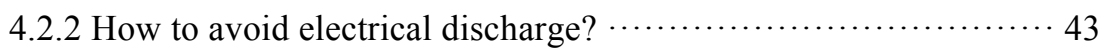

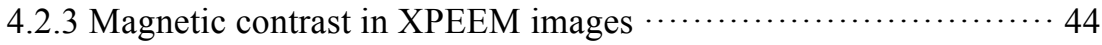

4.3 Oscillatory domain wall motion above the Walker limit $\cdots \cdots \ldots \ldots \ldots \ldots . \cdots, 45$

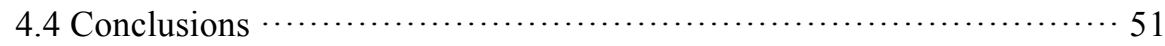

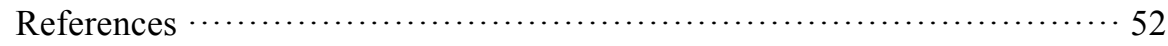

5 In-plane uniaxial magnetic anisotropy in epitaxial $\mathrm{Fe}_{3} \mathrm{O}_{4}$-based hybrid structure on GaAs(100)

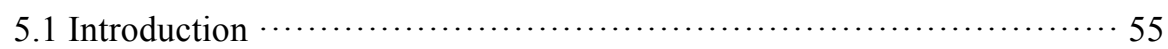

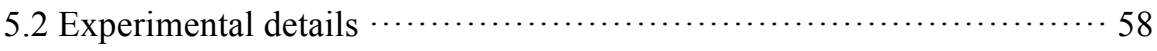

5.3 Anisotropy constants as a function of $\mathrm{Fe}_{3} \mathrm{O}_{4}$ thickness in $\mathrm{Fe}_{3} \mathrm{O}_{4} / \mathrm{GaAs} \cdots 61$

5.4 Anisotropy constants as a function of $\mathrm{MgO}$ thickness in

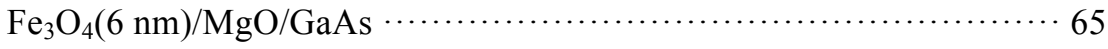

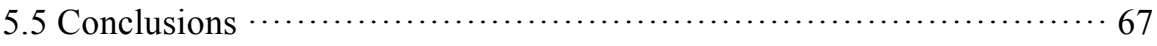

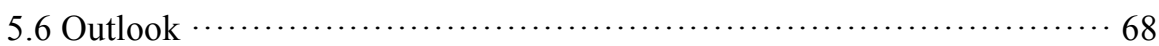

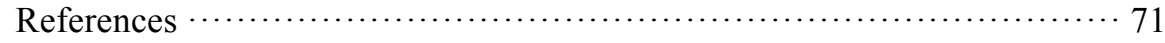

6 Enhanced magnetic anisotropy in FeGd thin films at low temperature 75

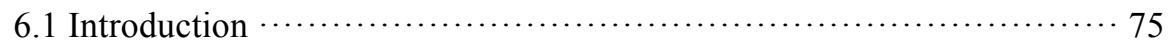

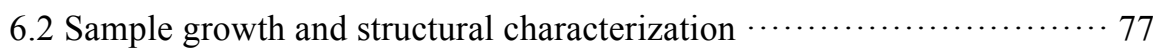

6.3 Magnetic characterization …...................................... 79

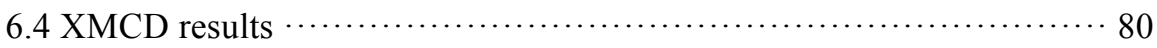

6.4.1 Element-specific XMCD hysteresis loops $\cdots \ldots \ldots \ldots \ldots \ldots \ldots \ldots \ldots \ldots \ldots \ldots \ldots \ldots \ldots$

6.4.2 Temperature-dependent Fe- and Gd orbital-to-spin moment 


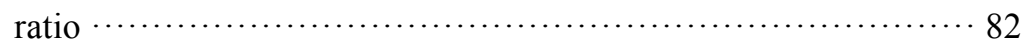

6.4.3 Fe- and Gd contribution to the macroscopic magnetization $\cdots \cdots \cdots 85$

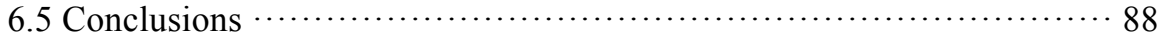

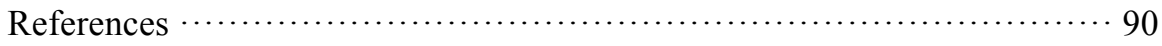

$\begin{array}{ll}\text { Summary } & 93\end{array}$

$\begin{array}{lr}\text { Samenvatting } & 97\end{array}$

$\begin{array}{ll}\text { Appendix } & 101\end{array}$

$\begin{array}{ll}\text { Acknowledgements } & 103\end{array}$

$\begin{array}{ll}\text { Author biography } & 107\end{array}$

$\begin{array}{lr}\text { Publications } & 109\end{array}$ 


\section{CHAPTER 1}

\section{Introduction}

\subsection{From "magnetic recording" to "spin storage"}

"Magnetism is one of the oldest phenomena studied in the history of natural science", 1 while it remains closely tied to applications. Today, the most advanced applications of magnetism are related to the technology underlying magnetic information storage and magnetic random access memory (magnetic RAM). ${ }^{2}$ As a leading technology in the field of data storage, ${ }^{3}$ magnetic recording has attracted great interest of research over decades, where magnetic fields are used to read and write the information stored on the magnetization of artificially engineered thin film structures, or in short, recording media. ${ }^{4}$

With the discovery of giant magnetoresistance (GMR) in allmetallic magnetic/non-magnetic multilayers, a new field of spintronics burst on the scene in $1988 .^{5}$ The physical origin of the GMR effect can be qualitatively understood based on the two-current 
model, in which the conduction electrons in ferromagnetic metals are divided into two spin subsystems: those whose spins are parallel to the magnetization of a given ferromagnet and those whose spins are antiparallel. Such a model holds, because spin flip scattering is rare compared to spin conserving scattering events on the time scale relevant for transport. Accordingly, when there are dissimilar scattering rates in the spin subchannels, the total scattering rate or the resistance of a given magnetic multilayer with non-magnetic metal spacers depends on the relative orientation of the magnetization in the ferromagnetic layers, which can be tuned by the external magnetic field.

Most of the present memory devices under development are based on conventional magnetic field data writing, which required ultra-fine processes, large writing currents, and were not easily scalable due to cross-talk between neighboring memory bits. ${ }^{7}$ To overcome these disadvantages of the magnetic field data writing, the so-called spin transfer torque (STT) writing technology has attracted great attention over the last few years.

STT is a magnetic phenomenon in which spin-polarized currents can be used to alter the magnetic state of a ferromagnet. STT-RAM is widely regarded as a major candidate among next-generation principles for new memory devices. The STT effect utilizes the transfer of angular momentum from a spin-polarized current to the magnetization of a ferromagnetic lattice to invert this magnetization, and writes data at very low power levels. As recently demonstrated, the STT effect can also be used to "de-pin" and displace a magnetic domain wall (DW) in a single layer nanostructure by injecting current pulses. The effect has shown potential for achieving fast and reproducible switching in nanoscale elements, in particular in the context of new memory- and logic devices based on DW propagation. In the near future, magnetic mass storage could rather depend on DW-based devices, which are conceptually close to former bubble magnetic memories. ${ }^{8}$

In short, the GMR effect opened a way to control charge transport through magnetization, while the STT effect offers an opportunity to control magnetization by spin transport, which closes the loop for a data storage paradigm shift from "magnetic recording" to "spin storage". 6 


\subsection{Utilization of $\mathrm{X}$-rays in magnetism research}

The goal of developing, understanding, and controlling the magnetic world, especially down to the nanoscale, is accompanied by the development of new experimental techniques offering capabilities that could not be afforded by conventional techniques. We can see from the two examples below that polarized X-rays provide us with unprecedented opportunities to get to the bottom of long-standing as well as novel problems in magnetism.

\subsubsection{XMCD study on the origin of magnetocrystalline anisotropy}

Giant perpendicular magnetization anisotropy mainly stems from magnetocrystalline anisotropy, an atomic effect correlated to the symmetry of the atomic environment. ${ }^{6}$ Bruno has predicted a proportional relationship between the magnetocrystalline anisotropy energy and the anisotropic orbital moment (AOM), ${ }^{9}$ the applicability of which has been demonstrated experimentally by Weller et al. in $\mathrm{Au} / \mathrm{Co} / \mathrm{Au}$ sandwiches, where the perpendicular magnetization anisotropy is a consequence of a large anisotropy of the Co orbital moment. ${ }^{10}$

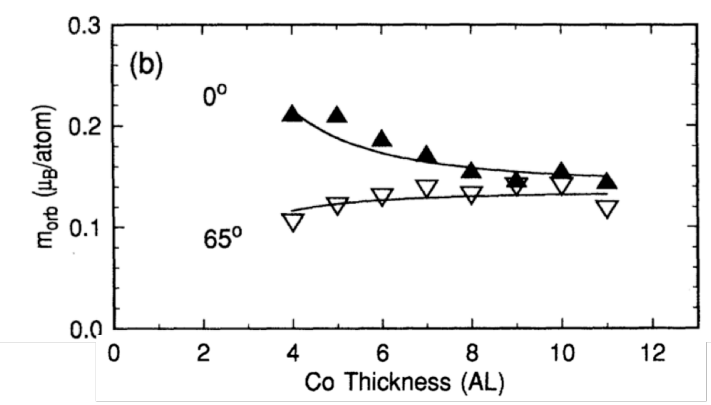

FIG. 1.1: Orbital moments under different geometries, derived from XMCD spectra by sum rules, as a function of Co thickness. ${ }^{10}$

Angle-dependent XMCD combined with sum rules analysis ${ }^{11}$ is 
an effective tool ${ }^{12-14}$ to evaluate the spin- and orbital moments, and therefore the AOM. In Weller's work, the XMCD measurements were carried out at room temperature as a function of Co thickness in two different geometries: the spectra were recorded at the Co $L_{2,3}$ edges in a $1 \mathrm{~T}$ external magnetic field parallel to the X-ray propagation direction, at angles $\gamma=0^{\circ}$ and $65^{\circ}$ with respect to the surface normal.

The orbital moments extracted from the XMCD spectra in two directions are shown in Fig. 1.1. A clear anisotropy is found for the orbital moment in the $\gamma=0^{\circ}$ relative to the $\gamma=65^{\circ}$ data at the thin edge of the Co wedge, ${ }^{15}$ and this anisotropy decays rapidly as Co thickness increases from $4 \mathrm{AL}$ to $7 \mathrm{AL}$, which is in accordance with the decreased magnetic anisotropy.

\subsubsection{XPEEM imaging of current-driven magnetic DW motion}

The application of different high resolution imaging techniques allows one to determine the nanoscale DW spin structures. Synchrotron radiation based magnetic imaging techniques, such as XMCD in photoemission electron microscopy (XPEEM) and transmission X-ray microscopy (TXM), have proven to be powerful techniques ${ }^{16}$ for the investigation of geometrically confined magnetic DWs and their dynamics due to the interaction with fields and spinpolarized currents.

(a)

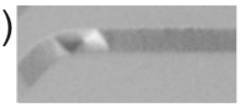

(b)

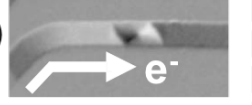

(c)

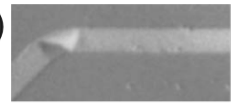

(d)

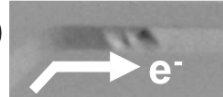

FIG. 1.2: XPEEM images taken before and after a current pulse of duration $25 \mu$ s and density $j \approx 10^{12} \mathrm{~A} / \mathrm{m}^{2}$. (a)-(b) For $j<1.05 \times 10^{12}$ $\mathrm{A} / \mathrm{m}^{2}$, the DW motion occurs without spin-structure transformations. (c)-(d) For $j>1.05 \times 10^{12} \mathrm{~A} / \mathrm{m}^{2}$, vortex-core nucleation and annihilation, and propagation of multi-vortex walls occur. ${ }^{17}$ 
Figures 1.2(a)-(d) show XPEEM images recorded before and after a $25 \mu$ s current pulse with a current density $j$ of up to $1.4 \times 10^{12}$ $\mathrm{A} / \mathrm{m}^{2}$, where they found that the current pulses displace the DWs in the direction of the electron flow. ${ }^{17}$ One more message delivered from Fig. 1.2 is the DW structural transformation above the so-called Walker limit. Below this limit, the DW can propagate in the magnetic strip without changing its structure, while above that the DW structure collapses and undergoes a series of complex cyclic transformations which results in a drastic reduction of the average DW speed. ${ }^{18}$ When $j$ is smaller than $1.05 \times 10^{12} \mathrm{~A} / \mathrm{m}^{2}$, the DW moves from Fig. 1.2(a) to (b), with its spin structure remaining as the vortex wall which is the lowest energy domain structure for this wire geometry in a width on the order of a few hundred $\mathrm{nm} .{ }^{19}$ When $j$ is larger than $1.05 \times 10^{12} \mathrm{~A} / \mathrm{m}^{2}$, the DW propagates from Fig. 1.2(c) to (d), accompanied by a structural transformation, as shown in Fig. $1.2(\mathrm{~d}){ }^{21}$ Therefore, $j \approx 1.05 \times 10^{12} \mathrm{~A} / \mathrm{m}^{2}$ corresponds to the onset of structural DW transformations as well as a deviation from the linear behavior of the DW motion velocity versus $j$, i.e., the Walker threshold current density.

\subsection{Objectives}

This $\mathrm{PhD}$ thesis investigates both conventional and novel magnetic materials that aim to meet the requirements needed for future data storage or spintronic applications, using mainly synchrotron radiation based techniques, namely, XMCD and XPEEM. The purpose is to gain a better understanding of several basic but timely issues, as detailed below, regarding conventional magnetic recording media as well as advanced DW-based memory devices, utilizing the advantage of synchrotron radiation techniques. The main objectives of this work are to address the following questions:

(A) In order to meet the requirements for high-density recording, different kinds of oxides have been incorporated into CoPt-based recording media to obtain smaller grain sizes. ${ }^{20,21}$ However, the problem arises simultaneously with how to retain the large magnetocrystalline anisotropy in order to resist thermally activated magnetization reversal. Using angle-dependent $\mathrm{XMCD}$, we aim to 
find out how the anisotropy of Co orbital moments is related to the magnetocrystalline anisotropy from a microscopic point of view, leading to a better understanding of the mechanism underlying the large magnetocrystalline anisotropy. A range of suitable oxide contents to realize an optimized combination of small grain size, high signal/noise ratio, and high thermal stability will be given.

(B) There are two important issues that need to be addressed to make a viable STT memory device based on DWs:

(i) High $D W$ velocities. At this point, the detailed process involved in DW motion is an important issue, i.e., the dynamics of DW displacements where the wall propagates a distance much larger than its lateral extent. ${ }^{22}$ XPEEM is a powerful tool to investigate the spin structures of nanoscale magnetic DWs, as well as their position and dynamics. In this work, XPEEM imaging is used to obtain a clear picture of DW motion in magnetic nanowires excited by nanosecond pulses, and a phenomenological model will be given for general cases.

(ii) Reduced threshold current. It has been theoretically predicted that the threshold current of DW motion due to an intrinsic pinning, $j_{\mathrm{C}}$, has the relation with the spin polarization $P$, as $j_{\mathrm{C}} \propto 1 / P$. ${ }^{23}$ Accordingly, a reduction in the threshold current may be realized when the current is highly polarized by utilizing magnetic materials with a high degree of spin polarization. Magnetite is one of such materials, combining a high Curie temperature with a high spin polarization of up to $\approx 80 \%$ at room temperature. ${ }^{24} \mathrm{We}$ have succeeded in growing single-crystal magnetite thin films that exhibit an in-plane uniaxial magnetic anisotropy. ${ }^{25}$ Such thin films have been tailored into nanoscale structures, where the magnetic domains are formed under the joint effects of shape- and intrinsic (magnetocrystalline) anisotropies of the films. With these nanostructures made of magnetite, we expect to obtain a relatively low threshold current density to drive the DW, which is crucial for the operation of future DW devices. 


\subsection{Thesis outline}

Chapter 2: The experimental methods used in this thesis are described, including the nanofabrication techniques and synchrotron radiation techniques.

Chapter 3: Angle-dependent XMCD spectra and magnetic hysteresis loops were taken at the $\mathrm{Co} L_{2,3}$ edges of $\mathrm{Co}_{80} \mathrm{Pt}_{20}$ :oxide perpendicular magnetic recording thin films. The magnetic anisotropy energy of the Co atoms, which is the main source of the magnetocrystalline anisotropy of the CoPt magnetic grains, has been determined directly from these element-specific hysteresis loops. While a larger oxide percentage helps to achieve a smaller grain size, we found that it reduces the magnetocrystalline anisotropy as demonstrated unambiguously from direct measurements of the magnetic anisotropy energy of the Co atoms. The microscopic origin of this phenomenon in the studied films can be attributed to an increasingly isotropic orbital moment with decreasing grain size, which arises from a more pronounced effect of symmetry breaking at the grain-oxide interface in smaller grains. Our results suggest that these $\mathrm{Co}_{80} \mathrm{Pt}_{20}$ :oxide films, with oxide volume fractions between $19.1 \%$ and $20.7 \%$, are suitable candidates for high-density magnetic recording.

Chapter 4: Direct observation by XPEEM of current-driven oscillatory domain wall motion above the Walker breakdown is reported in $\mathrm{Ni}_{80} \mathrm{Fe}_{20} / \mathrm{Co}$ nanowire, showing micrometer-scale displacement at $\sim 13 \mathrm{MHz}$. We identify two emerging key factors that enhance the oscillatory motion: $(i)$ increase of the hard-axis magnetic anisotropy field value $\left|H_{\Perp}\right|$; and (ii) increase of the non-adiabatic spintransfer parameter to the Gilbert damping factor ratio, $\beta / \alpha$, which is required to be larger than 1 . These findings point to an important route to tune the long-scale oscillatory domain wall motion using the appropriate geometry and materials.

Chapter 5: The evolution of the in-plane magnetic anisotropies has been studied and explained for the first time in $\mathrm{Fe}_{3} \mathrm{O}_{4} / \mathrm{GaAs}(100)$ and $\mathrm{Fe}_{3} \mathrm{O}_{4} / \mathrm{MgO} / \mathrm{GaAs}(100)$ hybrid spintronic structures. The surface- and volume contributions to the in-plane cubic- and uniaxial anisotropies have been distinguished in $\mathrm{Fe}_{3} \mathrm{O}_{4} / \mathrm{GaAs}$ by fitting the anisotropy 
constants, measured by ferromagnetic resonance, as a function of magnetic film thickness. It has been found that the interfacial chemical bonding rather than strain relaxation plays the dominant role in causing the unexpected uniaxial magnetic anisotropy in $\mathrm{Fe}_{3} \mathrm{O}_{4}$ films grown directly on GaAs surfaces. On the other hand, after insertion of a $\mathrm{MgO}$ barrier, the uniaxial anisotropy is strongly reduced. Strain relaxation in the magnetic layer is found to be the main origin of the uniaxial magnetic anisotropy in the $\mathrm{Fe}_{3} \mathrm{O}_{4} / \mathrm{MgO} / \mathrm{GaAs}$ structure.

Chapter 6: Recently, rare-earth dopants have also been used to alter the spin-transfer velocity and the critical current in permalloy nanowires, due to their effects on the material properties. It is noteworthy that relatively soft magnetism is usually desirable in domain-wall-based devices, to allow for tailoring via shape anisotropy. We performed, in this chapter, a temperature-dependent XMCD study on a series of FeGd thin films with in-plane easy magnetization for a Gd doping concentration of no more than $20 \%$. A strong enhancement in the magnetic anisotropy of these films is demonstrated at low temperature, and two possible origins have been evidenced by transmission electron microscopy, i.e., the presence of $\mathrm{Fe}$ clusters and Gd-Fe clusters. These findings demonstrate the possibilities for engineering magnetic properties by dissolving rareearth atoms into transition-metal lattices even when the rare-earth doping $\leq 20 \%$. 


\section{References}

${ }^{1}$ S. Chikazumi, Physics of Ferromagnetism (Clarendon press. Oxford 1997).

2 S. X. Wang, A. M. Taratorin, Magnetic Information Storage Technology (Academic, New York, 1999).

${ }^{3}$ B. Azzerboni, G. Asti, L. Pareti, and M. Ghidini, Magnetic Nanostructures in Modern Technology (Springer, Catona, 2008).

${ }^{4}$ H. J. Richter, J. Phys. D: Appl. Phys. 32, R147 (1999).

5 P. Grünberg, Magnetic field sensor with ferromagnetic thin layers having magnetically antiparallel polarized components, US patent 4949039 (1990).

${ }^{6}$ C. Chappert, A. Fert, and F. Nguyen Van Dau, Nature Materials 6, 813 (2007).

${ }^{7}$ M. Stiles, and J. Miltat, in Spin Dynamics in Confined Magnetic Structures III (eds. B. Hillebrands, and A. Thiaville) (Springer, Berlin, 2006).

${ }^{8}$ A. Hubert, and R. Schafer, in Magnetic Domains (Springer, Berlin, 1998).

${ }^{9}$ P. Bruno, Phys. Rev. B. 39, 865 (1989).

${ }^{10}$ D. Weller, J. Stöhr, et al., Phys. Rev. Lett. 75, 3752 (1995).

${ }^{11}$ B. T. Thole, P. Carra, F. Sette, and G. van der Laan, Phys. Rev. Lett. 68, 1943 (1992).

12 H. A. Dürr, S. S. Dhesi, E. Dudzik, D. Knabben, G. van der Laan, J. B. Goedkoop, and F. U. Hillebrecht, Phys. Rev. B. 59, R701 (1999).

13 E. Dudzik, H. A. Dürr, S. S. Dhesi, G. van der Laan, D. Knappen, and J. B. Goedkoop, J. Phys.: Condens. Matter. 11, 8445 (1999).

${ }^{14}$ N. Weiss et al., Phys. Rev. Lett. 95, 157204 (2005).

${ }^{15}$ J. Stöhr, J. Magn. Magn. Mater. 200, 470 (1999).

16 J. Stöhr, and H. C. Siegmann, Magnetism: From Fundamentals to Nanoscale Dynamics (Springer 2006).

${ }^{17}$ T. A. Moore, M. Kläui, Phys. Rev. B. 80, 132403 (2009).

${ }^{18}$ M. Yan, et al., Phys. Rev. Lett. 104, 057201 (2010). 
${ }^{19}$ M. Kläui, J. Phys.: Condens. Matter. 20, 313001 (2008).

${ }^{20}$ S. N. Piramanayagam, et al., Appl. Phys. Lett. 89, 162504 (2006).

${ }^{21}$ H. S. Jung, et al., IEEE. Trans. Magn. 43, 2088 (2007).

22 M. Kläui., in Magnetism and Synchrotron Radiation, Springer Proceedings in Physics 133, Ch. 13, p. 367 (Springer-Verlag, Berlin, Heidelberg, 2010).

${ }^{23}$ G. Tatar, and H. Kohno, Phys. Rev. Lett. 92, 086601 (2004); G. Tatara, et al., J. Phys. Soc. Jpn. 75, 064708 (2006).

${ }^{24}$ Y. S. Dedkov, et al., Appl. Phys. Lett. 80, 4181 (2002).

${ }^{25}$ Y. X. Lu, et al., Phys. Rev. B. 70, 233304 (2004) ; W. Zhang, et al., Phys. Rev. B. 84, 104451 (2011). 


\section{Experimental}

\subsection{Introduction}

In this chapter, we give a description of major experimental techniques that underpinned the work in this thesis. The chapter is organized as two main sections: Section 2.2 is devoted to the synchrotron radiation techniques applied in the following four chapters, and Section 2.3 present the fabrication techniques used to obtain the samples for Chapter 4.

\subsection{Synchrotron radiation techniques}

The development of synchrotron radiation sources through the second half of the 20th century has introduced the possibility of utilizing high-intensity, polarized photons with tunable energy typically from 
the UV- to hard X-ray regime in scientific experiments. Synchrotron radiation is produced when electrons that have been accelerated to ultrarelativistic speeds, i.e. close to the speed of light, are radially accelerated in an electromagnetic field. In a so-called electron storage ring, this radiation is emitted in a fan of photons as electrons travel through bending magnets distributed around the ring. In addition, radiation can be produced by periodic acceleration in special insertion devices, such as undulators or wigglers. A bending magnet offers a cheap and reliable radiation source, and is required to maintain the circular path in modern synchrotrons. An undulator is made up of a series of permanent magnets, which cause the electrons to move in a sinusoidal type motion, ejecting photons perpendicular to the direction of the applied field and parallel to the net particle direction.

For magnetic investigations, variable polarization, from right circular to left circular, is required, as well as a precisely variable energy range. Concerning transition metal ferromagnets, the $L_{3}$ - and $L_{2}$ edges are often favored since these peaks correspond to $2 p$ core electrons, excited into the unoccupied $3 d$ states, allowing direct investigation of the magnetically polarized $3 d$ band. The energies for these peaks lie in the soft X-ray region between 500 and $1000 \mathrm{eV}$ and hence all beamlines and related experimental equipment operate at ultra-high vacuum, or high vacuum.

\subsubsection{XMCD}

$\mathrm{X}$-ray magnetic circular dichroism (XMCD) is an element-specific probe for the spin- and orbital magnetic moments. It has the ideal capabilities to study element-specific magnetism in a given material ranging from simple element films to complex alloys and compounds. ${ }^{1}$ For example, XMCD combined with sum rules analysis $^{2}$ has been successfully used to study changes in the spin- and orbital moments and the magnetic anisotropy of Co particles. ${ }^{3-5}$

The working principle of XMCD is regarded as a magnetooptical effect, similar to the Faraday and Kerr effects. ${ }^{6}$ The latter are usually performed in the regime of visible light and thus the probed magnetic information is confined substantially within the valenceand conduction bands, owing to the excited optical transitions of samples by low energy photons of only a few eV. In contrast, XMCD 
has the advantage of tunable energy (and polarization) of X-rays, which makes magneto-optical studies involving core-level states of a given material possible. Since core levels of different elements are energetically well separated, the technique can probe element-specific magnetic properties. XMCD makes use of the absorption of circularly polarized X-rays near the resonant absorption edges of magnetic elements. The term dichroism refers to different absorption of rightand left circularly polarized light of a material. For $3 d$ transition metals, which we are mostly interested in, the X-ray absorption spectroscopy (XAS) is usually taken at the $L_{2,3}$ edges, using soft Xrays with an energy between 500 and $1000 \mathrm{eV}$.

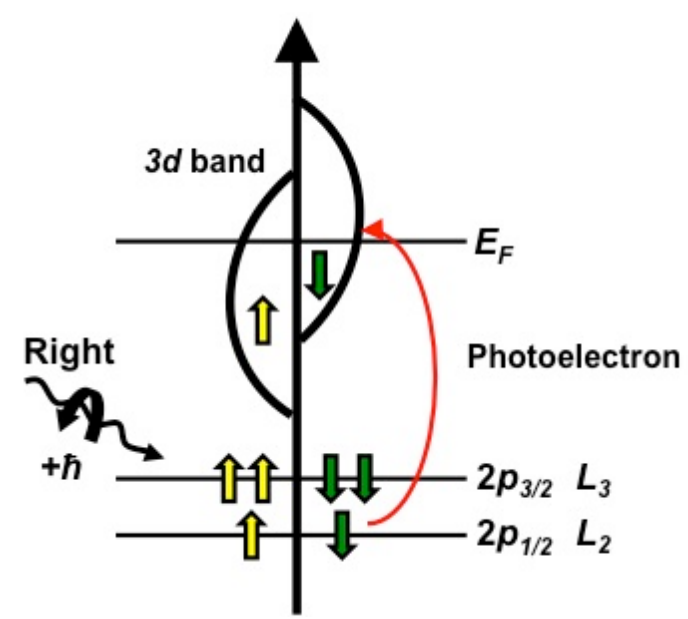

FIG. 2.1: Schematic diagram illustrating the principle of XMCD. The $3 d$ valence band of the transition metal is assumed to be Stoner paraboliclike, and the two subbands are split by the exchange interaction.

As shown in Fig. 2.1, a right circularly polarized photon carrying an angular momentum of $\hbar$ excites a photoelectron, and transfers its momentum to the photoelectron. If the photoelectron originates from a spin-orbit split band such as the $2 p_{1 / 2}\left(L_{2}\right)$ or the $2 p_{3 / 2}\left(L_{3}\right)$ edge of a $3 d$ transition metal, the angular momentum of the photon can be transferred partly to the spin of the electron via the spin-orbit coupling. Left circular photons transfer the opposite angular momentum to the electrons as right circular photons do, 
resulting in photoelectrons with opposite spins. Due to the opposite spin-orbit coupling in $2 p_{3 / 2}\left(L_{3}\right)$ and $2 p_{1 / 2}\left(L_{2}\right)$ levels, the spin polarization of the excited electrons will be opposite at the two edges, which allows for separating the spin- and orbital moments. Since the $d$-band of transition metals is also spin polarized, it acts as a spin detector. The difference in detected absorption between left and right circularly polarized light gives the XMCD signal.

As one of the commonly adopted detection modes for $\mathrm{XMCD}^{8}$, the total electron yield (TEY) mode measures the number of electrons escaping from the surface as a result of X-ray absorption processes. Besides Auger electrons produced via relaxation of core holes, the TEY signal contains secondary electrons as well, which are created by inelastic scattering of Auger electrons. When these secondary electrons are created deeper in the sample than the escape depth, they cannot be detected, making the TEY detection mode surface sensitive. The emitted electrons are lost from the sample and are drained away through a grounded vacuum chamber. A drain current from the ground to the sample plate replaces these electrons and this current is directly measured with a high-sensitivity pico-ammeter.

\subsubsection{Sum Rules analysis}

The method of Sum Rules analysis used in this thesis was developed from the theoretical approach of a group of researchers including Thole, Carra, Sette, Van der Laan, Wang and Altarelli in the early 1990s. ${ }^{9,10}$ A practical method of applying the Sum Rules to experimental data was then developed in 1995 by Chen et al. ${ }^{11}$ The process of calculating the orbital- and spin moments using the XMCD sum rules involves finding the solutions to Eq. (2.1a) and Eq. (2.1b), where $m_{\mathrm{S}}$ and $m_{\mathrm{L}}$ define the values for the spin- and orbital moments, respectively:

$$
\begin{aligned}
& m_{S}=\frac{n(4 q-6 p)}{r P} \\
& m_{L}=\frac{4 q n}{3 r P}
\end{aligned}
$$

The parameters $p$ and $q$, are derived from the integrals of the 
dichroic signal; and $r$ is derived from the sum of the two XAS signals recorded for opposite alignment between the photon helicity and magnetization of the sample, after removal of a fitted, stepped background. To be more precise: $p$ is the integral of the dichroic signal of the $L_{3}$ peak alone, $q$ is the integrated dichroism over both the $L_{3}$ - and $L_{2}$ edges, and $r$ represents the total area under the XAS $L_{3}$ and $L_{2}$ edges, as illustrated in Fig. 2.2. The other two parameters used in the sum rules equations, $n$ and $P$, correspond to the number of holes and the beam polarization. The number of holes used for the transition metals $\mathrm{Fe}$ and $\mathrm{Co}$ in this thesis is based on the calculations made for ultrathin $\mathrm{Fe}$ and Co films by Christian Teodorescu, formerly of Daresbury's magnetic spectroscopy group.

\subsubsection{XPEEM}

The photoemission electron microscope (PEEM) has been developed to study the surface and thin-film properties of various materials. Combining the power of synchrotron radiation spectroscopy with the imaging capabilities of PEEM, XPEEM ${ }^{12}$ offers a variety of possibilities such as topographic, elemental, chemical and magnetic measurements.

XPEEM is a surface-sensitive technique, based on the principle of X-ray-in/electrons-out ${ }^{13}$, where secondary electrons are used to image a sample. Most of the signal is generated in the top 2-5 nanometers. The working principle is similar to electron microscopy and the schematics are shown in Fig. 2.3.

In an XPEEM system, a monochromatic X-ray beam is moderately focused, typically to tens of micrometers. When monochromatic X-rays are impinging on the sample, all points on the sample surface will absorb the X-rays and create excited electrons.

The electrons are accelerated by a strong electric field between the sample and the outer electrode of the objective lens, to typically 10-30 keV. Then, a series of projection lenses is often used to magnify the intermediate image further and form a final image on a CCD camera. 

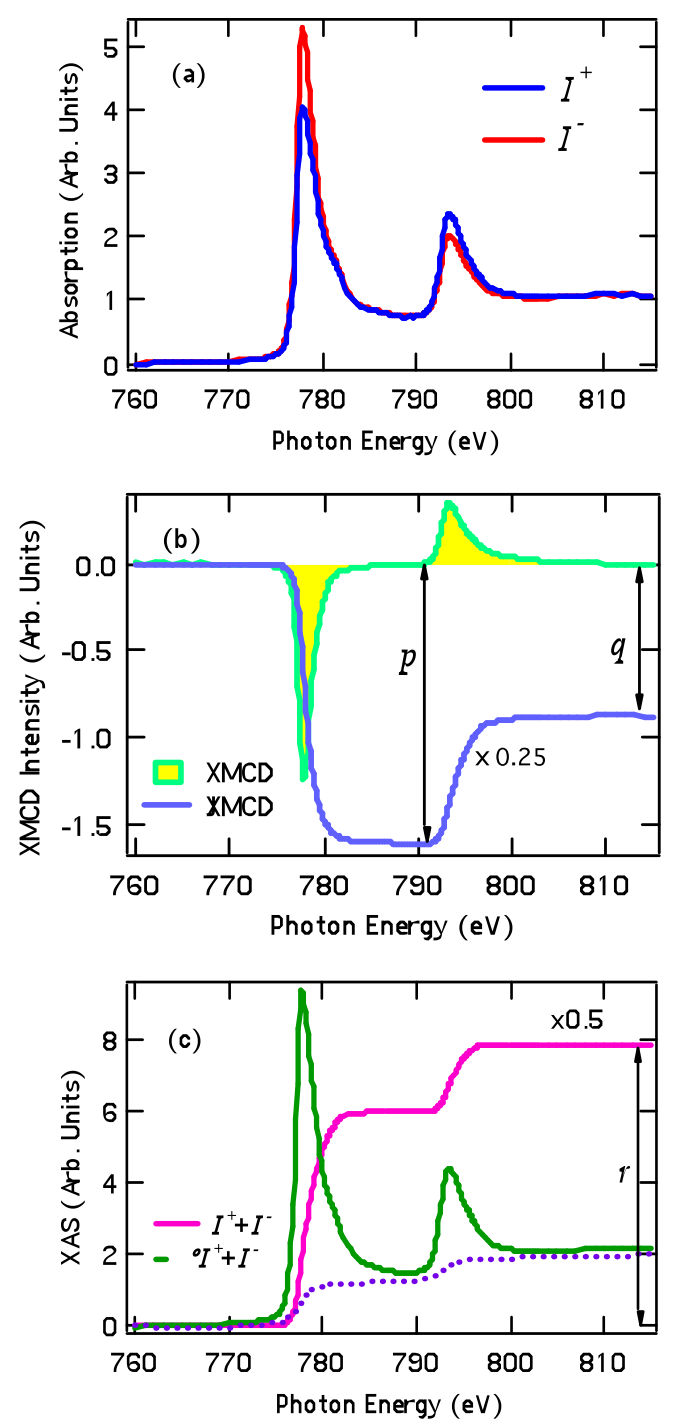

FIG. 2.2: Graphs illustrating the practical application of the Sum Rules constants $p, q$ and $r$. (a) Left- and right circularly polarized XAS spectra; (b) XMCD and (c) summed XAS spectra and their integrals. The dotted line shown in (c) is the two-step-like function for edge-jump removal before the integration. The $p, q$ and $r$ correspond to the integral of the dichroism spectra for the $L_{3}$ edge, the integral of the dichroism spectra over both the $L_{3}$ and $L_{2}$ edges shown in (b) and the area of the summed XAS signal after removal of a stepped background shown in (c), respectively. 


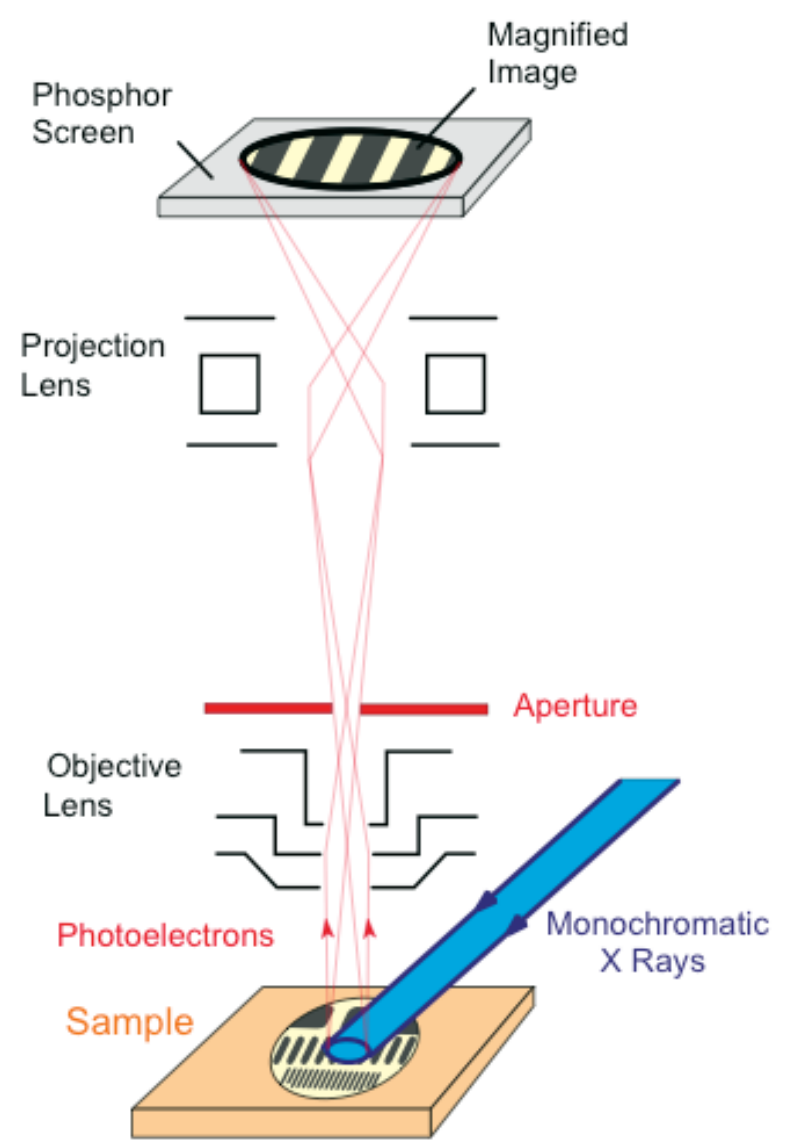

FIG. 2.3: Schematics of XPEEM. An area of the sample is illuminated with polarized X-rays. These X-rays excite photoelectrons and Auger electrons, which in turn produce secondary electrons in the sample. Electron optics is then used to gather the electrons that escape the sample and to reconstruct an image of where the electrons originated. Depending on the mode used for the measurement, an elemental, chemical, or magnetic image of the sample can be constructed. ${ }^{8}$

Most XPEEM microscopes do not incorporate an energy analyzer or filter. Therefore, all photoelectrons are detected in principle. In practice, the electron intensity is dominated by the secondary electron tail in the $0-20 \mathrm{eV}$ kinetic energy range, where zero kinetic energy corresponds to the work function of the sample. The secondary electron intensity determines the XPEEM intensity, and the large yield of secondary electrons upon exposure to X-rays 
provides a suitably large signal.

The excitation energy resolution is determined by the X-ray monochromator in the beamline and the spatial resolution is determined by the electron optics. An aperture in the back focal plane is used to select the low-energy secondary electrons within the electron path. The spatial resolution of XPEEM can be adjusted by the size of the aperture. Our XPEEM measurements were carried out at Beamline 7.3.1 and 11.0.1 of the Advanced Light Source in the Lawrence Berkeley National Laboratory, Berkeley, CA. Using the smallest available aperture, a resolution of the PEEM-2 station $(7.3 .1)^{14}$ of $60 \mathrm{~nm}$ was achieved at best without aberration correction, and that for the PEEM-3 station (11.0.1) was about $20 \mathrm{~nm}$.

\subsection{Sample fabrication}

\subsubsection{E-beam lithography}

Due to the required feature size (zigzag nanowires of $500 \mathrm{~nm}$ width), e-beam lithography has to be used. The basic setup is similar to that of a conventional scanning electron microscope (SEM), as shown in Fig. 2.4.

A conventional SEM consists of an electron optical column and a sample chamber under vacuum. The electron gun consists of an electron source, usually a tungsten filament or a lanthanum hexaboride crystal $\left(\mathrm{LaB}_{6}\right)$, and an anode to accelerate the electrons, which generates an electron beam of controlled energy ranging from $2 \mathrm{keV}$ to $40 \mathrm{keV}$. The electron beam is focused by one or two condenser lenses to a spot of about $2 \mathrm{~nm}$ to $10 \mathrm{~nm}$ in diameter, and then scanned in a raster over a region of the specimen by the scan coils. The most important SEM signals are those produced by secondary electrons and backscattered electrons.

In e-beam lithography, a focused beam of electrons is used to write a pattern into a resist layer. The e-beam lithography system used in this thesis work is a RAITH 50 e-beam writer, which is based on a SEM system with additional hardware and pattern generating software. The RAITH 50 system can produce structures with a minimum feature size smaller than $100 \mathrm{~nm}$, in a writing field of up to $400 \times 400 \mu \mathrm{m}^{2}$. 


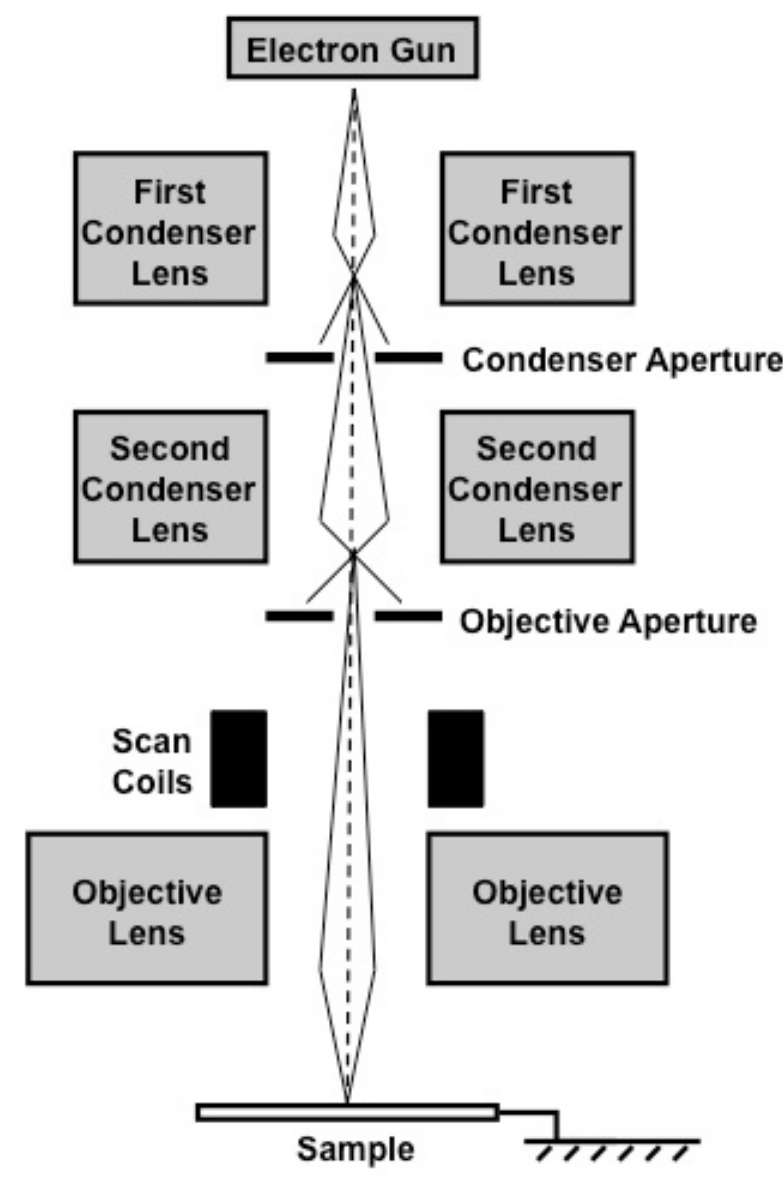

FIG. 2.4: Schematic diagram containing the principal components and the mode of operation of a conventional SEM. The components and their function are discussed in the text.

The e-beam resist used in our experiment is poly-methyl methacrylate, abbreviated as 950PMMA. The substrate is coated by covering it with a $4 \%$ solution of 950PMMA in anisole and spinning at $5000 \mathrm{rpm}$ for $40 \mathrm{~s}$ for obtaining the desired nanostructures. The pattern is then written into the resist by exposure to the e-beam as described previously. The exposed resist is developed for $29 \mathrm{~s}$ in a solution of methylisobutyl ketone (MIBK) 1:3 isopropanol (IPA), and for $30 \mathrm{~s}$ in IPA. 


\subsubsection{Photolithography}

In this thesis work, photolithography is used to fabricate bond pads for electrical contacting of the nano-objects. First, the whole sample is covered with S1813 photoresist. The resist is usually spun onto the samples using a spin coater with a speed of $3500 \mathrm{rpm}$ for $40 \mathrm{~s}$. The spinning operation provides a uniform coating of the resist and also pre-dries the resist solution, so that it no longer flows after spinning ceases.

Then the sample is baked at $105{ }^{\circ} \mathrm{C}$ for $1 \mathrm{~min}$, which removes the moisture and solvents that remained in the film after spinning. This also hardens the resist and improves adhesion to the substrate.

After soaking in chlorobenzene for $1 \mathrm{~min}$ to harden the resist, the sample is put on a mask aligner with a photomask on the top. The mask aligner serves for two main purposes:

(i) It provides a means to align a pattern on a sample to the pattern on a mask.

(ii) It exposes the sample to UV-light through the pattern on the photomask. The mask thus contains a real-size image of the pattern to be transferred to the resist, consisting of transparent and opaque portions, thus allowing the light to pass only through the transparent portions. After exposure to ultraviolet light, the resist is developed in MF319 for $1 \mathrm{~min}$.

This is followed by thermal evaporation of metals, and lift-off in acetone. The device thus obtained after deposition of electrical measurement pads is then scribed and placed on a chip. The electrical measurement pads are connected to the pins of the chip by use of a bonding machine to allow for electrical measurements.

\subsubsection{Lift-off technique}

The nanostructures discussed in Chapter 4 were fabricated using a lift-off process, which is shown schematically in Fig. 2.6.

A thin layer of electron-beam (e-beam) resist or photoresist is coated onto the surface of the substrate and forms a positive mask, as shown in Fig. 2.6(a). The desired pattern is written using lithographic techniques and the resist is partially etched away as a result. Figure 2.6(b) shows the substrate exposed at the desired positions. 


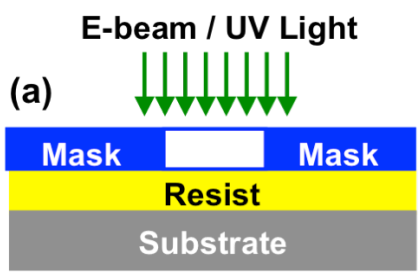

(b) Development

Substrate

(c) Metal Deposition

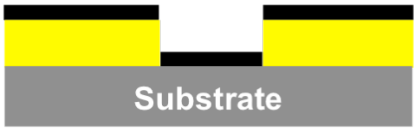

(d) Lift-off

Substrate

FIG. 2.6: Schematic of the lift-off process.

The metallization is then done by e-beam/thermal evaporation. As shown in black in Fig. 2.6(c), the metal is deposited over the whole sample.

Finally, the sample is dipped into acetone, which dissolves the resist but does not affect the desired structures. The resist, with the undesired material on top, is lifted off the substrate and the desired structures are retained [Fig. 2.6(d)]. 


\section{References}

${ }^{1}$ J. Stöhr, J. Electr. Spectr. and Rel. Phenom. 75, 253 (1995).

${ }^{2}$ B. T. Thole, P. Carra, F. Sette, G. van der Laan, Phys. Rev. Lett. 68, 1943 (1992).

3 H. A. Dürr, S. S. Dhesi, E. Dudzik, D. Knabben, G. van der Laan, J. B. Goedkoop, F. U. Hillebrecht, Phys. Rev. B. 59, R701 (1999).

4 E. Dudzik, H. A. Dürr, S. S. Dhesi, G. van der Laan, D. Knappen, J. B. Goedkoop, J. Phys.: Condens. Matter. 11, 8445 (1999).

${ }^{5}$ N. Weiss, et al., Phys. Rev. Lett. 95, 157204 (2005).

${ }^{6}$ H. Ebert, Rep. Prog. Phys. 59, 1665 (1996).

${ }^{7}$ J. Stöhr, and H. C. Siegmann, Magnetism (Springer, 2006).

${ }^{8}$ J. Stöhr, NEXAFS (Springer, Berlin Heidelberg, 25, 1992).

${ }^{9}$ B. T. Thole, P. Carra, F. Sette, and G. van der Laan, Phys. Rev. Lett. 68, 1943 (1992).

${ }^{10}$ P. Carra, B. T. Thole, M. Altarelli, and X. Wang, Phys. Rev. Lett. 70, 694 (1993).

${ }^{11}$ C. T. Chen, Y. U. Idzerda, et al., Phys. Rev. Lett. 75, 152 (1995).

${ }^{12}$ B. Tonner, et al., Rev. Sci. Instrum. 63, 564 (1992); B. Tonner, et al., J. Electron Spectrosc. Relat. Phenom. 75, 309 (1995).

${ }^{13}$ B. P. Tonner, G. R. Harp, Rev. Sci. Instrum. 59, 853 (1988).

${ }^{14}$ S. Anders S, H. Padmore, et al., Rev. Sci. Instrum. 70, 3973 (1999). 


\section{The relation between the Co orbital moment and magnetocrystalline anisotropy in $\mathrm{Co}_{80} \mathrm{Pt}_{20}$ :oxide thin films*}

\subsection{Introduction}

In order to increase areal storage densities in hard disk drives, and to achieve narrower bit boundaries, it is essential to reduce the magnetic grain size as well as the exchange and/or magnetostatic interaction between the magnetic grains. ${ }^{1,2}$ Oxide based grain boundaries, formed

- A part of this chapter appeared in Journal of Applied Physics 109, 113920 (2011), and the other part is under review. 
by adding oxides (such as $\left.\mathrm{SiO}_{2}\right)^{3}$ that easily precipitate at the grain boundary, are effective for this purpose. A well-known predicament in these composite oxide-doped CoPt-based thin films is that, while the desirable intergrain magnetic decoupling is improved with increasing oxide volume fraction (OVF) or decreasing grain size $(D)$, the magnetic anisotropy $\left(K_{1}\right)$ is adversely reduced. ${ }^{4-7}$ Revealing the underlying physical mechanism of this quandary is not only of great scientific importance, but could also provide technological benefits, in deciding the optimum OVF (or $D$ ) in the manufacturing process. ${ }^{8,9}$

Girt et al. ${ }^{10}$ succeeded in isolating the magnetic grains by cosputtering $\mathrm{Co}$ and $\mathrm{Pt}$ with nonmagnetic oxide material, which serves as a barrier to decouple neighboring grains. With increasing OVF, the magnetic grain size becomes smaller, while at the same time the magnetocrystalline anisotropy of the grains, $K_{1 \mathrm{~g}}$, was found to be significantly reduced. ${ }^{10}$ This result is critical, as it suggests that there is a limit for increasing the areal storage density by this method, caused by the dilemma between the simultaneous requirements for small grain size and large $K_{1 \mathrm{~g}}$. The value of $K_{1 \mathrm{~g}}$ is usually calculated from the magnetocrystalline anisotropy of the media, $K_{1}$, by taking account of the OVF. ${ }^{10,11}$ However, a direct observation and accurate experimental determination of the magnetic properties and anisotropies of the magnetic grains is presently lacking, but necessary.

On the other hand, several mechanisms have been proposed to explain the drop in $K_{1}$, including the possible impact of intergrain exchange coupling, surface anisotropy arising from the grain-oxide interface, and stacking faults within the magnetic grains. ${ }^{12-14}$ However, the microscopic origin of the $K_{1}$ drop is still ambiguous. Several phenomenological studies of experimental nature have been carried out, showing that the magnetic anisotropy of the core grains $\left(K_{1 \mathrm{~g}}\right)$ itself also drops when the grain size is decreased ${ }^{15-17}$, causing the reduction in $K_{1}$. Therefore, it is essential to determine the cause of this unexpected $K_{1 \mathrm{~g}}$ drop, which appears to be contradictory to the effect of shape anisotropy, where smaller grains, with a reduced width/height aspect ratio, should be easier to magnetize normal to the surface plane (see Fig. 3.3). 
In general, spin-orbit coupling is thought to play a dominant role in magnetic anisotropy. When magnetic grains become smaller, the orbital contribution to the total magnetic moment becomes more important and can no longer be neglected, which in turn has an impact on the magnetocrystalline anisotropy. ${ }^{18-20}$ It is therefore imminent to study the grain size dependence of the spin-orbit interaction and the orbital moment, which might be responsible for the observed changes in $K_{1 \mathrm{~g}}$, and thus $K_{1}$. X-ray magnetic circular dichroism (XMCD), combined with sum rule analysis, ${ }^{21}$ has been shown to be a powerful tool to study subtle changes in spin and orbital moments and magnetic anisotropy of Co particles, ${ }^{22-24}$ so that this technique has unique capabilities to tackle the problem at hand.

In this chapter, we use angle-dependent XMCD to record element-specific hysteresis loops at the Co $L_{2,3}$ edges for a series of $\mathrm{Co}_{80} \mathrm{Pt}_{20}$ :oxide thin films with variable OVF between $\sim 16.6 \%$ and $\sim 20.7 \%$, and quantify the spin- and orbital moments of Co, which represent the main source of magnetization in CoPt:oxide thin films. ${ }^{25}$

\subsection{Sample Preparation}

A series of samples, glass/Ta $(5 \mathrm{~nm}) / \mathrm{Ru}(13 \mathrm{~nm}) / \mathrm{Co}_{80} \mathrm{Pt}_{20}+\mathrm{WO}_{3}$ (total of $13 \mathrm{~nm}) / \mathrm{C}(7 \mathrm{~nm})$, were prepared in Seagate, USA. We succeeded in isolating the magnetic grains by co-sputtering CoPt with nonmagnetic oxide material serving as the barrier to decouple neighboring grains. The samples were deposited at room temperature using DC and RF magnetron sputtering in a Unaxis M12 sputter tool with base vacuum below $1 \times 10^{-8}$ mbar. The CoPt grains were grown on top of $\mathrm{Ru}$ grains, with oxide material segregation to the grain boundaries. The oxide co-sputtering power was varied from $5 \mathrm{~W}$ to $30 \mathrm{~W}$, which controls the OVF and the grain size, as described below. The carbon overcoat protects the magnetic layer from corrosion and oxidation ${ }^{1}$, and furthermore reduces frictional forces between disc and $\mathrm{read} / \mathrm{write}$ head. 


\subsection{Results and discussion}

\subsubsection{TEM measurement of OVF and grain size}

Plane-view transmission electron microscopy (TEM) was performed to investigate the OVF in the films and corresponding grain sizes. As shown in Fig. 3.1, recorded for a film with a nominal OVF of $\sim 20.4 \%$ the magnetic grains are well isolated by oxide material segregated into the grain boundary. The grain size distribution of this granular layer has been fitted with a log-normal distribution and is shown in the inset, and the mean grain size $D$ is estimated to be $7.8 \mathrm{~nm}$ with a standard deviation of $\pm 1.6 \mathrm{~nm}$.

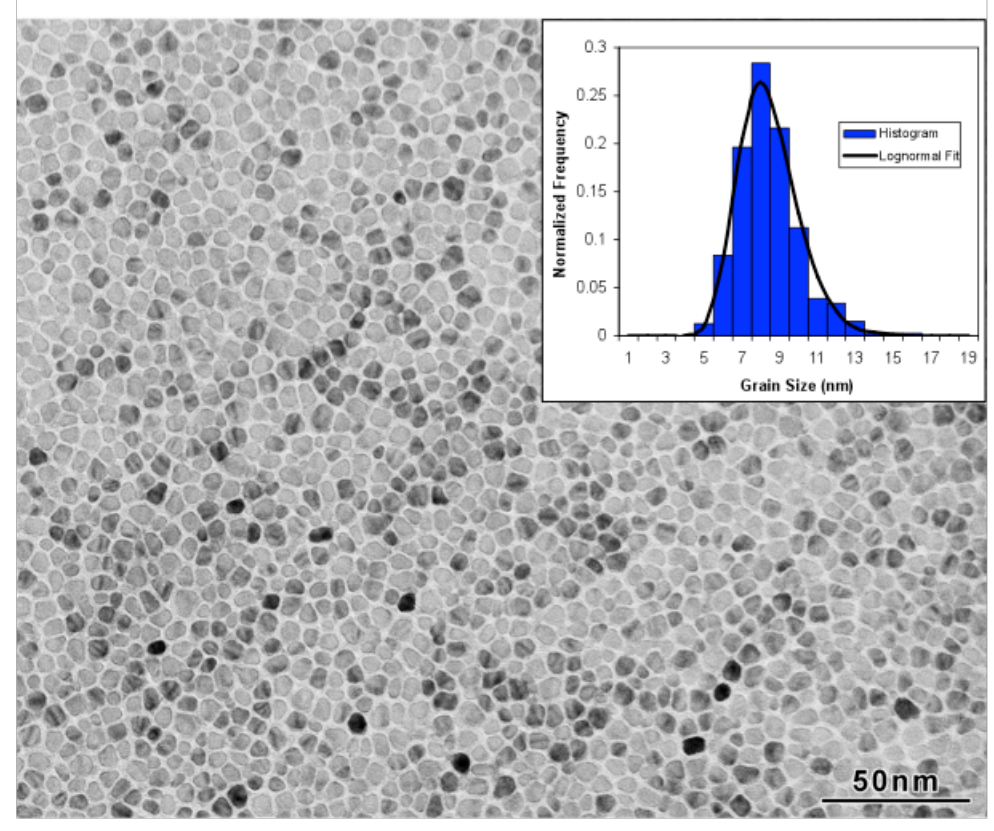

FIG. 3.1: Plane-view TEM image of the granular layer with an OVF of $20.4 \%$. Inset: From the grain size distribution of the granular layer the mean grain size $D$ is estimated to be $7.8 \mathrm{~nm}$.

From the TEM analysis, we found that the OVF and grain size dependences are almost linear with the oxide power. As the power increases from $5 \mathrm{~W}$ to $30 \mathrm{~W}$, the $\mathrm{OVF}$ in the magnetic layer increases 
from $16.6 \%$ to $20.7 \%$, and the grain size reduces from $10.0 \mathrm{~nm}$ to 7.7 nm.

\subsubsection{VSM results as a function of OVF}

Figure 3.2(a) shows a typical hysteresis loop of the sample with OVF

$\sim 16.6 \%$ measured by VSM, with the magnetic field applied along the film normal. The coercivity $H_{C}$, nucleation field $H_{N}$ and remanence magnetization $M_{\mathrm{r}}$ are marked on the loop. $H_{N}$ is conventionally defined as the field of the intercept between the saturation magnetization level and the tangent at $H_{C},{ }^{26}$ which is widely accepted and the mostly used (although there are some other definitions such as the onset of reverse nucleation, e.g., $95 \%$ of the $M_{\mathrm{S}}$ value ${ }^{27}$ ). One more important parameter, the remanence squareness $S$, is defined as the ratio of the remanence magnetization $M_{\mathrm{r}}$ against the saturation magnetization $M_{\mathrm{S}}$, i.e., $S=M_{\mathrm{r}} / M_{\mathrm{S} .}{ }^{28}$
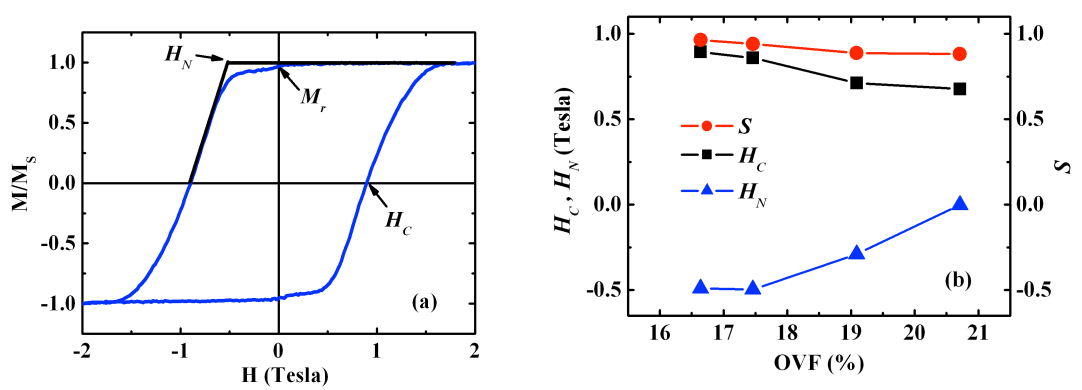

FIG. 3.2: (a) Hysteresis loop measured by VSM for a film with OVF $16.6 \%$, and definition of coercivity $H_{C}$, nucleation field $H_{N}$ and remanence magnetization $M_{\mathrm{r}}$; (b) $H_{C}, H_{N}$, and remanence squareness $S=M_{\mathrm{r}} / M_{\mathrm{S}}$, along the normal direction as a function of OVF.

The trends of $H_{C}, H_{N}$, and $S$ are shown in Fig. 3.2(b) as a function of OVF. For increasing OVF, the coercivity $H_{C}$ decreases and the absolute value of nucleation field $H_{N}$ decreases, which suggests that the recording-layer grains are magnetically exchange decoupled due to enhanced segregation between the media grains. ${ }^{29}$ It 
is commonly acknowledged that a large negative $H_{N}$ (using the definition of $H_{N}$ shown in Fig. 3.2) is essential for the stability of the recorded bit. ${ }^{10}$ As one can see in Fig. 3.2(b), here $H_{N}$ is far below zero when the OVF is lower than $20.7 \%$, reaching $-0.29 \mathrm{~T}$ when OVF $19.1 \%$. The value of $S$ reaches almost 1.0, indicating a high potential of thermal stability of the read-back signal even at low recording density. ${ }^{30}$ The lower $S$ for higher OVF indicates a less intergranular exchange coupling between smaller grains, and in this case the magnetic grains may be reversed individually. ${ }^{31}$

\subsubsection{XMCD results as a function of magnetic grain size}

XMCD measurements were carried out in total-electron-yield mode on bending magnet beamline 6.3.1 at the Advanced Light Source, Berkeley, using circularly polarized X-rays with a $\sim 60 \%$ degree of circular polarization. XMCD spectra, as well as XMCD hysteresis loops, were recorded at the Co $L_{2,3}$ edge for samples with the OVF ranging from $16.6 \%$ to $20.7 \%$, corresponding to the CoPt grain sizes $D=10.0,9.5,9.1,8.6,8.2$, and $7.7 \mathrm{~nm}$.
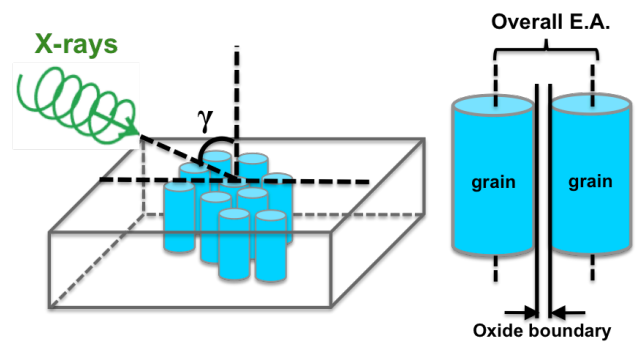

FIG. 3.3: Illustration of experimental geometry (left) and schematic diagram showing the grain, oxide boundary and the overall easy axis (E.A.) of the magnetic anisotropy (right). $\gamma$ is the X-ray incidence angle with respect to the surface normal of the sample.

Two different experimental geometries were used, i.e., at normal incidence $\left(\gamma=0^{\circ}\right)$ and at grazing incidence $\left(\gamma=60^{\circ}\right)$ of the X-ray beam, which allows for extracting the anisotropic behavior of the magnetic moments, as shown in the left panel of Fig. 3.3. 


\subsubsection{MAE as a function of OVF}

Figure 3.4 displays the hysteresis loops of samples with $D=8.6$ and $10.0 \mathrm{~nm}$, obtained by recording the peak height of the $\mathrm{Co}_{3}$ signal at $\sim 778 \mathrm{eV}$ divided by the Co $L_{2}$ signal at $\sim 793 \mathrm{eV}$ as a function of the applied magnetic field, for $\gamma=0^{\circ}$ and $60^{\circ}$. The curves show a pronounced hysteresis, indicating that the CoPt grains retain their grain-grain ferromagnetic alignment at room temperature, and the difference between the $0^{\circ}$ and $60^{\circ}$ loops shows that the films have an out-of-plane easy axis, as indicated by the dashed lines in the right panel of Fig. 3.3.

Figure 3.5 shows the coercivity of the samples determined from the XMCD hysteresis loops, $H_{\mathrm{C}, \mathrm{XMCD}}$, at $\gamma=0^{\circ}$ (red closed circles) and $60^{\circ}$ (black closed squares). The theoretical values of $H_{\mathrm{C}, \mathrm{XMCD}}$ for $\gamma=60^{\circ}$ using the domain wall motion (DWM) model $\left(H_{\mathrm{C}, \mathrm{XMCD}, 60^{\circ}} / H_{\mathrm{C}, \mathrm{XMCD}, 0^{\circ}}=1 / \cos 60^{\circ}\right)$ and the Stoner-Wohlfarth (S-W)

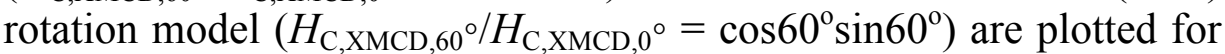
comparison. ${ }^{32}$ We see that the experimental data of $H_{\mathrm{C}, \mathrm{XMCD}}$ at $\gamma=60^{\circ}$ almost fully agrees with the calculation using the S-W rotation model. This suggests that the intergrain coupling can be eliminated as the main reason for the $K_{1}$ drop, and the reversal mechanism of these samples tends to comply with the SW model wherein coherent rotation dominates. Note that when the OVF is lower than $19.1 \%$, the magnetization reversal process is slightly towards DWM due to insufficient isolation of the CoPt grains. When the amount of oxide is insufficient to surround the CoPt grains, the oxide may exist as discontinuous sheets or clusters, which behaves as pinning sites and leads to a large coercivity during DWM. ${ }^{33}$

As expected, the reversal process of these samples tends to obey the SW model where the coherent rotation dominates, and the mechanism is the magnetization rotation of each grain. ${ }^{34}$ In this case the coercivity may be used to monitor relative changes in the magnetocrystalline anisotropy energy (MAE), and therefore one can derive the MAE from the angular dependence of the magnetization curves $M(H)$ using ${ }^{35,36}$ 


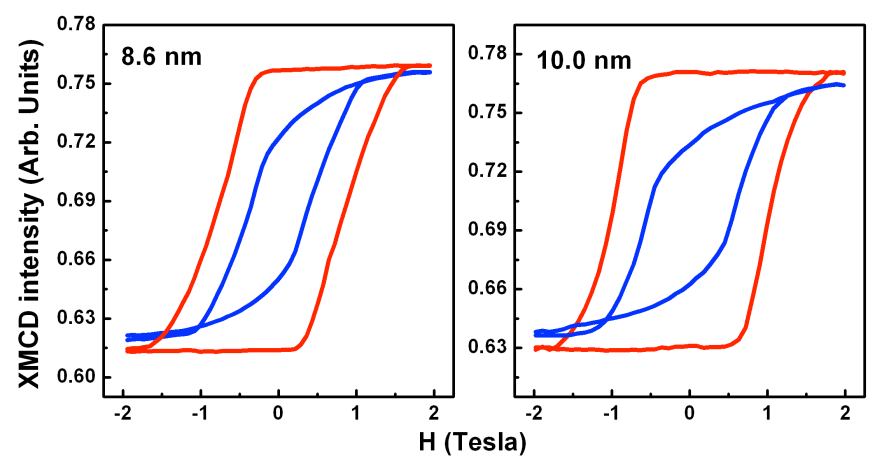

FIG. 3.4: Magnetization curves of $\mathrm{Co}_{80} \mathrm{Pt}_{20}$ :oxide films measured at the Co $L_{2,3}$ edge for angles $\gamma=0^{\circ}$ (red) and $60^{\circ}$ (blue) and grain sizes $D=8.6$ $\mathrm{nm}$ and $10.0 \mathrm{~nm}$.

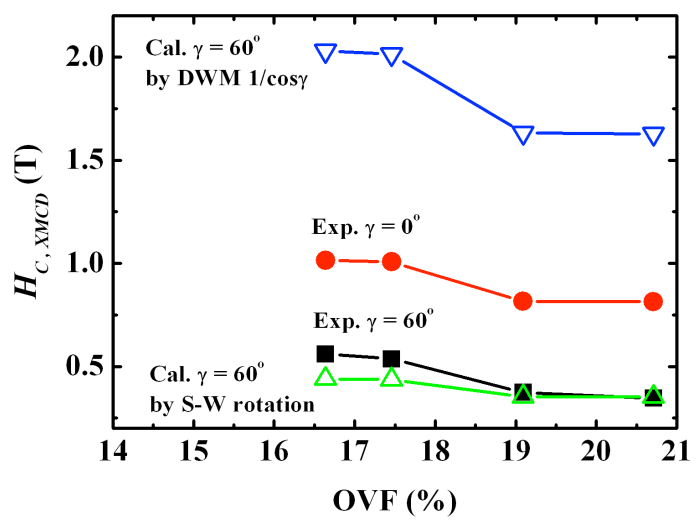

FIG. 3.5: Coercivity measured by XMCD hysteresis loop $\left(H_{\mathrm{C}, \mathrm{XMCD}}\right)$ for CoPt films with variable OVF at $\gamma=0^{\circ}$ (red closed circles) and $60^{\circ}$ (black closed squares). Also plotted are theoretical curves for $H_{\mathrm{C}, \mathrm{XMCD}}$ at $\gamma=60^{\circ}$.

$$
M A E=\frac{\int_{0}^{M_{s}}\left(H d M_{\gamma_{1}}-H d M_{\gamma_{2}}\right)}{\sin ^{2}\left(\gamma_{1}-\gamma_{2}\right)} .
$$

In Eq. (3.1), $H$ is the applied magnetic field, $\gamma_{1}=0^{\circ}$ and $\gamma_{2}=60^{\circ}$, and $M_{S}$ is the total magnetic moment estimated at the saturation field using 


$$
M_{\mathrm{S}}=m_{\mathrm{L}, \mathrm{Co}}+m_{\mathrm{S}, \mathrm{Co}}
$$

where $m_{L, \mathrm{Co}}$ and $m_{S, \mathrm{Co}}$ are the orbital and spin magnetic moments of Co, respectively, and can be evaluated from the Co XMCD spectra using the sum rules analysis, which will be presented in Section 3.3.2.

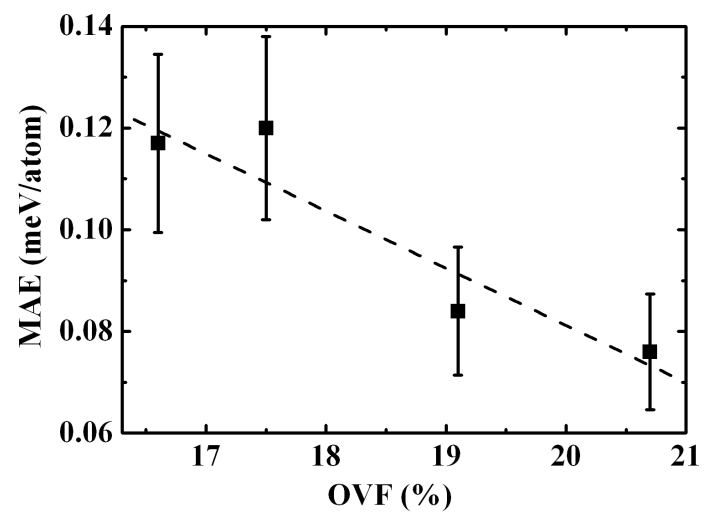

FIG. 3.6: Co MAE (black squares) vs. OVF determined from Eqs. (3.1) and (3.2). The dashed line is a linear fit to the MAE data.

A strong dependence of the MAE on OVF is observed in Fig. 3.6 with a trend similar to that of the $H_{C}$ measured by VSM as well as the Co $L$ edges XMCD. The Co MAE, which is the main source of the $K_{\mathrm{gg}},{ }^{37}$ decreases from $0.117 \mathrm{meV} /$ atom to $0.076 \mathrm{meV} /$ atom as the OVF increases from $16.6 \%$ to $20.7 \%$, which is consistent with the decreasing trend of $K_{1 \mathrm{~g}}$ with increasing OVF observed in Ref. 10.

\subsubsection{Co orbital anisotropy as a function of grain size}

The Co $3 \mathrm{~d}$ effective spin moment, $m_{\mathrm{S}}$, and orbital moment, $m_{\mathrm{L}}$, evaluated using the sum rules ${ }^{38}$ derived from the XMCD spectra, are plotted in Figs. 3.7(a) and 3.7(b), respectively, as a function of grain size. Note that the values at $\gamma=60^{\circ}, m_{\mathrm{S}, 60^{\circ}}$ and $m_{\mathrm{L}, 60^{\circ}}$, have been corrected for incomplete magnetic saturation, i.e., by multiplying a factor of $M_{2 \mathrm{~T}, 0^{\circ}} / M_{2 \mathrm{~T}, 60^{\circ}}$, where $M_{2 \mathrm{~T}, 0^{\circ}}(\approx$ saturation magnetization) and 
$M_{2 \mathrm{~T}, 60^{\circ}}$ represent the $0^{\circ}$ and $60^{\circ}$ magnetization obtained at a $2 \mathrm{~T}$ field by VSM. As seen in Fig. 3.7(a), $m_{\mathrm{S}}$ is isotropic, and shows a slightly decreasing trend as $D$ decreases due to the increasing oxide percentage. It also means that the magnetic dipole term in the sum rules, which causes an anisotropy in the spin distribution, can be neglected. ${ }^{39,40}$

As seen in Fig. 3.7(b), $m_{\mathrm{S}, 60^{\circ}}>m_{\mathrm{L}, 60^{\circ}}$ over the whole measured $D$ range, consistent with the hysteresis loops in Fig. 3.4(a), where the overall easy axis of $K_{1 \mathrm{~g}}$ is perpendicular to the film plane. As a consequence, the orbital anisotropy, defined as $\Delta m_{\mathrm{L}}=m_{\mathrm{S}, 60^{\circ}}-m_{\mathrm{L}, 60^{\circ}}$, has a positive sign. As the grain size decreases, the orbital anisotropy strongly decreases from $\sim 0.09 \mu_{\mathrm{B}}(D=10 \mathrm{~nm})$ to $\sim 0.02 \mu_{\mathrm{B}}(D=7.7$ $\mathrm{nm})$, which is consistent with the decreasing trend in $K_{1 \mathrm{~g}}$.

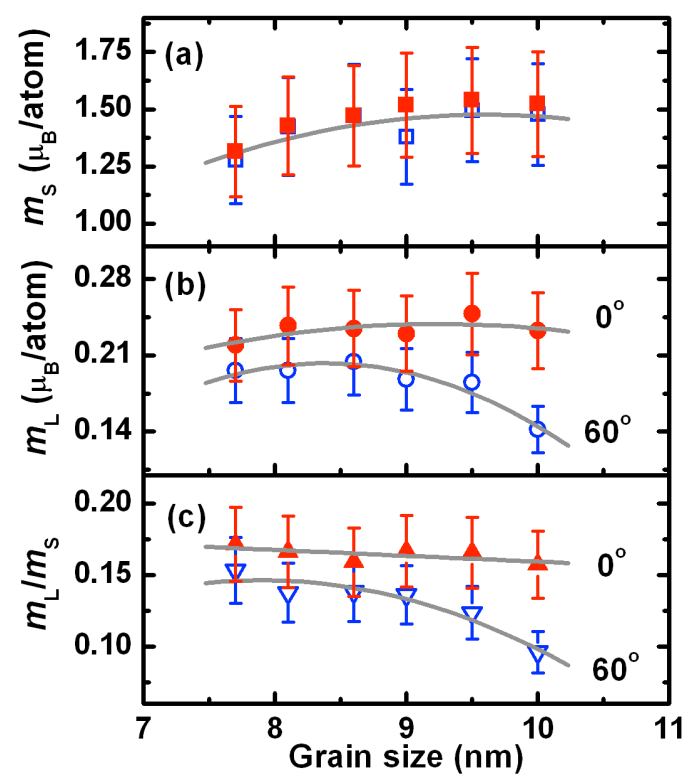

FIG. 3.7: (a) Spin moment, $m_{\mathrm{S}}$, (b) orbital moment, $m_{\mathrm{L}}$, and (c) orbital-tospin moment ratio, $m_{\mathrm{L}} / m_{\mathrm{S}}$, as a function of CoPt grain size, extracted from the Co $L_{2,3}$ XMCD spectra at incident X-ray angles $\gamma=0^{\circ}$ (red, filled symbols) and $\gamma=60^{\circ}$ (blue, open symbols). The grey solid lines are guides to the eye. 
The change in orbital anisotropy with grain size is mainly due to $m_{\mathrm{L}, 60^{\circ}}$. In contrast to a slight decrease in $m_{\mathrm{L}, 0^{\circ}}$ of only $\sim 0.01 \mu_{\mathrm{B}} /$ atom, $m_{\mathrm{L}, 60^{\circ}}$ strongly increases with decreasing $D$, reaching for $D=7.7 \mathrm{~nm}$ a high value of $\sim 0.19-0.20 \mu_{\mathrm{B}} /$ atom, which is $\sim 1.33 \times$ larger than for pure Co. ${ }^{41}$ The incident X-ray angle of $\gamma=60^{\circ}$ is close to the magic angle $\left(57.4^{\circ}\right)$, where the influence of the magnetocrystalline anisotropy on the orbital moment vanishes, so that $m_{\mathrm{L}, 60^{\circ}}$ can approximately be taken as the isotropic value of the orbital moment. ${ }^{42,43}$ Therefore, the enhancement of $m_{\mathrm{L}, 60^{\circ}}$ with decreasing grain size can be attributed to an increasingly isotropic orbital moment.

The orbital-to-spin moment ratio, $m_{\mathrm{L}} / m_{\mathrm{S}}$, as a function of $D$ is also shown in Fig. 3.7(c) for both X-ray angles. The $m_{\mathrm{L}, 0} / m_{\mathrm{S}}$ ratio appears to be nearly independent of grain size, with its value of (0.16-0.17) significantly larger than for pure $\mathrm{Co},{ }^{44}$ and comparable to values reported for various $\mathrm{CoPt}$ thin films. ${ }^{45-47}$ This behavior suggests that the effect of stacking faults would be negligible here, since it has been reported that a considerable decrease in spin-orbit coupling is expected due to stacking faults in magnetic grains. ${ }^{48}$ On the other hand, $m_{\mathrm{L}, 60} / m_{\mathrm{S}}$ shows a relatively large increasing trend from 0.09 to 0.15 as $D$ decreases, which is primarily due to the increasing $m_{\mathrm{L}, 60^{\circ}}$ or isotropic orbital moment. This increasing trend suggests an enhanced spin-orbit interaction, leading to a decrease in the overall magnetic anisotropy energy. Therefore, the microscopic origin of the reduction of $K_{1}$ in the films can be primarily interpreted as an increase in isotropic orbital moment with decreasing grain size. $^{49,50}$

This behavior can be understood as follows. When the grains become smaller, the influence of symmetry breaking at the grainoxide interface becomes more significant due to the increased surface-to-volume ratio. Hence, the enhanced isotropic orbital moment for small grain size is probably due to the reduced symmetry at the interface, as was also demonstrated for Co nanoparticles showing a giant magnetic anisotropy. ${ }^{51}$ These effects lead to an enhanced spin-orbit interaction arising from the grain-oxide interface, which partly counteracts the overall perpendicular magnetic 
anisotropy. With an increasing contribution of the orbital moment in smaller grains, the asymmetric grain-oxide interface will cause a further reduction in $K_{1 \mathrm{~g}}$. This seems to be in line with Zhu's experimental investigation on various oxide/Co bilayers yielding significant interfacial anisotropy with its easy axis orthogonal to the interface, ${ }^{52}$ and their theoretical prediction that the enhanced interfacial anisotropy in smaller grains would lead to a sizeable reduction in perpendicular magnetic anisotropy. ${ }^{53}$

\subsection{Conclusions}

We have measured for the first time the element-specific hysteresis loops for $\mathrm{Co}_{80} \mathrm{Pt}_{20}$ :oxide thin films with perpendicular magnetization using angle-dependent XMCD at the Co $L_{2,3}$ edges. The magnetization-reversal mechanism of these samples demonstrated to be dominated by the magnetization rotation of isolated grains. The magnetic anisotropy energy, evaluated from the angular dependence of $M(H)$ in the Co XMCD hysteresis loops accordingly, decreases from $0.117 \mathrm{meV} /$ atom to $0.076 \mathrm{meV} /$ atom when the oxide volume fraction increases from $16.6 \%$ to $20.7 \%$.

The XMCD sum-rules analysis showed that the isotropic orbital moment increases with increasing oxide volume fraction (decreasing grain size) due to the increasing surface-to-volume ratio of the magnetic grains, resulting in a reduced orbital anisotropy and thus the magnetic anisotropy energy, which is the main cause of the drop in the magnetocrystalline anisotropy. The present work clarifies the microscopic origin of the $K_{1}$ drop in $\mathrm{Co}_{80} \mathrm{Pt}_{20}$ :oxide thin films, which is instructive for optimizing the magnetic grain size involving the important factor of the surface-to-volume ratio of the magnetic grain. 


\section{References}

${ }^{1}$ S. N. Piramanayagam, J. Appl. Phys. 102, 011301 (2007).

${ }^{2}$ G. A. Bertero, D. Wachenschwanz, S. Mailhota, S. Velu, B. Bian, D. Stafford, Y. Wu, T. Yamashita, and S. X. Wang, IEEE Trans. Magn. 38, 1627 (2002).

${ }^{3}$ T. Oikawa, et al., IEEE. Trans. Magn. 38, 1976 (2002).

${ }^{4}$ S. N. Piramanayagam, J. Appl. Phys. 102, 011301 (2007).

${ }^{5}$ G. A. Bertero, et al., IEEE Trans. Magn. 38, 1627 (2002).

${ }^{6}$ S. Oikawa, et al., IEEE Trans. Magn. 36, 2393 (2000).

${ }^{7}$ T. Oikawa, et al., IEEE Trans. Magn. 38, 1976 (2002).

${ }^{8}$ V. Sokalski, et al., Appl. Phys. Lett. 95, 102507 (2009).

${ }^{9}$ S. J. Lister, et al., Appl. Phys. Lett. 97, 112503 (2010).

${ }^{10}$ E. Girt, S. Wu, B. Lu, and G. Ju, et al., J. Appl. Phys. 99, 08E715 (2006).

${ }^{11}$ T. Shimatsu, et al., IEEE. Trans. Magn. 40, 2483 (2004).

${ }^{12}$ J.-G. Zhu, et al., IEEE. Trans. Magn. 45, 911 (2009).

${ }^{13}$ J.-G. Zhu, et al., IEEE. Trans. Magn. 47, 74 (2011).

${ }^{14}$ S. Hinata, et al., J. Appl. Phys. 105, $07 \mathrm{~B} 718$ (2009).

${ }^{15}$ E. Girt, et al., J. Appl. Phys. 99, 08E715 (2006).

${ }^{16}$ W. Zhang, et al., J. Appl. Phys. 109, 113920 (2011).

${ }^{17}$ T. Shimatsu, et al., IEEE Trans. Magn. 40, 2483 (2004).

${ }^{18}$ Y. Wu, et al., Phys. Rev. Lett. 69, 2307 (1992).

${ }^{19}$ G. van der Laan et al., Phys. Rev. Lett. 69, 3827 (1992).

${ }^{20}$ G. van der Laan, J. Phys.: Condens. Matter 10, 3239 (1998).

${ }^{21}$ B. T. Thole et al., Phys. Rev. Lett. 68, 1943 (1992). 
${ }^{22}$ H. A. Dürr et al., Phys. Rev. B 59, R701 (1999).

${ }^{23}$ E. Dudzik et al., J. Phys.: Condens. Matter 11, 8445 (1999).

${ }^{24}$ N. Weiss et al., Phys. Rev. Lett. 95, 157204 (2005).

${ }^{25}$ N. Ishimatsu et al., J. Appl. Phys. 106, 033902 (2009).

${ }^{26}$ T. Keitoku, et al., J. Magn. Magn. Mater. 235, 34 (2001).

${ }^{27}$ X. W. Wu, H. Zhou, R. J. M. van de Veerdonk, G. Ju, B. Lu, D. Weller, Appl. Phys. Lett. 81, 2409 (2002).

${ }^{28}$ B. Lu, D. Weller, et al., IEEE. Trans. Magn. 39, 1908 (2003).

${ }^{29}$ S. N. Piramagnayagam, K. Srinivasan, Appl. Phys. Lett. 91, 142508 (2007).

${ }^{30}$ T. Shimatsu, et al., J. Magn. Magn. Mater. 235, 273 (2001).

${ }^{31}$ N. Powers, M. L. Yan, L. Gao, S. H. Liou, and D. J. Sellmyer, J. Appl. Phys. 91, 8641 (2002).

${ }^{32}$ K. K. M. Pandey, J. S. Chen, J. F. Hu, and G. M. Chow, J. Phys. D: Appl. Phys. 42, 015009 (2009).

${ }^{33}$ D. I. Paul, J. Appl. Phys. 53, 2362 (1982); M. T. Rahman, C. H. Lai, Y. C. Wu, N. N. Shams, and D. Suess, Appl. Phys. Lett. 91, 132505 (2007).

${ }^{34}$ G. Moulas, et al., Phys. Rev. B. 78, 214424 (2008).

${ }^{35}$ R. M. Bozorth, Phys. Rev. 50, 1076 (1936).

${ }^{36}$ P. Gambardella, A. Dallmeyer, K. Maiti, M. C. Malagoli, S. Rusponi, P. Ohresser, W. Eberhardt, C. Carbone, and K. Kern, Phys. Rev. Lett. 93, 077203 (2004).

${ }^{37}$ K. H. J. Buschow, et al., J. Magn. Magn. Mater. 38, 1 (1983); F. Menzinger and A. Paoletti, Phys. Rev. 143, 365 (1966).

${ }^{38}$ B. T. Thole, et al., Phys. Rev. Lett. 68, 1943 (1992).

${ }^{39}$ J. Stöhr and H. König, Phys. Rev. Lett. 75, 3748 (1995).

${ }^{40}$ H. A. Dürr, et al., Phys. Rev. B. 54, R760 (1996).

${ }^{41}$ C. T. Chen, et al., Phys. Rev. Lett. 75, 152 (1995). 
42 J. Stöhr and H. König, Phys. Rev. Lett. 75, 3748 (1995).

${ }^{43}$ H. A. Dürr, et al., Phys. Rev. B. 54, R760 (1996).

${ }^{44}$ C. T. Chen, et al., Phys. Rev. Lett. 75, 152 (1995).

${ }^{45}$ N. Ishimatsu, et al., J. Appl. Phys. 106, 033902 (2009).

${ }^{46}$ W. Grange, et al., Phys. Rev. B. 58, 6298 (1998).

${ }^{47}$ W. Grange, et al., Phys. Rev. B. 62, 1157 (2000).

${ }^{48}$ S. Hinata, et al., J. Appl. Phys. 105, 07 B718 (2009).

${ }^{49}$ D. Weller, et al., Phys. Rev. Lett. 75, 3752 (1995)

${ }^{50}$ T. Koide, et al., Phys. Rev. Lett. 87, 257201 (2001).

${ }^{51}$ P. Gambardella, et al., Science 300, 1130 (2003).

${ }^{52}$ J.-G. Zhu, et al.., IEEE. Trans. Magn. 47, 74 (2011).

${ }^{53}$ J.-G. Zhu, et al., IEEE. Trans. Magn. 45, 911 (2009). 



\section{Observation of current-driven oscillatory domain wall motion in $\mathrm{Ni}_{80} \mathrm{Fe}_{20} /$ Co bilayer nanowire*}

\subsection{Motivation}

The possibility to manipulate magnetic domain walls (DWs) via spintransfer torque opens up the possibility to develop conceptually novel DW-based devices ${ }^{1-4}$, such as racetrack memories. ${ }^{5,6}$ A spin-polarized current transfers spin-angular momentum to the DW via spindependent scattering of the electrons, which results in DW motion. ${ }^{7}$ For technological purposes, which aim to achieve high DW

- A large part of this chapter is under review. 
velocities, a major hurdle is the so called "Walker breakdown", which occurs when DWs are driven strongly enough to reach a critical velocity of typically around a few $100 \mathrm{~m} / \mathrm{s}^{8-11}$ Above the Walker breakdown, the DW's average velocity drops abruptly, ${ }^{12-16}$ which is caused by a series of cyclic structural transformations of the $\mathrm{DW}^{12,18}$ and consequent oscillations of its instantaneous (as opposed to average) velocity. ${ }^{9,14,16}$

Experimentally, this kind of oscillatory DW motion has been reported under the driving force of a magnetic field ${ }^{14,15}$ where the oscillation period is on the order of nanoseconds and the oscillation amplitude ranges from nano- to micro-meters, depending on the field strength. $^{15,16}$ However, a direct observation of current-driven oscillatory DW motion above the Walker breakdown, without the application of any additional magnetic field, is still lacking. Important details, such as the oscillation period and amplitude, thus remain unclear, and in particular quantitative information is unavailable.

In order to establish the underlying mechanism of DW motion, we apply a one-dimensional(1D)-model, with the inclusion of both adiabatic and non-adiabatic spin torque terms. The dynamics of the local magnetization can be described by the Landau-Lifshitz-Gilbert equation: $^{17}$

$$
\frac{\partial \vec{m}}{\partial t}=-\gamma \vec{m} \times \vec{H}_{e f f}+\alpha \vec{m} \times \frac{\partial \vec{m}}{\partial t}-u\left(\frac{\partial \vec{m}}{\partial z}-\beta \vec{m} \times \frac{\partial \vec{m}}{\partial z}\right)
$$

where $\vec{m}(\sin \theta \cos \phi, \sin \theta \sin \phi, \cos \theta, t)$ is the magnetization vector with polar angle $\theta$ and azimuthal angle $\phi$, $\vec{H}_{e f f}=\frac{1}{\mu_{0} M_{S}}\left(K m_{z} \hat{z}-K_{\perp} m_{x} \hat{x}\right)+\frac{J}{\mu_{0} M_{S}} \frac{\partial^{2} \vec{m}}{\partial z^{2}}$ the effective field, $\gamma$ the gyromagnetic ratio, $\alpha$ the Gilbert damping factor, $\beta$ the non-adiabatic spin-transfer parameter, $u=P j_{e} g \mu_{\mathrm{B}} /\left(2|e| M_{\mathrm{S}}\right), K$ is the magnetic anisotropy along the easy $z$-axis, $K_{\perp}$ the magnetic anisotropy along the hard $x$-axis [cf., inset to Fig. 4.5(b)], $J$ the exchange coefficient, $M_{\mathrm{S}}$ the saturation magnetization, $j_{e}$ the current density, $P$ the spinpolarization of the current, $g$ the electron $g$-factor, $\mu_{\mathrm{B}}$ the Bohr magneton, and $e$ the electron charge. Assuming all local spins lie in a fixed plane and $\phi=\phi(t)$, and using the Walker ansatz, $\ln [\tan (\theta / 2)]=$ 
$(z-v t) / \Delta$, with an effective DW width $\Delta=\left[J /\left(K+K \cos ^{2} \phi\right)\right]^{1 / 2}$, we obtain the solution above the Walker breakdown, and find the condition for the DW moving back and forth by current as:

$$
(1+\alpha \beta) \frac{u}{\Delta}<\frac{\gamma K_{\perp}}{2 \mu_{0} M_{S}}<\left(\frac{\beta}{\alpha}-1\right) \frac{u}{\Delta}
$$

Correspondingly, the instantaneous velocity of the DW is found as:

$$
v(t)=\frac{1+\alpha \beta}{1+\alpha^{2}} u-\frac{\Delta}{1+\alpha^{2}} \frac{\gamma K_{\perp}}{2 \mu_{0} M_{S}} \sin 2 \phi(t) .
$$

The left-hand inequality in Eq. (4.2) implies that a small damping coefficient $\alpha$ is beneficial for attaining oscillatory DW motion. This can be understood from the principle that for smaller damping coefficients the energy dissipation is reduced, thereby easing a change in magnetization direction. ${ }^{16}$ Based on this, the widely used ferromagnet Py (permalloy $=\mathrm{Ni}_{80} \mathrm{Fe}_{20}$ ), with its small damping coefficient $(\alpha \approx 0.008)$, is regarded as a favorite material to undertake studies on DW motion. ${ }^{19}$

The right-hand inequality in Eq. (4.2) further implies that the oscillatory motion only occurs when $\beta / \alpha>1$. The value of $\beta / \alpha$ can be extracted from a theoretical simulation of the experimental data, as described in later paragraphs, which is an important result to clarify the ongoing debate about whether the $\beta / \alpha$ ratio is either below, equal, or above $1 .^{4,21} \mathrm{We}$ will also show that, unlike the field-driven case, the $\beta / \alpha$ ratio offers tunability for the current-driven oscillatory DW motion, depending on the geometry and materials.

The key result in the above model, i.e., the expression of the DW's instantaneous velocity above the Walker breakdown, is given by Eq. (4.3). From the second term on the right-hand side, we see that $\left|K_{\perp} / M_{\mathrm{S}}\right|$, or the absolute value of magnetic anisotropy field along the hard axis, $\left|H_{\perp}\right| \propto\left|K_{\perp} / M_{\mathrm{S}}\right|$, is the most important parameter determining the oscillation amplitude of the DW velocity. In other words, in a system with higher $\left|H_{\perp}\right|$ a stronger oscillation is expected to be observed.

In this chapter, we present a simple but effective method to 
increase $\left|H_{\Perp}\right|$ effectively by capping $\mathrm{Py}^{20,21}$ with an ultrathin layer of $\mathrm{Co},{ }^{22,23}$ without altering the soft magnetic character of the Py nanowire which remains in-plane magnetized along the easy axis. ${ }^{24}$ Direct imaging of the DW motion upon injection of nanosecond current pulses in the nanowires patterned from Py and Py/Co thin films is performed, by using the element-specific technique of X-ray magnetic circular dichroism in photoemission electron microscopy (XPEEM). While the effect remained undetected in the Py single-layer nanowire, direct evidence of current-driven oscillatory DW motion above the Walker breakdown is obtained in the Py/Co bilayer nanowire, which can be attributed to the enhancement of the oscillation amplitude due to the increased $\left|H_{\perp}\right|$. Subsequently, we use the favorable conditions of this bilayer system for detailed investigations of the oscillatory motion. Supported by theoretical simulation of the response of the DW position to the current pulse, we are able to present a clear picture of the oscillatory behavior and demonstrated two key factors for the oscillation enhancement.

\subsection{Experimental}

\subsubsection{Sample preparation}

The experiments were performed on magnetic nanowires with zigzag geometry of 500-nm-width to allow control over the magnetic domain formation by changing the orientation of the external magnetic field relative to the zigzag axis. ${ }^{27,28}$ The bilayer wire was defined on an undoped $\mathrm{Si}(100)$ substrate by electron-beam lithography and a lift-off process. Layers of $8 \mathrm{~nm}$ Py and $2 \mathrm{~nm}$ Co were grown by electron-beam evaporation, followed by a $2 \mathrm{~nm} \mathrm{Au}$ protecting layer to prevent oxidation. For comparison, a single-layer $\operatorname{Py}(8 \mathrm{~nm}) / \operatorname{Au}(2 \mathrm{~nm})$ zigzag nanowire was prepared by the same method. Each wire was contacted with separate Au electrodes at both ends. 


\subsubsection{How to avoid electrical discharge?}

During the XPEEM experiments, a voltage of between $15 \mathrm{kV}$ and 20 $\mathrm{kV}$ is used to accelerate the photoemitted electrons from the sample for imaging. Such a high voltage will probably cause an electrical discharge if the sample is not well grounded. As shown in Fig. 4.1, the ninth pin from the left in the top row of the chip is connected to ground (corresponding to the right pad of wire 1), and so does that in the bottom row (corresponding to the right pad of wire 3 ). Note that the right pad of wire 2 is connected to the bottom of the chip, which is grounded too. Therefore, it means that all the magnetic nanowires are grounded through the electrical pads.

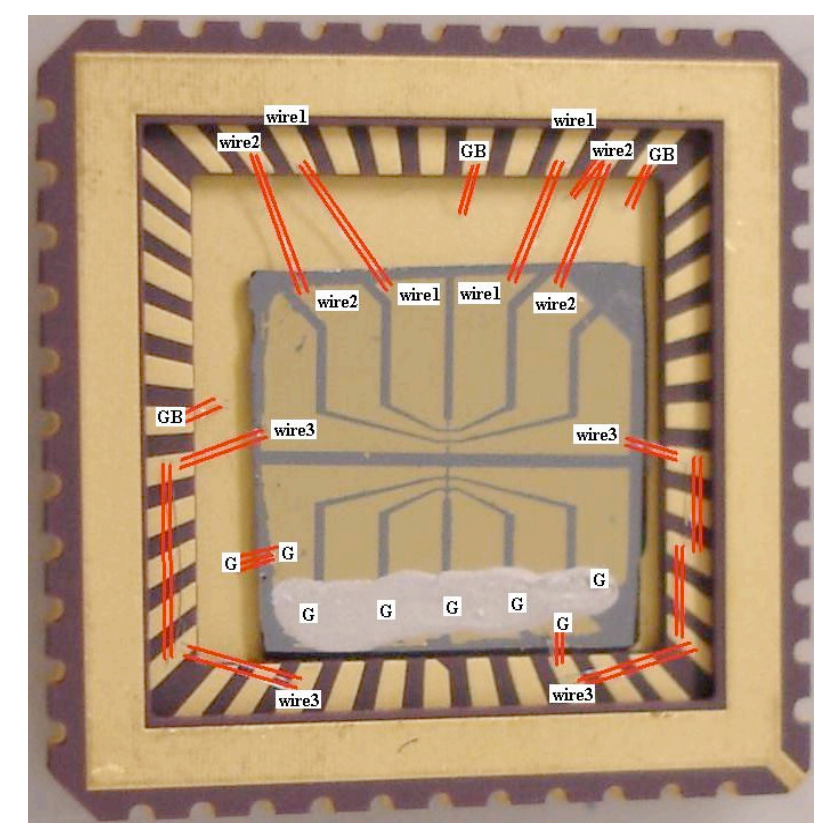

FIG. 4.1: Sample bonded in the chip. Three wires are located at the top, marked as "wire 1", "wire 2", and "wire 3", and are attached to the center of the chip. The red solid lines indicate the bonding wires. For static measurements, we should choose a pin as common "ground" and all the wires should be grounded. The bottom of the chip is grounded too.

As shown in Fig. 4.1, the red lines indicate where the bonding 
wires are. They are necessary to connect the Au pads on the sample to the separate pins on the chip. These bonding wires with their diameters of only $25 \mu \mathrm{m}$ each, if visible to the X-ray beam, would possibly cause the discharge as well due to the effect of point discharge. The solution is to make a cover with an aperture over the sample. Anything outside the aperture will be invisible to the beam, as shown in Fig. 4.2.
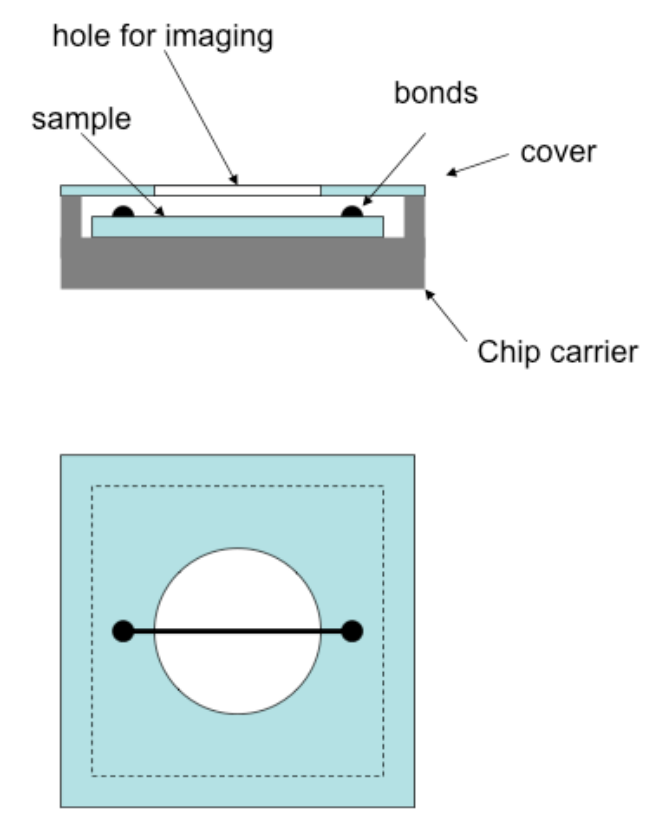

FIG. 4.2: Diagram of chip carrier which will be mounted into the XPEEM sample holder. Top: Sectional view. Bottom: Top view.

\subsubsection{Magnetic contrast in XPEEM images}

Images of magnetic domain structures were captured by XPEEM ${ }^{29,30}$ in zero field and at room temperature utilizing the PEEM-3 endstation on beamline 11.0.1.1 at the Advanced Light Source, Berkeley. In contrast to other imaging techniques, such as magnetic force microscopy, which can influence and even switch the magnetic configurations $^{31}$ by the stray field from the detector, XPEEM is a nonintrusive technique, which even allows for imaging of magnetic objects that do not exhibit stray fields. ${ }^{22}$ The ratio of the X-ray 
absorption signals at the $\mathrm{Ni}(\mathrm{Co}) L_{3}$ and $L_{2}$ edges measured with right-circularly polarized X-rays is used to obtain the XPEEM images. ${ }^{32}$ The magnetic contrast in these images is proportional to the projection of the magnetization along the X-ray helicity vector, so that domains aligned parallel and antiparallel to the right-circular polarization vector $(p)$ show up in light and dark shade, respectively. ${ }^{33}$
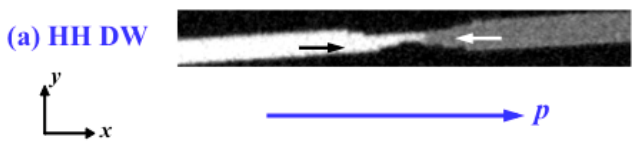

(b) TT DW

FIG. 4.3: Magnetic contrast in XPEEM images taken at Ni $L_{2,3}$ edges: (a) Head-to-head (HH) DW and (b) Tail-to-tail (TT) DW in a 500-nmwide Py nanowire with a 120 -nm-wide contact located at the center. The $x$ axis is along both the X-ray polarization and the wire axis. $p$ indicates the right-circular polarization direction of the incident X-rays. Light contrast corresponds to a domain aligned parallel to $p$, and dark contrast to domain aligned antiparallel to $p$. Black and white arrows represent the magnetization direction parallel and antiparallel to $p$, respectively.

As an example, Fig. 4.3 shows an XPEEM image with magnetic contrast for a Py nanowire with the wire axis along the polarization direction of the X-ray beam. DWs are located at the central constriction of the wire with opposite types due to different magnetization processes: (a) head-to-head DW, and (b) tail-to-tail DW.

\subsection{Oscillatory DW motion above the Walker limit}

Figure 4.4(a) shows XPEEM images of a 500-nm-wide Py 8 $\mathrm{nm}) / \mathrm{Co}(2 \mathrm{~nm})$ bilayer wire, where the DW is trapped near the kink in the wire. The image recorded at the Co $L_{2,3}$ edges, taken immediately after recording the Ni $L_{2,3}$ edges image, shows that both have exactly 
the same domain structure. This means that, from a static viewpoint, the rotation of the magnetization in Co follows that of the Py, which is due to the ferromagnetic coupling between both layers. This was persistently observed during the whole measurement process, and hereafter we will mainly present images of the Ni edges.

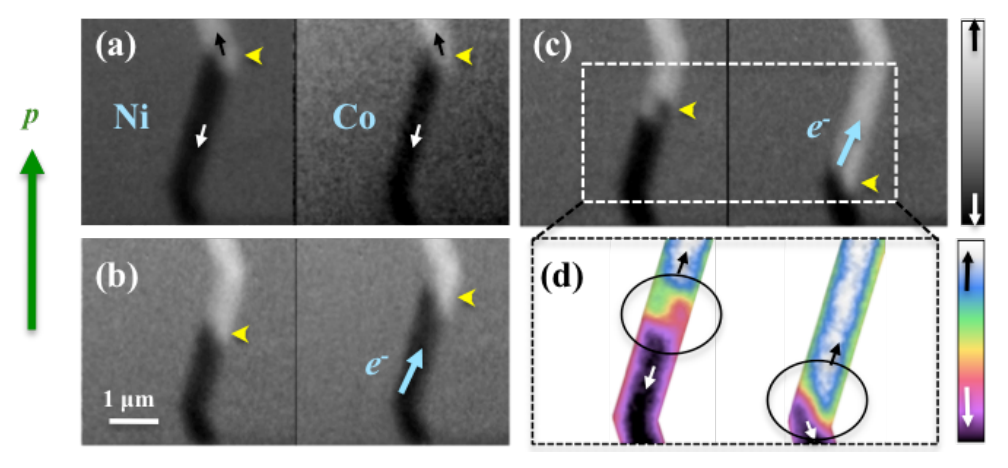

FIG. 4.4: (a) XPEEM images of a 500-nm-wide $\operatorname{Py}(8 \mathrm{~nm}) / \mathrm{Co}(2 \mathrm{~nm})$ bilayer wire, recorded at the $\mathrm{Ni}$ and $\mathrm{Co} L_{2,3}$ edges, respectively, showing the same domain structure. (b) Ni-edge images showing the DW propagation upon current injection in the direction of electron flow. (c) Niedge images showing the DW propagation against the direction of electron flow. The electron flow direction is marked by the blue arrows, and the DW position is indicated by the yellow arrow heads. (d) False-color images of the in-plane magnetization, constructed from the images in (c).

Figure 4.4(b) and (c) show two separate sets of XPEEM images for the DW motion in the bilayer nanowire before (left panel) and after (right panel) the injection of a current pulse, and without any assistance of an additional magnetic field. The current pulse length is $30 \mathrm{~ns}$, which is comparable to the oscillation period for domain wall motion under application of an external magnetic field. ${ }^{15}$ Applying these nanosecond pulses rather than microsecond pulses ${ }^{18}$ enables us to obtain the current-driven oscillation period. The injected current density in Fig. 4.4(b) and (c) is $\sim 1.4 \times 10^{12} \mathrm{~A} / \mathrm{m}^{2}$, which is above the Walker threshold current density. ${ }^{19,34}$

The normal DW motion is illustrated in Fig. 4.4(b), where the DW propagates in the direction of the electron flow (we call it forward motion of the DW), in accordance with the spin transfer 
torque effect. However, this is not always observed in the Py/Co nanowire, and a distinct phenomenon which is seemingly anomalous is revealed in Fig. 4.4(c). Here the DW moves against the direction of the electron flow (we will call this backward motion of the DW), which is not observed in the Py nanowire. This unprecedented backward motion occurred in $\mathrm{Py} / \mathrm{Co}$ with a statistical probability of $27 \%$ (14 out of 52 pulses), suggesting a possibility of the observation of the oscillatory DW motion. It was found that although the DW structure [encircled in Fig. 4.4(d)] transforms after the pulse injection, its backward motion is still much larger than its lateral extent. This provides an unambiguous evidence that the observed DW backward motion is a true displacement instead of a structural distortion. ${ }^{35}$
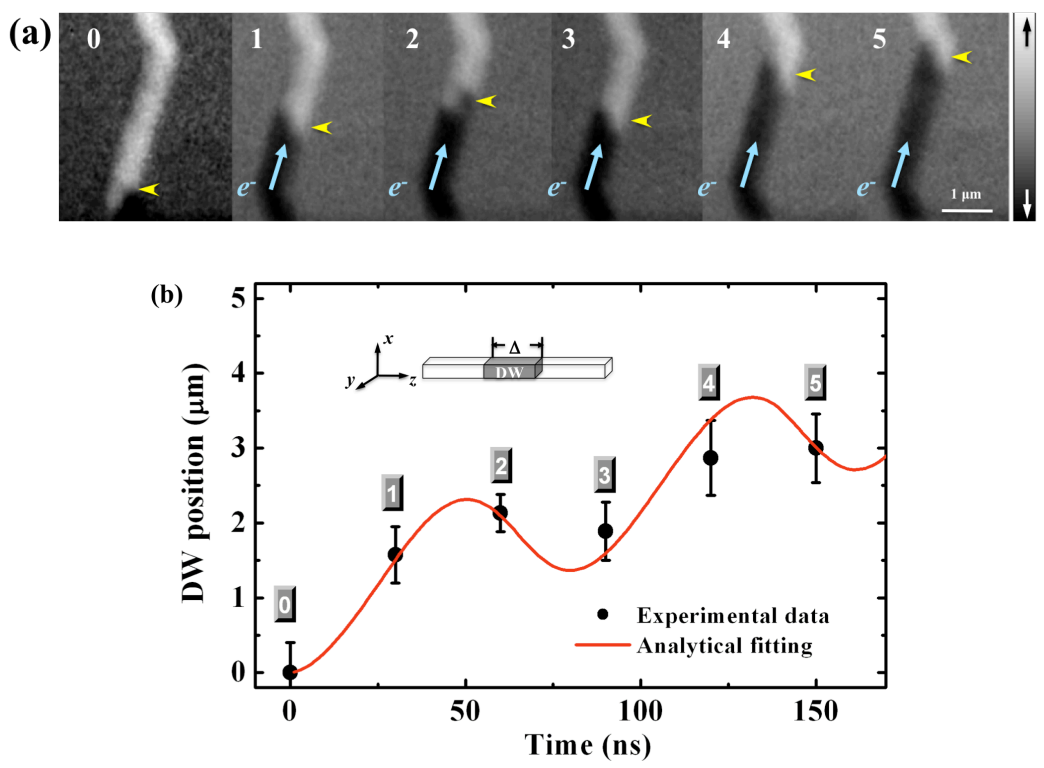

FIG. 4.5: (a) Continuous series of XPEEM images of the DW motion in $\mathrm{Py} / \mathrm{Co}$ bilayer nanowire taken at the $\mathrm{Ni} L_{2,3}$ edge, after consecutive injection of $30 \mathrm{~ns}$ current pulses of $\sim 1.6 \times 10^{12} \mathrm{~A} / \mathrm{m}^{2}$. The yellow arrow heads are a guide to the eye marking the displacement of the DW. The oscillatory behavior is clearly visible. (b) 1D-model simulation for the oscillatory DW motion displayed in (a). The length of the vertical bar gives the lateral extent of the DW in each image. Inset: Schematic diagram of DW in a magnetic nanowire. 
It is worth pointing out that, although the inertial effect of current-driven DWs has been predicted theoretically ${ }^{36-38}$, the XPEEM images still reliably give the real position of the DW after the pulse injection. Because the DW motion deceleration after the pulse exactly offsets the acceleration at the beginning of the pulse, the net displacement of the DW is exactly proportional to the current pulse length independent of its inertia. ${ }^{39}$ Therefore, we conclude that the observation of the DW oscillatory motion here is a real effect instead of being due to any relaxation behavior after the pulse.

By repetitively injecting pulses, we obtain snapshots of the DW position that allows us to observe its forward and backward motions. A series of XPEEM images reflecting the oscillatory DW motion is displayed in Fig. 4.5(a), using consecutive pulses with the current density of $\sim 1.6 \times 10^{12} \mathrm{~A} / \mathrm{m}^{2}$, which is slightly higher than that used in Fig. 4.4. Applying the 1D-model as described above, we calculated the oscillating curve (red curve) to fit the measured data of the DW position (black dots) after each consecutive pulse, as shown in Fig. 4.5(b). The calculation reproduces the oscillatory motion rather well for the relevant parameters $\alpha=0.0085, \beta=0.24, \Delta=39 \mathrm{~nm}, u=7$ $\mathrm{m} / \mathrm{s}$, and $\gamma K_{\perp} / \mu_{0} M_{\mathrm{S}}=3 \times 10^{9} \mathrm{~s}^{-1}$. An oscillation period of $\sim 76 \mathrm{~ns}$, corresponding to a frequency of $\sim 13 \mathrm{MHz}$, was then identified from the best fit. In addition, the backward motion of the DW is found to be up to $1 \mu \mathrm{m}$ [see Fig. 4.5(b)], indicating a large amplitude of the oscillatory motion, exceeding the reported oscillation amplitude around an artificial pinning site. ${ }^{40,41}$ It is noteworthy that the oscillation also shows a dependence on the current density, which is reflected in the longer-scale backward motion observed in Fig. 4.4(c) under smaller current density than that from point 2 to point 3 as shown in Fig. 4.5(a). Quantitatively, with present parameters used for simulation, the oscillation frequency is safely assumed to be proportional to the current density, while the amplitude shows an inversely proportionality. Accordingly, by decreasing the current density from $1.6 \times 10^{12} \mathrm{~A} / \mathrm{m}^{2}$ to $1.4 \times 10^{12} \mathrm{~A} / \mathrm{m}^{2}$, oscillation period of around 86 ns was obtained in Fig. 4.4(c), which is nearly 3 (integer) times the pulse length of the injecting current. This enables us to observe the largest backward motion, which is even more than $1 \mu \mathrm{m}$ due to slight increase of the oscillation amplitude. On the other hand, the relatively large current density of $1.6 \times 10^{12} \mathrm{~A} / \mathrm{m}^{2}$ in Fig. 4.5(a) 
favors us to observe more than one oscillation period within the limited field of view of the microscope.

The value of $\alpha$ is obtained from a numerical fit to a separate spin dynamics measurement of a $\operatorname{Py}(8 \mathrm{~nm}) / \mathrm{Co}(2 \mathrm{~nm})$ thin film, using time-resolved magneto-optical Kerr effect measurements.

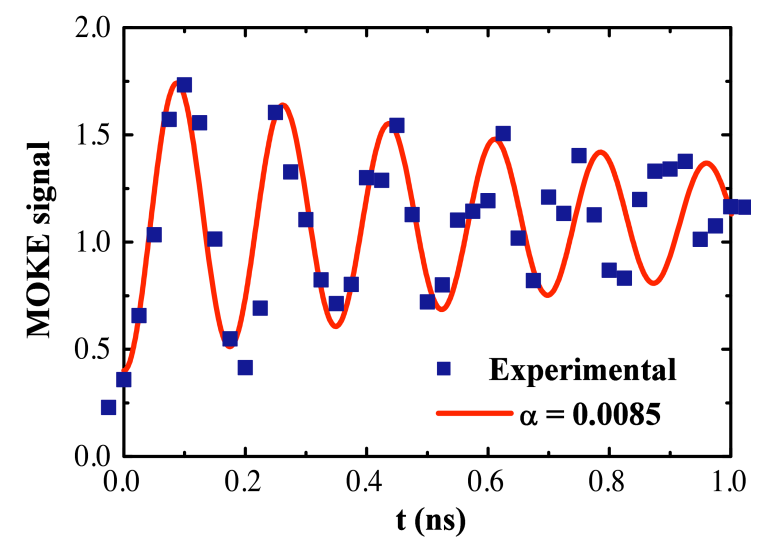

FIG. 4.6: Time-resolved MOKE responses of the Py/Co thin film with magnetic field of 150 Oe applied along the easy magnetic axis.

Figure 4.6 shows the spin dynamics responses of the $\operatorname{Py}(8 \mathrm{~nm}) / \operatorname{Co}(2$ $\mathrm{nm})$ thin film with a magnetic field of 150 Oe applied in the sample plane. Through a simple fitting by an exponentially damped sinusoid

$$
\Phi(t)=A \sin (\omega t+\varphi) e^{-t / \tau},
$$

where $\Phi(t)$ is the in-plane magnetization angle and $\Phi=0$ is the equilibrium position, $A$ and $\varphi$ are the amplitude and phase of the oscillation, ${ }^{42,43}$ and $t$ is the time, we got the value of the effective damping constant $\alpha=0.0085$, which varies only slightly from the value for Py. ${ }^{19}$

We now elaborate on the reason why the current-driven oscillatory DW motion is not observed in a Py single-layer nanowire, which arises from the role of $\left|H_{\downarrow}\right|$. For in-plane magnetized nanowires, $H_{\perp}$ amounts to the difference between the out-of-plane (growth 
direction, $x$ ) and transverse (width direction, $y$ ) demagnetizing fields. ${ }^{24}$ Here the widths for both the $\mathrm{Py} / \mathrm{Co}$ and Py wires are almost the same of around $500 \mathrm{~nm}$, which are far larger than the thickness dimension of 8-10 nm, resulting in a very big width/thickness aspect ratio and therefore the value of $H_{\perp}$ is mainly determined by the demagnetizing field in the thickness direction, approaching the value of $\mu_{0} M_{S}{ }^{44,45}$ Due to its saturation magnetization $M_{S}$ of $33 \%-40 \%$ larger than that of single layer Py, the $\mathrm{Py} / \mathrm{Co}$ bilayer is therefore believed to show a larger $H_{\star}$. In order to further prove this, we carried out ferromagnetic resonance measurements on $\operatorname{Py}(8 \mathrm{~nm}) / \mathrm{Co}(2$ $\mathrm{nm})$ and $\mathrm{Py}(8 \mathrm{~nm})$ thin films. From a numerical fit of the dependence of the resonance field on the magnetic field direction, the value of the out-of-plane effective demagnetizaing field in the $\mathrm{Py} / \mathrm{Co}$ bilayer is found to increase by $34 \%-37 \%$ compared to that in the Py single layer. This enhancement is expected to remain after patterning of the bilayer thin film into a nanowire, leading to a much larger difference between the out-of-plane and the transverse demagnetizing fields than in the Py nanowire. Through the 1D-model calculation, we found that with decreasing $H_{\perp}$ by $37 \%$, the magnitude of the backward motion has already decreased as one-sixth that of the current simulation result shown in Fig. 4.5(b). Therefore, the absence of any observable current-driven oscillatory DW motion in the Py nanowire can be mainly explained by its relatively low $\left|H_{\star}\right|$, while an enhanced oscillation amplitude is observed in the presence of the Co cap due to the increased $\left|H_{\star}\right|$.

We will finally discuss the $\beta / \alpha$ ratio. From the fit of the time dependence of the DW motion in Fig. 4.5(b), we obtain a ratio of $\beta / \alpha$ $\approx 28$, which is well above 1 . This large magnitude of $\beta$ found here may be ascribed to the high magnetization gradient across relatively narrow $\mathrm{DW}^{46}$ in bilayer nanowire (comparing to the DW width in single-layer Py nanowire) caused by relatively large anisotropy constant in $\mathrm{Co}$, and possible spin-flip scattering ${ }^{13}$ from the Co/Py interface, which appears to shed light on the origin of the nonadiabatic spin-transfer term. Figure 4.7 shows the calculated DW position versus time as a function of the $\beta / \alpha$ ratio, while keeping the other parameters the same as those used for the best fit in Fig. 4.5(b). The oscillation frequency shows a strong dependence on the $\beta / \alpha$ ratio, i.e., it increases with increasing $\beta / \alpha$ ratio. As a result, the $\beta / \alpha$ ratio is 
identified as another important parameter in addition to $\left|H_{\downarrow}\right|$, which has a significant effect on the frequency of the oscillatory DW motion. Moreover, the $\beta / \alpha$ dependence of the oscillation frequency opens up interesting possibilities to measure the non-adiabatic spintransfer parameter, which is usually difficult to determine. ${ }^{12,13,20}$

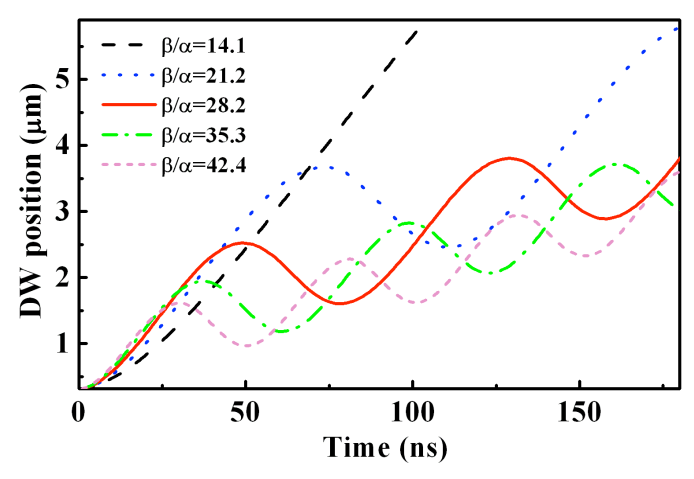

FIG. 4.7: Time dependence of the DW motion for varying $\beta / \alpha$ ratio, calculated using the 1D-model.

\subsection{Conclusions}

In summary, we provide direct experimental evidence of currentdriven oscillatory DW motion above the Walker breakdown, without the application of any external magnetic fields, in a Py/Co nanowire by imaging the magnetic domain structure using XPEEM. New insights into the underlying mechanism were obtained from the observed oscillatory motion. It is found that the DW motion can be enhanced in amplitude and frequency by increasing the following two parameters, respectively, the magnetic anisotropy field along the hard axis of the wire $\left|H_{\downarrow}\right|$ and the $\beta / \alpha$ ratio. By observing an oscillation period of several tens of nanoseconds and an amplitude of no less than $1 \mu \mathrm{m}$, the present study conveys a perspective of paramount importance for developing new functional DW-based operational devices, where the high-frequency and long-scale DW oscillation in this regime can be tuned by engineering the nanowire geometry and the magnetic properties of the materials involved. 


\section{References}

${ }^{1}$ X. Jiang et al., Nano Lett. 11, 96 (2011).

${ }^{2}$ I. M. Miron et al., Nature Mater. 10, 419 (2011).

${ }^{3}$ P. Yan, X.S. Wang, and X.R. Wang, Phys. Rev. Lett. 107, 177207 (2011)

${ }^{4}$ C. Burrowes et al., Nature Phys. 6, 17 (2011).

${ }^{5}$ S. Parkin, U.S. Patent No. 309,6,834,005 (2004).

${ }^{6}$ S. Parkin et al., Science 320, 190 (2008).

${ }^{7}$ C. Chappert and A. Fert, Nature Mater. 6, 813 (2007).

${ }^{8}$ N. L. Schryer and L. R. Walker, J. Appl. Phys. 45, 5406 (1974).

${ }^{9}$ G. S. D. Beach et al., Phys. Rev. Lett. 97, 057203 (2006).

${ }^{10}$ M. Hayashi et al., Phys. Rev. Lett. 96, 197207 (2006).

${ }^{11}$ M. Hayashi et al., Nature Phys. 3, 21 (2007).

${ }^{12}$ M. Yan et al., Phys. Rev. Lett. 104, 057201 (2010).

${ }^{13}$ L. Heyne et al., Phys. Rev. Lett. 105, 187203 (2010).

${ }^{14}$ G. S. D. Beach et al., Nature Mater. 4, 741 (2005).

${ }^{15}$ J. Yang et al., Phys. Rev. B. 77, 014413 (2008).

${ }^{16}$ X. R. Wang et al., Europhys. Lett. 86, 67001 (2009).

17 A. Thiaville, Y. Nakatani, J. Miltat, and Y. Suzuki, Europhys. Lett. 69, 990 (2005).

${ }^{18}$ L. Heyne et al., Phys. Rev. Lett. 100, 066603 (2008).

${ }^{19}$ T. A. Moore et al., Phys. Rev. B. 80, 132403 (2009).

${ }^{20}$ S. Lepadatu et al., Phys. Rev. Lett. 102, 127203 (2009).

${ }^{21}$ M. Eltschka et al., Phys. Rev. Lett. 105, 056601 (2010).

${ }^{22}$ M. Kläui et al., Phys. Rev. B. 68,134426(2003). 
${ }^{23}$ A. Yamaguchi et al., Phys. Rev. Lett. 92, 077205 (2004).

${ }^{24}$ S. Emori et al., Appl. Phys. Lett. 98, 132508 (2011)

${ }^{25}$ M. Yamanouchi et al., Nature 428, 539 (2004).

${ }^{26}$ D. Ravelosona et al., Phys. Rev. Lett. 95, 117203 (2005).

${ }^{27}$ T. Taniyama et al., Phys. Rev. Lett. 82, 2780 (1999).

${ }^{28}$ M. Kläui et al., Phys. Rev. Lett. 95, 026601 (2005).

${ }^{29}$ J. Stöhr et al., Science 259, 658 (1993).

${ }^{30}$ J. Stöhr and S. Anders, IBM J. Res. Dev. 44, 535 (London, Pentech, 2000).

${ }^{31}$ S. P. Li et al., Phys. Rev. Lett. 86, 1102 (2001).

${ }^{32}$ K. S. Buchanan et al., Phys. Rev. B. 72, 134415 (2005).

${ }^{33}$ L. Thomas et al., Appl. Phys. Lett. 87, 262501 (2005).

${ }^{34}$ A. Vanhaverbeke et al., Phys. Rev. Lett. 101, 107202 (2008).

${ }^{35}$ J. Grollier et al., C.R.Physique. 12, 309 (2011).

${ }^{36}$ G. Tatara and H. Kohno, Phys. Rev. Lett. 92, 086601 (2004).

${ }^{37}$ Z. Li and S. Zhang, Phys. Rev. Lett. 92, 207203 (2004).

${ }^{38}$ S. E. Barnes and S. Maekawa, Phys. Rev. Lett. 95, 107204 (2005).

${ }^{39}$ L. Thomas et al., Science 330, 1810 (2010).

${ }^{40}$ L. Thomas et al., Nature 443, 197 (2006).

${ }^{41}$ E. Saltoh et al., Nature 432, 203 (2004).

${ }^{42}$ T. J. Silva, C. S. Lee, et al., J. Appl. Phys. 85, 7849 (1999).

${ }^{43}$ J. Fassbender, et al., Phys. Rev. B. 73, 184410 (2006).

${ }^{44}$ A. A. Aharoni, J. Appl. Phys. 83, 3432 (1998). 
${ }^{45}$ G. S. D. Beach, et al., J. Magn. Magn. Mater. 320, 1272 (2008).

${ }^{46}$ G. Tatara, and P. Entel, Phys. Rev. B. 78, 064429 (2008). 


\section{In-plane uniaxial magnetic anisotropy in epitaxial $\mathrm{Fe}_{3} \mathrm{O}_{4}-$ based hybrid structures on $\operatorname{GaAs}(100)^{*}$}

\subsection{Introduction}

The combination of strongly spin-polarized materials with semiconductors to form hybrid magnetic/semiconductor structures is an important theme in spintronics, which is aimed at straightforward integration with current magnetic technologies in microelectronics. ${ }^{1}$ A strong advantage of linking ferromagnetic materials with III-V

* A large part of this chapter appeared in Physical Review B 84, 104451 (2011). 
semiconductors ${ }^{2}$ is the benefit of utilizing materials widely employed in the microelectronics industry, i.e., such systems are well understood and enable the integration with existing technologies. ${ }^{3}$ One particularly interesting candidate for room-temperature spintronic applications that is readily available nowadays is halfmetallic $\mathrm{Fe}_{3} \mathrm{O}_{4}$ (magnetite), which is a ferrimagnet with a high Curie temperature, $T_{C}=858 \mathrm{~K} .{ }^{4}$ The strong spin polarization $(80 \%$ at room temperature) near the Fermi level ${ }^{5}$ in magnetite is expected to benefit the injection and electrical detection of carrier spins in a given semiconductor. ${ }^{6}$ For instance, magnetic tunnel transistors based on a $\mathrm{Fe}_{3} \mathrm{O}_{4}$ emitter have demonstrated a high efficiency of spin-dependent hot electron transport by utilizing the high degree of spin polarization in the oxide material. ${ }^{7}$

We previously realized the growth of epitaxial $\mathrm{Fe}_{3} \mathrm{O}_{4}$ films on $\mathrm{GaAs}(100)$ by combining the techniques of molecular beam epitaxy (MBE) and post-growth annealing of $\mathrm{Fe}$ thin films under an oxygen atmosphere. ${ }^{8-10}$ These films show an in-plane uniaxial magnetic anisotropy (UMA) with easy axis along the [0-11] direction of the GaAs(100) substrate, which is unexpected from a bulk crystal symmetry perspective.

In general, two distinctly different yet widely accepted mechanisms, viz., unidirectional interface bonding and anisotropic lattice relaxation, have been proposed to explain the presence of the UMA in hybrid ferromagnet/GaAs structures such as Fe/InAs ${ }^{11}$ and Fe/GaAs. ${ }^{12,13}$ The former effect is believed to be the source of the $\mathrm{UMA}$ in $\mathrm{Fe} / \mathrm{GaAs}$ heterostructures, given the close connection between magnetism and structural/electronic properties. ${ }^{14}$ Considering that $\mathrm{Fe}$ and $\mathrm{GaAs}$ have different electronic structures and bonding geometries, the Fe atoms have to adapt to a different bonding partner and also a different bonding geometry at the interface. The dangling Ga- and As bonds at GaAs(100) surfaces are oriented along orthogonal axes. The unidirectional interface bonding is thus thought to occur due to the uniaxial nature of $\mathrm{Fe} / \mathrm{Ga}$ and/or $\mathrm{Fe} / \mathrm{As}$ bonds at the interface between the two materials, where the detailed mechanism depends on the GaAs surface termination and reconstruction. ${ }^{14}$ Magnetic anisotropy caused by "unidirectional interface bonding" is strictly a surface term. In contrast, the effect of "anisotropic lattice 
relaxation" caused by initial anisotropic lattice mismatch is thickness dependent. The lattice constants of the ultrathin films deviate from that of the bulk due to the mismatch, and the strain is partially relaxed over a certain thickness range before reaching the bulk lattice constant. Uniaxial strain relaxation, occurring at different rates along two orthogonal directions, is thus thought to be another source for the UMA, ${ }^{15}$ and persists to the relaxation length of the lattice constant. Therefore, it should be possible to identify which of the two effects is dominant by measuring the strength of the anisotropies as a function of film thickness. ${ }^{16}$

In this chapter, we aim to correlate the observation of the UMA in the $\mathrm{Fe}_{3} \mathrm{O}_{4}$-based structures on GaAs to these two possible mechanisms by studying the anisotropy constants obtained using ferromagnetic resonance (FMR) measurements compared with detailed numerical simulations. Two specific systems are studied, namely $\mathrm{Fe}_{3} \mathrm{O}_{4} / \mathrm{GaAs}$ and $\mathrm{Fe}_{3} \mathrm{O}_{4} / \mathrm{MgO} / \mathrm{GaAs}$. The $\mathrm{MgO}$ tunneling barriers were already used ${ }^{17}$ to overcome the well-known conductivity mismatch between ferromagnetic metals and semiconductors in the diffusive regime. ${ }^{18}$ Half-metallic $\mathrm{Fe}_{3} \mathrm{O}_{4}$ with a $\mathrm{MgO}$ tunneling barrier ${ }^{19-21}$ is therefore an intriguing hybrid structure for a highly efficient spin injector in semiconductors at room temperature. ${ }^{22,23}$ The quality of the magnetite films fabricated by our approach was confirmed previously by a wide range of experimental techniques including x-ray photoelectron spectroscopy (XPS), X-ray magnetic circular dichroism (XMCD), reflection high energy electron diffraction (RHEED), magneto-optical Kerr effect (MOKE), and superconducting quantum interference device (SQUID) magnetrometry, as can be found elsewhere. ${ }^{24,25}$ In the following, we will show that in $\mathrm{Fe}_{3} \mathrm{O}_{4} / \mathrm{GaAs}$, the interfacial chemical bonding rather than strain relaxation is responsible for the presence of UMA. On the contrary, the UMA has a distinctly different origin in $\mathrm{Fe}_{3} \mathrm{O}_{4} / \mathrm{MgO} / \mathrm{GaAs}$, where strain relaxation in the $\mathrm{Fe}_{3} \mathrm{O}_{4}$ film dominates. 


\subsection{Experimental details}

Fe epitaxial films with a thickness spanning from 3 to $8 \mathrm{~nm}$ were deposited in a vacuum MBE system with a base pressure of $6 \times 10^{-9}$ mbar on $\operatorname{GaAs}(100)$ substrates at room temperature at a rate of 2 $\AA /$ min using electron-beam evaporation. The $\mathrm{Fe}$ films were then oxidized at $5 \times 10^{-5} \mathrm{mbar} \mathrm{O}_{2}$ pressure for $180 \mathrm{~s}$ at $500 \mathrm{~K}$ to form the $\mathrm{Fe}_{3} \mathrm{O}_{4}$ films (a higher oxygen pressure of $8 \times 10^{-4}$ mbar was used for the 8 -nm films), as has been described in our previous work. ${ }^{8,9}$ The GaAs surface was flat and well crystallized as evidenced by the RHEED pattern in Fig. 5.1(a). The thickness of the Fe layer before oxidation was monitored by an in situ microbalance. After oxidation, the thickness of the $\mathrm{Fe}_{3} \mathrm{O}_{4}$ film becomes twice the original $\mathrm{Fe}$ thickness, i.e., $t_{\mathrm{Fe} 3 \mathrm{O} 4}=6-16 \mathrm{~nm}$, as confirmed by atomic force microscopy and magnetization measurements. ${ }^{26}$

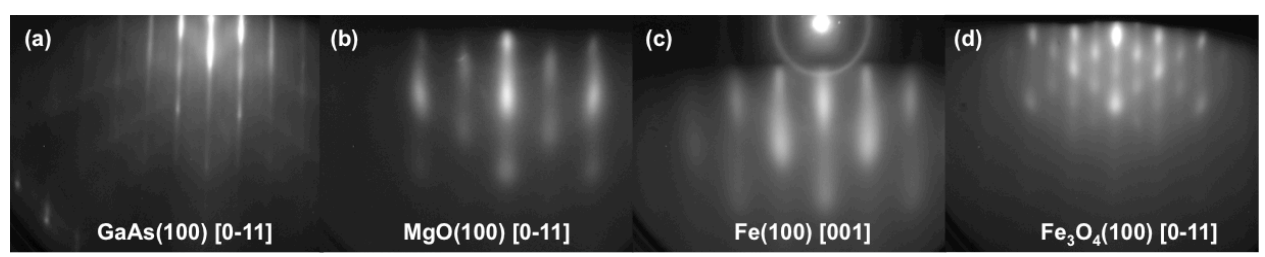

FIG. 5.1: RHEED patterns of (a) $\mathrm{GaAs}(100)$ with the electron beam along $\mathrm{GaAs}$ [0-11], (b) $\mathrm{MgO} / \mathrm{GaAs}$ along $\mathrm{MgO}$ [0-11], (c) $\mathrm{Fe} / \mathrm{MgO} / \mathrm{GaAs}$ along $\mathrm{Fe}[001]$, and (d) $\mathrm{Fe}_{3} \mathrm{O}_{4} / \mathrm{MgO} / \mathrm{GaAs}$ along $\mathrm{Fe}_{3} \mathrm{O}_{4}$ [0-11].

Thin films of $\mathrm{Fe}_{3} \mathrm{O}_{4}$ on top of $\mathrm{MgO} / \mathrm{GaAs}(100)$ were grown using the same procedures as described above. Figure 1(b) shows the RHEED pattern of a $2.0 \mathrm{~nm} \mathrm{MgO}$ layer epitaxially grown on a $\mathrm{GaAs}(100)$ surface by electron-beam evaporation of single crystal $\mathrm{MgO}$ at around $500 \mathrm{~K}$. The pattern is streaky with several elongated spots, indicating the presence of some small crystalline islands on the smooth surface of the $\mathrm{MgO}$ film. This is attributed to the relatively large lattice mismatch $(25.5 \%)$ between $\mathrm{GaAs}$ and $\mathrm{MgO}$ with an epitaxial relationship $\mathrm{MgO}(100)[001] / / \mathrm{GaAs}(100)[001] .{ }^{27}$ A $45^{\circ}$ rotation of the $\mathrm{Fe}$ unit cell with respect to the $\mathrm{MgO}$ lattice is seen in Fig. 5.1(c), which results in a small lattice mismatch of $3.8 \%$ and an 

epitaxial relationship $\mathrm{Fe}(100)[011] / / \mathrm{MgO}(100)[001] .^{28} \quad$ After annealing the Fe film in the oxygen environment, the typical RHEED pattern of $\mathrm{Fe}_{3} \mathrm{O}_{4}$ is obtained, which is illustrated in Fig. 1(d). It is noteworthy that the magnetite cell is rotated back by $45^{\circ}$ relative to the $\mathrm{MgO}$ lattice because such a configuration gives a nearly perfect lattice mismatch of $\sim 0.33 \%{ }^{29,30}$ with the $\mathrm{MgO}$ layer and the overall epitaxial relationship is thus given as $\mathrm{Fe}_{3} \mathrm{O}_{4}(100)[001] / / \mathrm{MgO}(100)[001] / / \mathrm{GaAs}(100)[001]$.

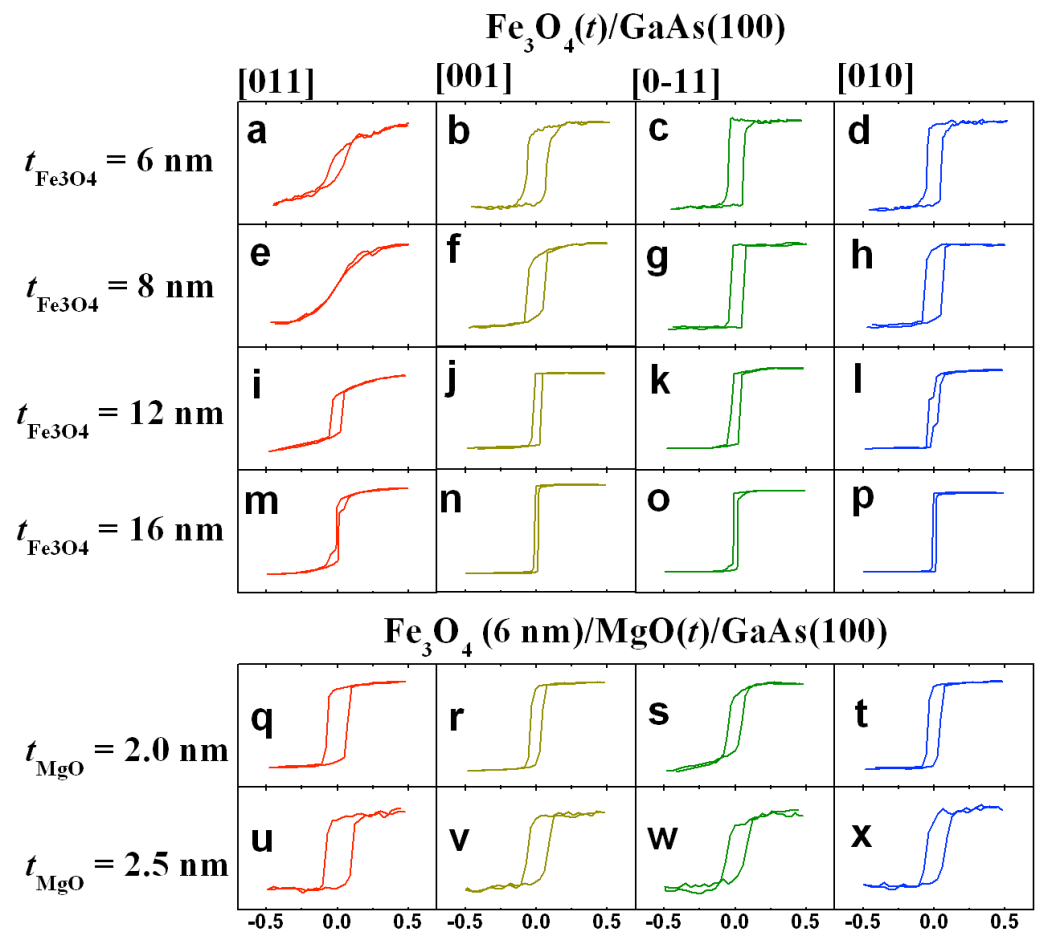

FIG. 5.2: $\mathrm{MOKE}$ loops of $\mathrm{Fe}_{3} \mathrm{O}_{4} / \mathrm{GaAs}(100)$ [upper panels: (a)-(p)] and $\mathrm{Fe}_{3} \mathrm{O}_{4} / \mathrm{MgO} / \mathrm{GaAs}(100)$ [lower panels: (q)-(x)]. The external magnetic field direction is labeled above each column with respect to the $\operatorname{GaAs}(100)$ substrate. The horizontal axis gives the magnetic field ranging from -0.5 to $+0.5 \mathrm{kOe}$, and the vertical axis gives the MOKE signal.

Magnetic hysteresis loops of the resulting Fe oxide films on $\operatorname{GaAs}(100)$ and $\mathrm{MgO} / \mathrm{GaAs}(100)$ were measured by MOKE. The 
magnetic field was applied along the four major axes of the $\operatorname{GaAs}(100)$ substrate, i.e., [011], [001], [0-11], and [010]. As is evident from Fig. 5.2, the MOKE results show a clear magnetic anisotropy in both film stacks.

A UMA with an easy axis along the [0-11] direction was found in $\mathrm{Fe}_{3} \mathrm{O}_{4} / \mathrm{GaAs}$, while the magnetic hard axis was along the [011] direction of the GaAs, as is seen from Fig. 5.2(a)-5.2(p). For the thicker films the UMA becomes weaker, while the cubic anisotropy becomes stronger with easy axes along $<011>$ directions (see also Fig. 5.3). In contrast with $\mathrm{Fe}_{3} \mathrm{O}_{4} / \mathrm{GaAs}$, the UMA easy axis in $\mathrm{Fe}_{3} \mathrm{O}_{4} / \mathrm{MgO} / \mathrm{GaAs}$ was found to be along the [011] direction and the hard axis along [0-11]. Furthermore, from Fig. 5.2(q)-5.2(x) we can see that the UMA is drastically reduced after insertion of the $\mathrm{MgO}$ barrier, in addition to an increase of the cubic anisotropy.

So far, such a UMA has only been observed in our epitaxial $\mathrm{Fe}_{3} \mathrm{O}_{4} / \mathrm{GaAs}$ and $\mathrm{Fe}_{3} \mathrm{O}_{4} / \mathrm{MgO} / \mathrm{GaAs}$ - not in similar structures grown by other techniques. ${ }^{31-33}$ To further investigate the origin of the UMA, we have extracted quantitative values for the anisotropy constants from FMR measurements and compared the magnitude of the surface and volume contributions to the anisotropy terms. The FMR measurements were performed at room temperature with a microwave frequency of $9.78 \mathrm{GHz}$, using a Bruker electron spin resonance setup (model ER-200D-SRC). The Landau-Lifshitz equation without damping for the magnetization dynamics is used to describe the precession of magnetization: ${ }^{34}$

$$
\frac{d \vec{M}}{d t}=-\gamma \vec{M} \times \vec{H}_{e f f}+\frac{G}{\gamma M^{2}}\left(\vec{M} \times \frac{d \vec{M}}{d t}\right),
$$

where $G$ is the Gilbert damping constant, and $H_{\text {eff }}$ is the effective magnetic field $H_{\text {eff }}=-d F / d \vec{M}$. Here $F$ is the total free energy for the single-crystal ultrathin film system, including the Zeeman energy, the demagnetizing energy, the perpendicular anisotropy energy, the inplane UMA energy and the cubic magnetocrystalline anisotropy energy.

The in-plane resonance fields $H_{\text {res }}$ can be calculated by using the following equation derived from the Landau-Lifshitz equation: ${ }^{35}$ 


$$
\begin{aligned}
& \left(\frac{\omega}{\gamma}\right)^{2}=\left[H \cos \left(\phi-\phi_{H}\right)+4 \pi M_{e f f}+H_{U} \cos 2 \phi+H_{1} \cos 4 \phi\right], \\
& \times\left[H \cos \left(\phi-\phi_{H}\right)+2 H_{U} \cos 2 \phi+4 H_{1} \cos 4 \phi\right]
\end{aligned}
$$

where the effective magnetization and the anisotropy fields are defined here as $4 \pi M_{\text {eff }}=4 \pi M-\frac{3 K_{1}+4 K_{\perp}}{2 M}$, and $H_{\mathrm{U}}=2 K_{\mathrm{U}} / M, H_{1}=$ $K_{1} /(2 M) . \phi$ and $\phi_{H}$ are the angles for the magnetization and applied field vector, respectively, in spherical coordinates. $\phi$ represents the inplane orientation with respect to the [0-11] direction of the GaAs substrate. $K_{\perp}$ is the perpendicular anisotropy constant, $K_{\mathrm{U}}$ is the inplane UMA constant, and $K_{1}$ is the cubic magnetic anisotropy constant. By fitting the experimental data with the calculated angle dependence of $H_{\text {res }}$, the values of the above anisotropy constants were obtained.

\subsection{Anisotropy constants as a function of $\mathrm{Fe}_{3} \mathrm{O}_{4}$ thickness in $\mathrm{Fe}_{3} \mathrm{O}_{4} / \mathrm{GaAs}$}

The initial Fe expitaxial film thicknesses were chosen to be in the range of 3-8 $\mathrm{nm}$ for investigating the magnetic anisotropies of our $\mathrm{Fe}_{3} \mathrm{O}_{4}$ films, based on our previous analysis: When the Fe thickness is close to $1.6 \mathrm{~nm}$, an $S$-shaped MOKE loop with zero hysteresis was observed, suggesting that the $\mathrm{Fe}_{3} \mathrm{O}_{4}$ film after oxidation is superparamagnetic. ${ }^{8}$ A good starting point is a Fe film thickness of 3 $\mathrm{nm}$, in which case the $\mathrm{Fe}$ is just fully oxidized and the $\mathrm{Fe}_{3} \mathrm{O}_{4}$ (thickness $6 \mathrm{~nm}$ ) shows ferrimagnetic behavior after oxidation. ${ }^{23}$ When the Fe thickness becomes $>8 \mathrm{~nm}$, the film will not be fully oxidized resulting in a $\mathrm{FeO}$ or even $\mathrm{Fe}$ layer underneath the $\mathrm{Fe}_{3} \mathrm{O}_{4}$ near the interface. ${ }^{10,24}$

FMR measurements provide the magnetic-field direction dependence of the resonance field for varying $\mathrm{Fe}_{3} \mathrm{O}_{4}$ thickness $\left(t_{\mathrm{Fe} 3 \mathrm{O} 4}\right.$ $=6-16 \mathrm{~nm})$, as depicted in Fig. 5.3. It is evident that the $\mathrm{Fe}_{3} \mathrm{O}_{4}(6$ $\mathrm{nm}) / \mathrm{GaAs}$ film shows a dominant uniaxial symmetry, $\sim \sin ^{2}\left(\phi_{H}\right)$, with an easy axis along [0-11] $\left(\phi_{H}=0^{\circ}\right)$ and hard axis along [011] $\left(\phi_{H}=\right.$ 
$90^{\circ}$ ), which are in good agreement with our previous work. ${ }^{9}$ For $t_{\mathrm{Fe} 3 \mathrm{O} 4}$ $\geq 8 \mathrm{~nm}$, fourfold cubic magnetocrystalline anisotropy starts to set in with the global hard axis still along the [011] direction of the GaAs; the [010] and [001] become equivalent magnetic easy directions, which is much more pronounced in the thicker films.

The values of the cubic anisotropy constant $K_{1}$ and the UMA constant $K_{\mathrm{U}}$ were extracted from a theoretical fit of the resonance field data. The saturation magnetization used for data fitting is 480 $\mathrm{emu} / \mathrm{cm}^{3}$, which is based on previous work on the magnetic moment of ultrathin $\mathrm{Fe}_{3} \mathrm{O}_{4}$ films. ${ }^{36}$ The moments of the $\mathrm{Fe}_{3} \mathrm{O}_{4}$ films in the thickness range of 8-12 $\mathrm{nm}$ were found to be close to the bulk value of single-crystalline magnetite. For the film thickness of $16 \mathrm{~nm}$, we adopted a higher oxygen partial pressure during the growth, in order to prevent the presence of residual $\mathrm{Fe}$ which has been found in Ref. 29. Figure 5.4 shows the values of $K_{1}$ and $K_{\mathrm{U}}$ obtained for $\mathrm{Fe}_{3} \mathrm{O}_{4} / \mathrm{GaAs}$ as a function of the inverse $\mathrm{Fe}_{3} \mathrm{O}_{4}$ thickness $1 / t_{\mathrm{Fe} 3 \mathrm{O} 4}$. The absolute value of the cubic anisotropy $\left|K_{1}\right|$ dominates at higher coverage but is strongly reduced for thinner films. In contrast, the uniaxial term, $K_{\mathrm{U}}$, is the largest for the thinnest film $\left(t_{\mathrm{Fe} 3 \mathrm{O} 4}=6 \mathrm{~nm}\right)$ and decreases with increasing $t_{\mathrm{Fe} 3 \mathrm{O} 4}$. The strong $1 / t_{\mathrm{Fe} 3 \mathrm{O} 4}$ dependences of $K_{\mathrm{U}}$ and $K_{1}$ in Fig. 5.4 demonstrate that the change in the surface term with $\mathrm{Fe}_{3} \mathrm{O}_{4}$ thickness is not significant. This implies that the surface contribution is constant (independent of the thickness), and therefore that the oxidation is almost uniform at the interface for various thicknesses.

Here, we treat $K_{\mathrm{U}}$ and $K_{1}$ as effective anisotropy constants; each is a combination of a volume- and surface (or interface) term, as suggested by Néel. ${ }^{37,38}$ The latter contains contributions from both the top surface as well as the bottom interface, but will be modeled in a single parameter because experimentally these two contributions cannot be easily separated. Following Néel's phenomenological theory, the effective in-plane uniaxial and fourfold cubic anisotropy constants $K_{\mathrm{U}}$ and $K_{1}$ can be written as:

$$
\begin{gathered}
K_{\mathrm{U}}=K_{\mathrm{U}, \mathrm{V}}+\frac{K_{\mathrm{U}, \mathrm{S}}}{t}, \\
K_{1}=K_{1, \mathrm{~V}}+\frac{K_{1, \mathrm{~S}}}{t},
\end{gathered}
$$


where $K_{\mathrm{U}, \mathrm{V}}$ and $K_{\mathrm{U}, \mathrm{S}}$ are the volume and surface terms for $K_{\mathrm{U}}, K_{1, \mathrm{~V}}$ and $K_{1, \mathrm{~S}}$ are those for $K_{1}$, and $t$ is here equal to the $\mathrm{Fe}_{3} \mathrm{O}_{4}$ thickness

$t_{\mathrm{Fe} 3 \mathrm{O} 4}$.

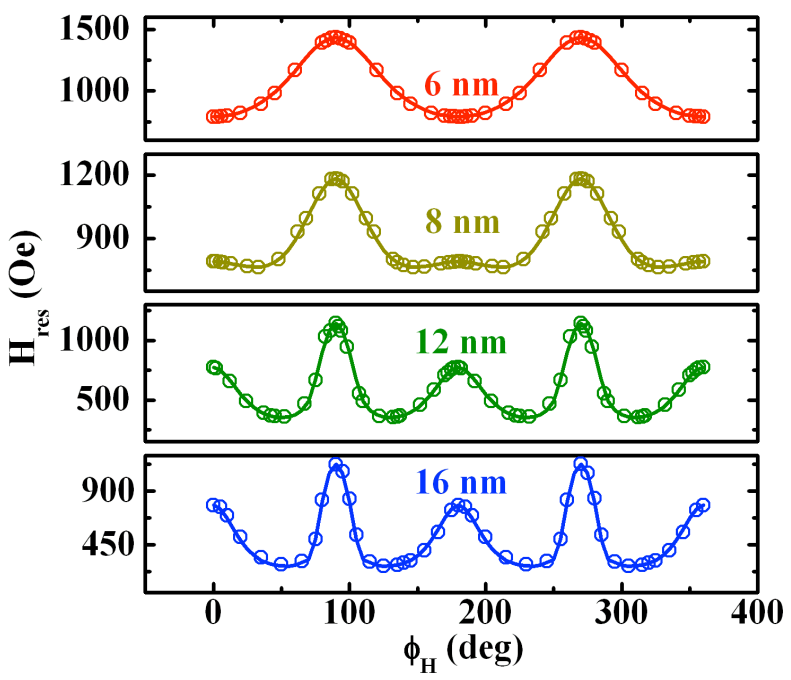

FIG. 5.3: Angular dependence of the FMR resonance field $H_{\text {res }}$ for $\mathrm{Fe}_{3} \mathrm{O}_{4}(6-16 \mathrm{~nm}) / \mathrm{GaAs}$, where $\phi_{H}=0^{\circ}, 45^{\circ}, 90^{\circ}$, and $135^{\circ}$ correspond respectively to the magnetic field applied along [0-11], [001], [011], and [010] of the GaAs(100). The circles represent the experimental data and the solid lines are theoretical fitted curves using the Landau-Lifshitz equation.

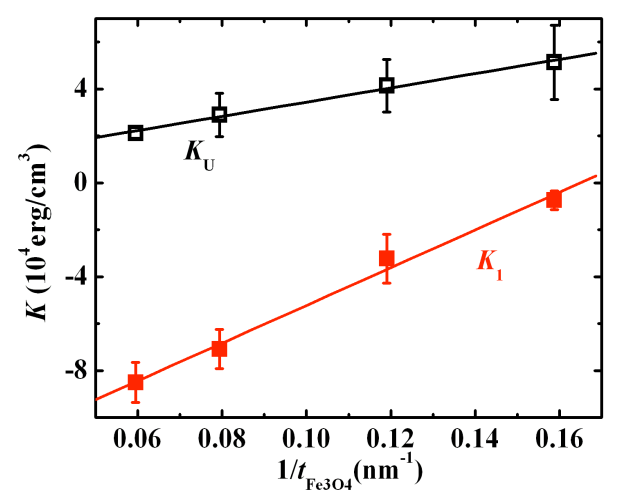

FIG. 5.4: Thickness dependence of the cubic $\left(K_{1}\right)$ and uniaxial $\left(K_{\mathrm{U}}\right)$ magnetic anisotropies of $\mathrm{Fe}_{3} \mathrm{O}_{4} / \mathrm{GaAs}(100)$. The straight lines are linear fits to the data points. 
Linear fits performed on the two data sets in Fig. 5.4 for $K_{1}$ and $K_{\mathrm{U}}$ as a function of $1 / t_{\mathrm{Fe} 3 \mathrm{O} 4}$, give important values of the volume and surface contributions to $K_{1}$ and $K_{\mathrm{U}}$, as listed in Table 5.1. For comparison, also included in the table are anisotropy constants for $\mathrm{Fe} / \mathrm{GaAs}$ taken from the literature.

TABLE 5.1. Values of the surface and volume terms of the magnetic anisotropy constants $K_{1}$ and $K_{\mathrm{U}}$ for epitaxial $\mathrm{Fe}_{3} \mathrm{O}_{4} / \mathrm{GaAs}(100)$ obtained from a linear fit of the experimental data as a function of $1 / t_{\mathrm{Fe} 3 \mathrm{O} 4}$. The lower entrees in the table give magnetic anisotropy constants taken from the literature. For bulk $\mathrm{Fe}_{3} \mathrm{O}_{4}, K_{1, \mathrm{~V}}=K_{1}=-11.8 \times 10^{4} \mathrm{erg} / \mathrm{cm}^{3}$.

\begin{tabular}{ccccc}
\hline \hline & $\begin{array}{c}K_{1, \mathrm{~V}} \\
\left(10^{5} \mathrm{erg} / \mathrm{cm}^{3}\right)\end{array}$ & $\begin{array}{c}K_{1, \mathrm{~S}} \\
\left(10^{-2} \mathrm{erg} / \mathrm{cm}^{2}\right)\end{array}$ & $\begin{array}{c}K_{\mathrm{U}, \mathrm{V}} \\
\left(10^{5} \mathrm{erg} / \mathrm{cm}^{3}\right)\end{array}$ & $\begin{array}{c}K_{\mathrm{U}, \mathrm{S}} \\
\left(10^{-2} \mathrm{erg} / \mathrm{cm}^{2}\right)\end{array}$ \\
\hline $\mathrm{Fe}_{3} \mathrm{O}_{4} / \mathrm{GaAs}^{2}$ & $-1.33 \pm 0.06$ & $8.04 \pm 0.52$ & $0.04 \pm 0.02$ & $3.03 \pm 0.19$ \\
\hline $\mathrm{Cu} / \mathrm{Fe} / \mathrm{GaAs}^{13}$ & $3.4 \pm 0.3$ & $-1.2 \pm 0.4$ & $-0.05 \pm 0.1$ & $2.2 \pm 0.1$ \\
$\mathrm{Cu} / \mathrm{Fe} / \mathrm{GaAs}^{39}$ & $4.6 \pm 0.3$ & $-5.1 \pm 0.5$ & - & $3.2 \pm 1.2$ \\
$\mathrm{Au} / \mathrm{Fe} / \mathrm{GaAs}^{16}$ & $3.7 \pm 0.3$ & $-3.2 \pm 0.5$ & - & $10.0 \pm 1.0$ \\
\hline \hline
\end{tabular}

From the results in Table 5.1, we see that the UMA has a distinct interface origin, while the cubic anisotropy contains both the expected volume term $K_{1, \mathrm{~V}}$ and a positive surface term $K_{1, \mathrm{~S}} \cdot{ }^{13}$ The thickest film $\left(t_{\mathrm{Fe} 3 \mathrm{O} 4}=16 \mathrm{~nm}\right)$ is predominantly fourfold, whereas the thinner films are mainly uniaxial.

In $\mathrm{Fe}_{3} \mathrm{O}_{4} / \mathrm{GaAs}, K_{1, \mathrm{~S}}$ has a sign opposite to the one in $\mathrm{Fe} / \mathrm{GaAs}$. This is caused by the negative sign of $K_{1}$ in the former, and implies that the easy axes of $K_{1}$ are rotated by $45^{\circ}$ compared to those of $\mathrm{Fe} / \mathrm{GaAs}$. The value of $K_{1, \mathrm{~V}}$ is slightly lower than expected for the bulk (See Table 5.1), indicating that even the thickest film studied here $\left(t_{\mathrm{Fe} 304}=16 \mathrm{~nm}\right)$ is not thick enough to recuperate entirely the bulk-like magnetic anisotropy that, as we found from the fits, should occur at $t_{\mathrm{Fe} 3 \mathrm{O} 4} \approx 54 \mathrm{~nm}$.

The results discussed above, and in particular the linear dependence of the uniaxial- and cubic anisotropy constants on $1 / t_{\mathrm{Fe} 3 \mathrm{O} 4}$, confirm that interface bonding rather than strain relaxation plays a dominant role in causing the UMA in the $\mathrm{Fe}_{3} \mathrm{O}_{4} / \mathrm{GaAs}$, which is the same as in the Fe/GaAs. Compared to the $K_{\mathrm{U}} \approx 10^{5} \mathrm{erg} / \mathrm{cm}^{3}$ for $\mathrm{Fe} / \mathrm{GaAs},{ }^{13,16,39}$ the $K_{\mathrm{U}} \approx 10^{4} \mathrm{erg} / \mathrm{cm}^{3}$ for the $\mathrm{Fe}_{3} \mathrm{O}_{4} / \mathrm{GaAs}$ structure is 
almost an order of magnitude smaller, implying that the uniaxial nature of the $\mathrm{Fe} / \mathrm{Ga}$ interface bonding is greatly reduced after the oxidation.

\subsection{Anisotropy constants as a function of $\mathrm{MgO}$ thickness in $\mathrm{Fe}_{3} \mathrm{O}_{4}(6 \mathrm{~nm}) / \mathrm{MgO} / \mathrm{GaAs}$}

We performed FMR measurements on $\mathrm{Fe}_{3} \mathrm{O}_{4}(6 \mathrm{~nm}) / \mathrm{MgO} / \mathrm{GaAs}$ with varying $\mathrm{MgO}$ thickness to determine the magnetic anisotropy in such structures. Figure 5.5 illustrates the variation of the FMR field as a function of the in-plane orientation for $\mathrm{Fe}_{3} \mathrm{O}_{4}$ films $\left(t_{\mathrm{Fe} 3 \mathrm{O} 4}=6 \mathrm{~nm}\right)$ with varying $\mathrm{MgO}$ thickness $\left(t_{\mathrm{MgO}}=0,2.0\right.$, and $\left.2.5 \mathrm{~nm}\right)$. The $\mathrm{Fe}_{3} \mathrm{O}_{4} / \mathrm{GaAs}$ film in Fig. 5.5(a) shows a dominant uniaxial anisotropy, as already pointed out in Sec. 5.3. In contrast, Fig. 5.5(b) and 5.5(c) both show a global hard axis along [0-11] of the $\operatorname{GaAs}(100)$, indicating a $90^{\circ}$ rotation of the UMA axes in $\mathrm{Fe}_{3} \mathrm{O}_{4} / \mathrm{MgO} / \mathrm{GaAs}$ with respect to $\mathrm{Fe}_{3} \mathrm{O}_{4} / \mathrm{GaAs}$. Figure 5.5(b) shows that for the $\mathrm{Fe}_{3} \mathrm{O}_{4}$ film with $t_{\mathrm{MgO}}=2.0 \mathrm{~nm}$, the angular dependence of the resonance field contains a small component of fourfold symmetry, $\sim \sin ^{2}\left(2 \phi_{H}\right)$, superimposed on the UMA, indicating an in-plane cubic magnetocrystalline anisotropy coexisting with the UMA. Figure 5.5(c) shows a similar trend for the $\mathrm{Fe}_{3} \mathrm{O}_{4}$ film with $t_{\mathrm{MgO}}=2.5 \mathrm{~nm}$ as in Fig. 5.5(b), but with increased fourfold symmetry contribution due to stronger cubic anisotropy. These results have been quantified by theoretical fitting, resulting in the $K_{\mathrm{U}}$ and $K_{1}$ values that are listed in Table 5.2.

TABLE 5.2. Anisotropy constants for $\mathrm{Fe}_{3} \mathrm{O}_{4}(6 \mathrm{~nm}) / \mathrm{MgO} / \mathrm{GaAs}(100)$ with varying $\mathrm{MgO}$ thickness $t_{\mathrm{MgO}}$ obtained from FMR.

\begin{tabular}{ccc}
\hline \hline$t_{\mathrm{MgO}}(\mathrm{nm})$ & $K_{1}\left(10^{4} \mathrm{erg} / \mathrm{cm}^{3}\right)$ & $K_{\mathrm{U}}\left(10^{4} \mathrm{erg} / \mathrm{cm}^{3}\right)$ \\
\hline 0 & -0.49 & 4.05 \\
2.0 & -1.42 & -1.32 \\
2.5 & -2.75 & -0.86 \\
\hline \hline
\end{tabular}



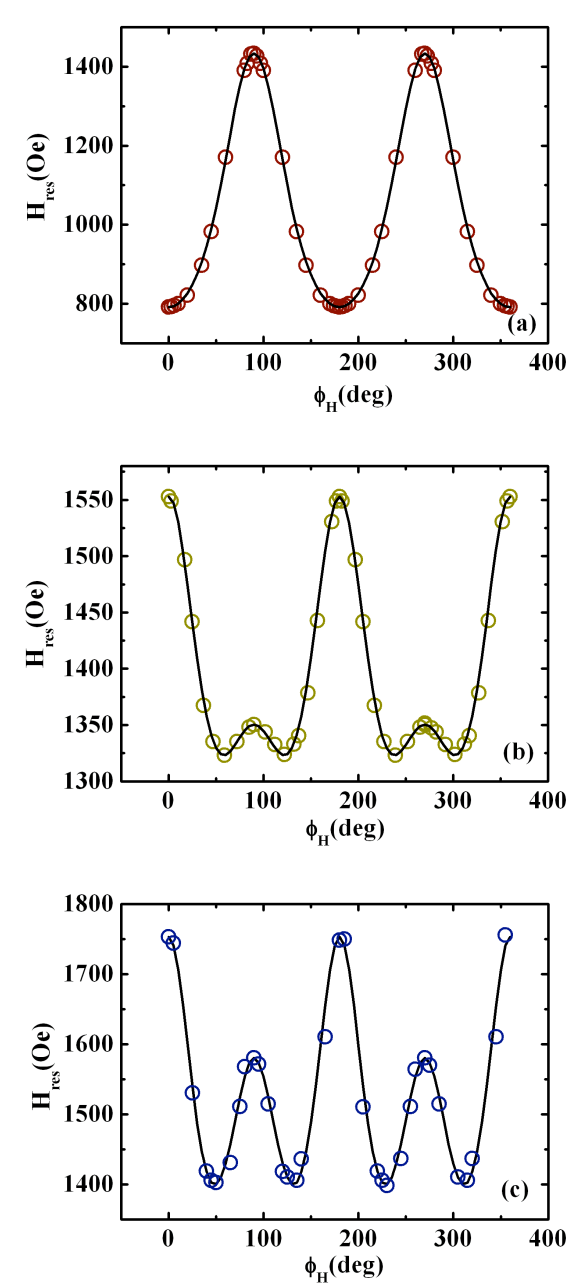

FIG. 5.5: Angular dependence of the FMR resonance field $H_{\text {res }}$ for $\mathrm{Fe}_{3} \mathrm{O}_{4} / \mathrm{MgO} / \mathrm{GaAs}$, where $\phi_{H}=0^{\circ}, 45^{\circ}, 90^{\circ}$, and $135^{\circ}$ correspond respectively to the magnetic field applied along [0-11], [001], [011], and [010] of the $\mathrm{GaAs}(100)$. (a) $\mathrm{Fe}_{3} \mathrm{O}_{4}(6 \mathrm{~nm}) / \mathrm{GaAs}$, (b) $\mathrm{Fe}_{3} \mathrm{O}_{4}(6 \mathrm{~nm}) / \mathrm{MgO}(2.0$ $\mathrm{nm}) / \mathrm{GaAs}$, and (c) $\mathrm{Fe}_{3} \mathrm{O}_{4}(6 \mathrm{~nm}) / \mathrm{MgO}(2.5 \mathrm{~nm}) / \mathrm{GaAs}$. The dots represent the experimental data and the solid lines are theoretical fitted curves.

There are two important observations that transpire from Table 5.2: (i) the opposite signs of $K_{\mathrm{U}}$ for $\mathrm{Fe}_{3} \mathrm{O}_{4} / \mathrm{GaAs}(100)$ and $\mathrm{Fe}_{3} \mathrm{O}_{4} / \mathrm{MgO} / \mathrm{GaAs}(100)$, indicating a $90^{\circ}$ rotation of the magnetic axes of the UMA between both structures, and (ii) the large decrease 
in magnitude of $K_{\mathrm{U}}$ in the $\mathrm{Fe}_{3} \mathrm{O}_{4} / \mathrm{MgO} / \mathrm{GaAs}$ system with increasing $\mathrm{MgO}$ thickness. By comparing the 6-nm-thick $\mathrm{Fe}_{3} \mathrm{O}_{4}$ film on GaAs with those of the same thickness on $\mathrm{MgO} / \mathrm{GaAs}$, where the former has negligible cubic anisotropy but a strong in-plane UMA while the latter exhibits dominant cubic anisotropy and a weak UMA, we can already see the following: (i) the interfacial contact between the GaAs substrate and the $\mathrm{Fe}_{3} \mathrm{O}_{4}$ layer plays an important and direct role in causing the observed UMA in $\mathrm{Fe}_{3} \mathrm{O}_{4} / \mathrm{GaAs}$, which is consistent with the conclusion drawn in Sec. 5.3, and (ii) the GaAs substrate underneath the $\mathrm{MgO}$ interlayer plays a crucial role in inducing the weak UMA in the case of $\mathrm{Fe}_{3} \mathrm{O}_{4} / \mathrm{MgO} / \mathrm{GaAs}$, which we explain next.

The presence of UMA in $\mathrm{Fe}_{3} \mathrm{O}_{4} / \mathrm{MgO} / \mathrm{GaAs}(100)$ seems surprising, since any mechanism related to interfacial uniaxial bonding can readily be ruled out, because no in-plane UMA is observed for $\mathrm{Fe}_{3} \mathrm{O}_{4}$ films grown on $\mathrm{MgO}$ substrates. ${ }^{29,40-43}$ Therefore, it is plausible that the GaAs substrate underneath the $\mathrm{MgO}$ plays a crucial role in inducing this unexpected anisotropy. Given the relatively large lattice mismatch between GaAs and $\mathrm{MgO}(25.5 \%)^{27}$, it is expected that the $\mathrm{MgO}$ interlayer is highly strained after deposition on the GaAs substrate, which has a direct consequence on the strain in the $\mathrm{Fe}_{3} \mathrm{O}_{4}$ layer due to the extremely small lattice mismatch between $\mathrm{Fe}_{3} \mathrm{O}_{4}$ and $\mathrm{MgO}(0.33 \%)^{29,30}$. When the $\mathrm{MgO}$ is thicker, the magnitude of $K_{\mathrm{U}}$ becomes smaller, which confirms that a strain or strain-induced disorder mechanism originating from the $\mathrm{MgO} / \mathrm{GaAs}$ interface is therefore one possible source responsible for the UMA observed in the $\mathrm{Fe}_{3} \mathrm{O}_{4} / \mathrm{MgO} / \mathrm{GaAs}$.

\subsection{Conclusion}

The magnetic anisotropy constants of $\mathrm{Fe}_{3} \mathrm{O}_{4} / \mathrm{GaAs}$ and $\mathrm{Fe}_{3} \mathrm{O}_{4} / \mathrm{MgO} / \mathrm{GaAs}(100)$ epitaxial spintronic structures were quantitatively determined using FMR measurements. From a linear fit of the anisotropy constants as a function of the inverse thickness of the magnetic film, the surface and volume contributions to both the cubic and uniaxial anisotropies were distinguished. It was found that the unidirectional interface bonding rather than the strain effect is the main origin of the observed UMA in $\mathrm{Fe}_{3} \mathrm{O}_{4} / \mathrm{GaAs}$. In contrast, in the 
$\mathrm{Fe}_{3} \mathrm{O}_{4} / \mathrm{MgO} / \mathrm{GaAs}$ system the magnetic easy axes of the UMA are rotated by $90^{\circ}$ compared to $\mathrm{Fe}_{3} \mathrm{O}_{4} / \mathrm{GaAs}$, along with a decrease in the magnitude of the UMA. The residual strain in the $\mathrm{Fe}_{3} \mathrm{O}_{4}$ films is responsible for the unexpected UMA in $\mathrm{Fe}_{3} \mathrm{O}_{4} / \mathrm{MgO} / \mathrm{GaAs}$, which is distinctively different from that in $\mathrm{Fe}_{3} \mathrm{O}_{4} / \mathrm{GaAs}$.

Keeping in mind that strain relaxation may occur gradually as the film thickness is increased, leading to a UMA that is thickness dependent, those two preceding mechanisms are not necessarily easy to separate and are likely to contribute simultaneously. Although the experimental results of this work are in good agreement with our proposed mechanisms, detailed structural information, which can be provided by x-ray diffraction and transmission electron microscopy, would be needed to provide further insight into the atomic scale origin of the UMA in such epitaxial $\mathrm{Fe}_{3} \mathrm{O}_{4}$-based hybrid structures on $\operatorname{GaAs}(100)$.

\subsection{Outlook}

Combining the advantage of high Curie temperature $T_{\mathrm{C}}=851 \mathrm{~K}$ with that of high spin polarization of up to $80 \%$ at room temperature, ${ }^{44}$ magnetite is a promising material for current-driven domain wall (DW) displacement via the spin transfer torque effect, where the performance of these DW-based devices depends on the spin polarization of the current. In practice, however, a disadvantage might be the more complicated magnetic anisotropies present in crystalline magnetite thin films, which will lead to more complex domain structures than in the commonly used polycrystalline $3 d$ metals such as permalloy.

Kläui et al. have studied the domain structure in a $\mathrm{Fe}_{3} \mathrm{O}_{4}$ ring with a diameter of $10 \mu \mathrm{m}$ and nominal width of $1135 \mathrm{~nm}$ using XPEEM imaging, as shown in Fig. 5.6. ${ }^{45}$ The magnetization is divided into four domains, which is a consequence of the strong cubic in-plane magnetocrystalline anisotropy of $\mathrm{Fe}_{3} \mathrm{O}_{4}$ films. The appearance of the zigzag DW structure (marked with B) results from the energetic balance between the cubic magnetocrystalline anisotropy, the exchange, and dipolar coupling. This illustrates that the anisotropies in magnetite nano-scale objects are not as simple as those in soft magnetic permalloy nano-objects. In particular, the 
intrinsic cubic magnetocrystalline anisotropy ${ }^{46}$ should also be taken into account in magnetite structures besides shape anisotropy.

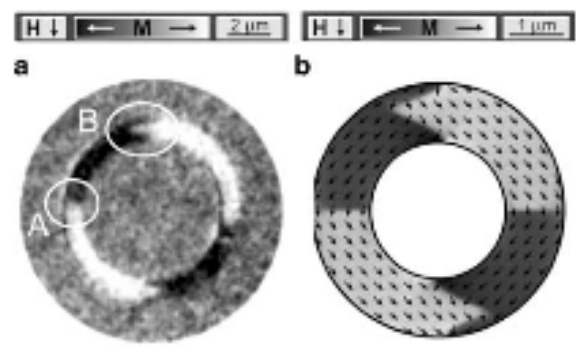

FIG. 5.6: (a) High-resolution XPEEM image of a $\mathrm{Fe}_{3} \mathrm{O}_{4}$ ring at remanence. A $90^{\circ}$ DW (marked with A) and a tail-to-tail zigzag DW (marked with B) are visible. At the opposite side of the ring one more $90^{\circ}$ DW and a head-to-head zigzag DW are also present. The black (white) contrast in the XPEEM image indicates the horizontal component of the in-plane magnetization direction pointing to the left (right). (b) Micromagnetic simulation for the $\mathrm{Fe}_{3} \mathrm{O}_{4}$ ring in the remanent state after saturation. ${ }^{45}$

From the above study on the $\mathrm{Fe}_{3} \mathrm{O}_{4} / \mathrm{GaAs}(100)$ and $\mathrm{Fe}_{3} \mathrm{O}_{4} / \mathrm{MgO} / \mathrm{GaAs}(100)$ thin films grown by us, we found that for a certain thickness of magnetite, namely, in $\mathrm{Fe}_{3} \mathrm{O}_{4}(6 \mathrm{~nm}) / \mathrm{GaAs}(100)$, the cubic anisotropy is very small. As a result, the complex DW structure arising from the cubic anisotropy could be avoided in nanowires patterned from our $\mathrm{Fe}_{3} \mathrm{O}_{4}(6 \mathrm{~nm}) / \mathrm{GaAs}(100)$ thin films, which exhibit UMA only. One may even be able to control the domain structure in DW-based devices by taking advantage of this inplane UMA, provided that the magnetic field is applied in a proper direction with respect to its easy or hard axis.

Based on the above, an XPEEM study of current-driven DW motion in nanowires patterned from single-crystalline 6-nm-thick $\mathrm{Fe}_{3} \mathrm{O}_{4}$ thin films on $\mathrm{GaAs}(100)$ is proposed as future work. Unlike techniques such as magnetic force microscopy, it is possible to observe magnetic states without any magnetic field produced from the detector by taking advantage of the nonintrusive XPEEM imaging technique. ${ }^{47}$ As shown in the scanning electron microscopy (SEM) 
picture in Fig. 5.7, we have succeeded in patterning several sets of such wires by focused ion beam (FIB) lithography after the growth of the 6-nm-thick film on GaAs substrate. They are 1- $\mu \mathrm{m}$-wide wires with a range of nanocontacts from $100 \mathrm{~nm}$ to $600 \mathrm{~nm}$ wide, located at the wire center. The long axes of the wires are either parallel or perpendicular to the easy axis of the UMA in the film, so that we can investigate the domain structures in different directions. The elliptical pads and the sharp tips in the top wires could be used to control the nucleation and annihilation of DWs, respectively. ${ }^{48}$

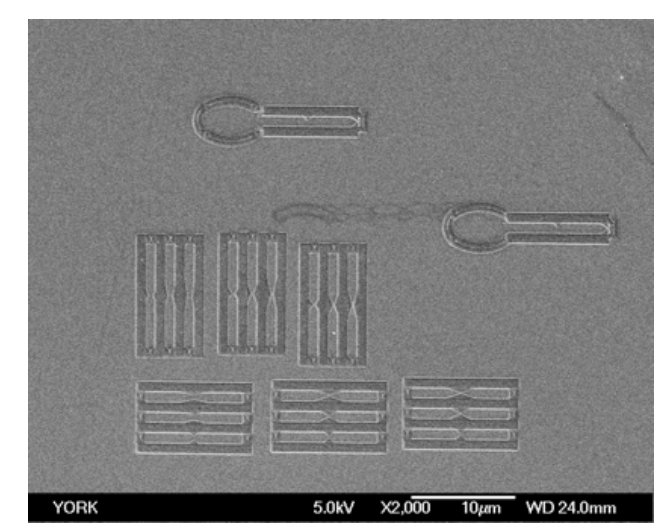

FIG. 5.7: $\mathrm{SEM}$ picture of patterned $\mathrm{Fe}_{3} \mathrm{O}_{4}$ nanowires with artificial notches.

As has been mentioned in Chapter 1, it is expected that the high degree of spin polarization in magnetite could help reduce the threshold current density of DW motion in these kinds of nanowires and improve the performance of devices based on current-induced DW dynamics. 


\section{References}

${ }^{1}$ I. Zutic, J. Fabian, S. Das Sarma, Rev. Mod. Phys. 76, 323 (2004).

2 J. J. Krebs, B. T. Jonker, and G. A. Prinz, J. Appl. Phys. 61, 2596 (1987).

${ }^{3}$ P. K. J. Wong and Y. B. Xu, in Spintronic Material and Technology, (Taylor \& Francis Group, New York \& London, 2006), Chap. 15, pp. 337-370.

${ }^{4}$ M. L. Glasser and F. J. Milford, Phys. Rev. 130, 1783 (1963).

${ }^{5}$ Y. S. Dedkov, U. Rudiger, and G. Guntherodt, Phys. Rev. B. 65, 064417 (2002).

${ }^{6}$ R. Mansell, J. -B. Laloe, S. N. Holmes, P. K. J. Wong, Y. B. Xu, I. Farrer, G. A. C. Jones, D. A. Ritchie, and C. H. W. Barnes, J. Appl. Phys. 108, 034507 (2010).

${ }^{7}$ K. S. Yoon, J. Y. Yang, K. W. Kim, J. H. Koo, C. O. Kim, and J. P. Hong, J. Appl. Phys. 95, 6933 (2004).

${ }^{8}$ Y. X. Lu, J. S. Claydon, Y. B. Xu, D. M. Schofield, and S. M. Thompson, J. Appl. Phys. 95, 7228 (2004).

${ }^{9}$ Y. X. Lu, J. S. Claydon, Y. B. Xu, S. M. Thompson, K. Wilson, and G. van der Laan, Phys. Rev. B 70, 233304 (2004),

${ }^{10}$ E. Liu, J. Z. Zhang, W. Zhang, P. K. J. Wong, L. Y. Lv, Y. Zhai, Y. B. Xu, and H. R. Zhai, J. Appl. Phys. 109, 07C121 (2011).

${ }^{11}$ Y. B. Xu, D. J. Freeland, M. Tselepi, J. A. C. Bland, Phys. Rev. B 62, 1167 (2000).

${ }^{12}$ O. Thomas, Q. Shen, P. Schieffer, N. Tournerie, and B. Lepine, Phys. Rev. Lett. 90, 017205 (2003).

${ }^{13}$ M. Madami, S. Tacci, G. Carlotti, G. Gubbiotti, R. L. Stamps, Phys. Rev. B 69, 144408 (2004).

${ }^{14}$ G. Wastlbauer, and J. A. C. Bland, Adv. Phys. 54, 137 (2005).

${ }^{15}$ Y. B. Xu, D. J. Freeland, M. Tselepi, and J. A. C. Bland, J. Appl. Phys. 87, 6110 (2000).

${ }^{16}$ S. Mcphail, C. M. Gurtler, F. Montaigne, Y. B. Xu, M. Tselepi, J. A. C. Bland, Phys. Rev. B 67, 024409 (2003).

${ }^{17}$ R. Wang, X. Jiang, R. M. Shelby, R. M. Macfarlane, S. S. P. Parkin, S. R. Bank, 
and J. S. Harris, Appl. Phys. Lett. 86, 052901 (2005).

${ }^{18}$ G. Schmidt, D. Ferrand, L. W. Molenkamp, A. T. Filip, and B. J. van Wees, Phys. Rev. B 62, R4790 (2000).

${ }^{19}$ X. W. Li, A. Gupta, G. Xiao, W. Qian, and V. P. Dravid, Appl. Phys. Lett. 73, 3282 (1998).

${ }^{20}$ T. Kiyomura, M. Gomi, Y. Maruo, and H. Toyoshima, IEEE Trans. Magn. 35, 3046 (1999).

${ }^{21}$ S. Kale, S. M. Bhagat, S. E. Lofland, T. Scabarozi, S. B. Ogale, A. Orozco, S. R. Shinde, T. Venkatesan, B. Hannoyer, B. Mercey, and W. Prellier, Phys. Rev. B 64, 205413 (2001).

${ }^{22}$ P. K. J. Wong, W. Zhang, and Y. B. Xu, Phys. Stat. Solidi. A (accepted) DOI: 10.1002/pssa. 201084175.

${ }^{23}$ P. K. J. Wong, W. Zhang, Y. B. Xu, S. Hassan, and S. M. Thompson, IEEE. Trans. Magn. 44, 2640 (2008).

${ }^{24}$ Y. X. Lu, J. S. Claydon, E. Ahmad, Y. B. Xu, S. M. Thompson, K. Wilson, and G. van der Laan, IEEE Trans. Magn. 41, 2808 (2005).

${ }^{25}$ P. K. J. Wong, W. Zhang, X. G. Cui, Y. B. Xu, J. Wu, Z. K. Tao, X. Li, Z. L. Xie, R. Zhang, and G. van der Laan, Phys. Rev. B 81, 035419 (2010).

${ }^{26}$ Z. C. Huang, Y. Zhai, Y. X. Lu, G. D. Li, P. K. J. Wong, Y. B. Xu, Y. X. Xu, and H. R. Zhai, Appl. Phys. Lett. 92, 113105 (2008).

${ }^{27}$ K. Nashimoto, D. K. Fork, and T. H. Geballe, Appl. Phys. Lett. 60, 1199 (1992); W. Y. Hsu, and R. Raj, Appl. Phys. Lett. 60, 3105 (1992).

${ }^{28}$ C. M. Boubeta, A. Cebollada, et al., J. Appl. Phys. 93, 2126 (2003).

${ }^{29}$ D. T. Margulies, F. T. Parker, F. E. Spada, R. S. Goldman, J. Li, R. Sinclair, and A. E. Berkowitz, Phys. Rev. B. 53, 9175 (1996).

${ }^{30}$ T. Hibma, F. C. Voogt, L. Niesen, P. A. A. van der Heijden, W. J. M. de Jonge, J. J. T. M. Donkers, and P. J. van der Zaag, J. Appl. Phys. 85, 5291 (1999).

${ }^{31}$ M. Luysberg, R. G. S. Sofin, S. K. Arora, and I. V. Shvets, Phys. Rev. B 80, 024111 (2009).

${ }^{32}$ E. J. Preisler, J. Brooke, N. C. Oldham, and T. C. McGill, J. Vac. Sci. Technol. B. 21, 1745 (2003). 
In-plane uniaxial magnetic anisotropy in epitaxial $\mathrm{Fe}_{3} \mathrm{O}_{4}$-based hybrid structures on GaAs(100)

${ }^{33}$ F. C. Voogt, T. Fujii, P. J. M. Smulders, L. Niesen, M. A. James, and T. Hibma, Phys. Rev. B 60, 11193 (1999).

${ }^{34}$ S. V. Vonsovskii, Ferromagnetic Resonance (Pergamon, London, 1966).

35 J. Smit and H. C. Beljers, Philips Res. Rep. 10, 113 (1955).

${ }^{36}$ Y. Zhai, L. Sun, Z. C. Huang, Y. X. Lu, G. D. Li, Q. Li, Y. B. Xu, J. Wu, and H.

R. Zhai, J. Appl. Phys. 107, 09B110 (2010).

${ }^{37}$ L. Néel, J. Phys. Radium. 15, 225 (1954).

${ }^{38}$ G. Bayreuther, M. Dumm, B. Uhl, R. Meier, and W. Kipferl. J. Appl. Phys. 93, 8230 (2003).

${ }^{39}$ T. L. Monchesky, B. Heinrich, R. Urban, K. Myrtle, M. Klaua, and J. Kirschner, Phys. Rev. B 60, 10242 (1999).

${ }^{40}$ D. M. Lind, S. D. Berry, G. Chern, H. Mathias, and L. R. Testardi, Phys. Rev. B 45, 1838 (1992).

${ }^{41}$ W. Eerenstein, T. T. M. Palstra, T. Hibma, and S. Celotto, Phys. Rev. B. 68, 014428 (2003).

${ }^{42}$ X. W. Li, A. Gupta, G. Xiao, and G. Q. Gong, J. Appl. Phys. 83, 7049 (1998).

${ }^{43}$ F. C. Voogt, T. T. M. Palstra, L. Niesen, O. C. Rogojanu, M. A. Janes, and T. Hibma, Phys. Rev. B. 57, R8107 (1998).

${ }^{44}$ Y.S. Dedkov, et al., Appl. Phys. Lett. 80, 4181 (2002).

45 M. Kläui, in Magnetism and Synchrotron Radiation, Springer Proceedings in Physics 133, Ch. 13, p. 367 (Springer-Verlag, Berlin, Heidelberg, 2010).

${ }^{46}$ M. Ziese, et al., Phys. Rev. B. 66, 134408 (2002).

${ }^{47}$ M. Kläui, et al., Phys. Rev. B. 66, 134426 (2003).

${ }^{48}$ L. Thomas, C. Rettner, M. Hayashi, M. G. Samant, and S. S. P. Parkin, Appl. Phys. Lett. 87, 262501 (2005). 



\section{CHAPTER 6}

\section{Enhanced magnetic anisotropy of FeGd thin films at low temperature}

\subsection{Introduction}

Rare earth (RE) and transition metal (TM) compounds are technologically important materials which, for over two decades, have been widely used in applications such as high-performance permanent magnets and magneto-optic recording media. ${ }^{1-6}$ Such intermetallic compounds present complex and also interesting macroscopic and microscopic magnetic properties due to the interplay between the strong coupling from itinerant magnetism of the TM and the anisotropic and localized magnetic properties of the RE. ${ }^{7}$

More recently, these intermetallic compounds have attracted a vast amount of renewed experimental and theoretical interests owing

Some part of this chapter, combined with further measurement results and calculations, is in preparation for submission to a journal. 
to their potential applications in spintronics, which is a rapidly emerging field of research with particular emphasis on controlling the spin degree of freedom as well as the charge. ${ }^{8,9}$ The most widely used ferromagnetic materials for room-temperature (RT) spintronic applications are $\mathrm{Fe}$ or Fe-based alloys, such as $\mathrm{Fe}, \mathrm{FeCo}$ and $\mathrm{FeNi}$, due to their advantages of relatively strong spin polarization and high Curie temperature. ${ }^{10,11}$ It is thus intriguing to tailor the magnetic properties of this kind of TM or its alloys by doping with RE atoms in order to facilitate the design of next generation solid-state devices.

Usually high RE content in RE-TM alloys has been found to effectively enhance the magnetization damping because of the large RE spin-orbit interaction ${ }^{12,13}$ and to produce strong perpendicular magnetic anisotropy ${ }^{14-16}$. However, this strong perpendicular anisotropy is not always desirable in some areas of spintronic applications, e.g., domain-wall-based devices, which relatively soft magnetism, to allow for tailoring via shape anisotropy. In this regard, the study of appropriate RE dosages that preserve the soft magnetic properties of transition metals deserves to be paid attention to.

For this purpose, we studied the magnetic anisotropy and magnetic moments of a series of binary Fe-Gd thin films with Gd impurities of no more than $20 \%$, which exhibit an in-plane uniaxial magnetic anisotropy, via element-specific X-ray magnetic circular dichroism (XMCD), which is an ideal technique to characterize the magnetic properties of different elements in a multicomponent material. ${ }^{17}$ Gadolinium has been chosen due to its high Curie temperature approaching RT and the collinear alignment of its moments at RT. ${ }^{18}$ Most recently, Gd doped permalloy has also been used to advantageously alter the spin-transfer velocity in magnetic nanostrips, ${ }^{19-21}$ which are the base for future racetrack memory technology. ${ }^{22}$ In this chapter, by exploiting the advantages of XMCD, we aim to investigate the role of the Gd doping $\leq 20 \%$ on the magnetic anisotropy of the Fe-Gd thin films. In addition, outstanding questions regarding amorphous RE-TM alloys, such as the relationship between magnetization and local structure, where the latter is described by the TM-TM, TM-RE and RE-RE pairs, ${ }^{23}$ is also addressed. 


\subsection{Sample growth and structural characterization}

A series of 30-nm-thick $\mathrm{Fe}_{1-x} \mathrm{Gd}_{x}$ thin films with buffer layer of 5-nmthick $\mathrm{Ta}$ were deposited on $\mathrm{Si}$ substrates at $\mathrm{RT}$ by magnetron sputtering with a base pressure of $1.0 \times 10^{-5} \mathrm{~Pa}$, argon pressure of 0.3 $\mathrm{Pa}$, and an incident $\mathrm{DC}$ power of $30 \mathrm{~W}$ in Southeast University, China. A thin layer of 1-nm-thick Ta was deposited afterwards as a cap in order to prevent oxidization, and simultaneously allow for the XMCD measurement for the FeGd thin films underneath. A magnetic field of 50 Oe was applied during film growth to induce a small inplane uniaxial anisotropy. The Gd content was adjusted by the number of $\mathrm{Gd}$ chips, which were located symmetrically on the surface of a Fe target. ${ }^{24}$ The composition of the films was characterized by energy dispersive x-ray fluorescence spectrometry (EDS), and their structures were investigated by x-ray diffraction (XRD).

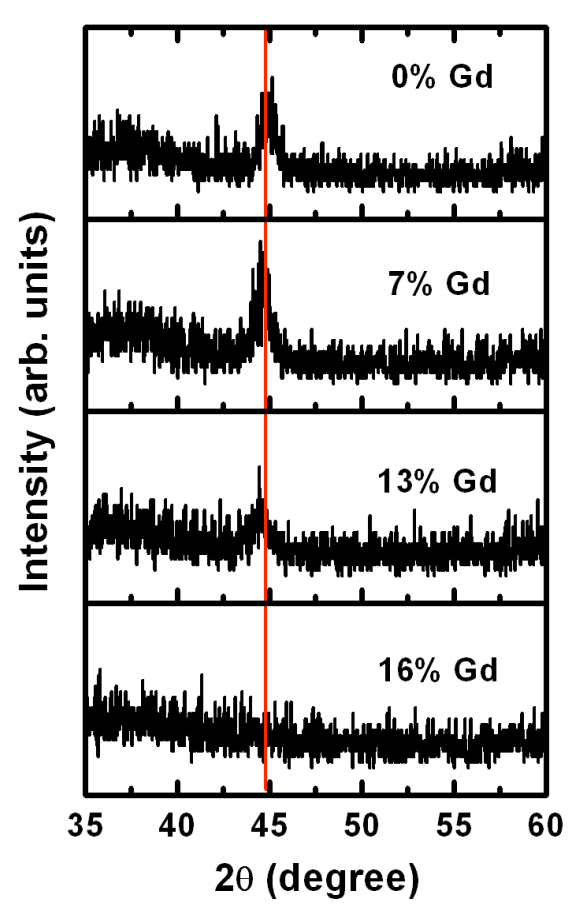

FIG. 6.1: $\mathrm{XRD} \theta-2 \theta$ curves for FeGd thin films with different $\mathrm{Gd}$ contents. 
Figure 6.1 shows the XRD $\theta-2 \theta$ curves of the $\mathrm{Fe}_{1-x} \mathrm{Gd}_{x}$ films with a Gd concentration $x$ of $0-16 \%$. At $x=0$, we see that the pure Fe film exhibits a crystalline (110) orientation at $2 \theta \approx 45^{\circ}$. The intensity of the Fe (110) peak drops clearly when $x$ increases to $13 \%$, and then disappears completely at $x=16 \%$, showing a gradual structural transformation from a polycrystalline to an amorphous state with increasing Gd concentration.

Two more parameters can be obtained from the XRD patterns, i.e., the lattice constant $a$ and the grain size $D$. First, the Fe (110) peak shifts to a smaller angle when $x$ is higher, suggesting an increasing lattice constant $a$ with increasing Gd concentration, the values of which calculated by Bragg's law are shown in Table 6.1. Second, the grain size $D$ can also be evaluated according to the Scherrer's formula ${ }^{25}$, i.e., $D=0.89 \lambda /((\mathrm{FWHM}) \cos \theta)$, where the x-ray wavelength $\lambda=0.1541 \mathrm{~nm}$ and the FWHM is the full width half maximum of the XRD peak. As shown in Table 6.1, $D$ decreases with increasing Gd concentration, the trend of which is similar to the previous work by Mimura, et al. ${ }^{26}$

TABLE 6.1. Lattice constant and grain size vs. Gd contents.

\begin{tabular}{cccc}
\hline \hline$x(a t . \%)$ & 0 & 7 & 13 \\
\hline$a(\AA)$ & 2.86 & 2.87 & 2.88 \\
$D(\mathrm{~nm})$ & 9 & 8 & 7 \\
\hline \hline
\end{tabular}

Based on the above analysis of XRD, we propose a picture of structural transition from low- to high Gd concentration as below: When $x<7 \%$, some Gd atoms have entered the Fe grains while most of them stay at the grain boundaries of $\mathrm{Fe}$, so that the value of $a$ remains similar to that for pure $\mathrm{Fe}$ and the grain size $D$ does not change much; When $x$ reaches $13 \%$, the value of $a$ increases, which may be ascribed to the lattice expansion caused by the large difference between the radius of the $\mathrm{Gd}$ and $\mathrm{Fe}$ atoms. This suggests a possibility of the incorporation of $\mathrm{Gd}$ atoms into Fe lattices by replacing the $\mathrm{Fe}$ atoms, therefore resulting in the breaking of grains, and the film becomes amorphous. 


\subsection{Magnetic characterization}

Temperature-dependent magnetic hysteresis loops were measured by Superconducting Quantum Interference Device (SQUID) in Nanjing University, China, for the samples with a Gd concentration ranging from 0 to $20 \%$. The areas of the samples under measurement are kept almost the same, for the ease of comparison between their magnetization. Figure 6.2 shows the results for three samples displaying different degrees of polycrystallinity versus amorphousness, i.e., $x \approx 8 \%, x \approx 14 \%$ and $x \approx 20 \%$. The coercivity $H_{\mathrm{C}}$ is found to increase with decreasing temperature, and this increase becomes more pronounced with higher Gd concentration; while the net magnetic moment shows relatively small variation with the temperature, as shown in Fig. 6.3.

(a) $8 \%$ Gd

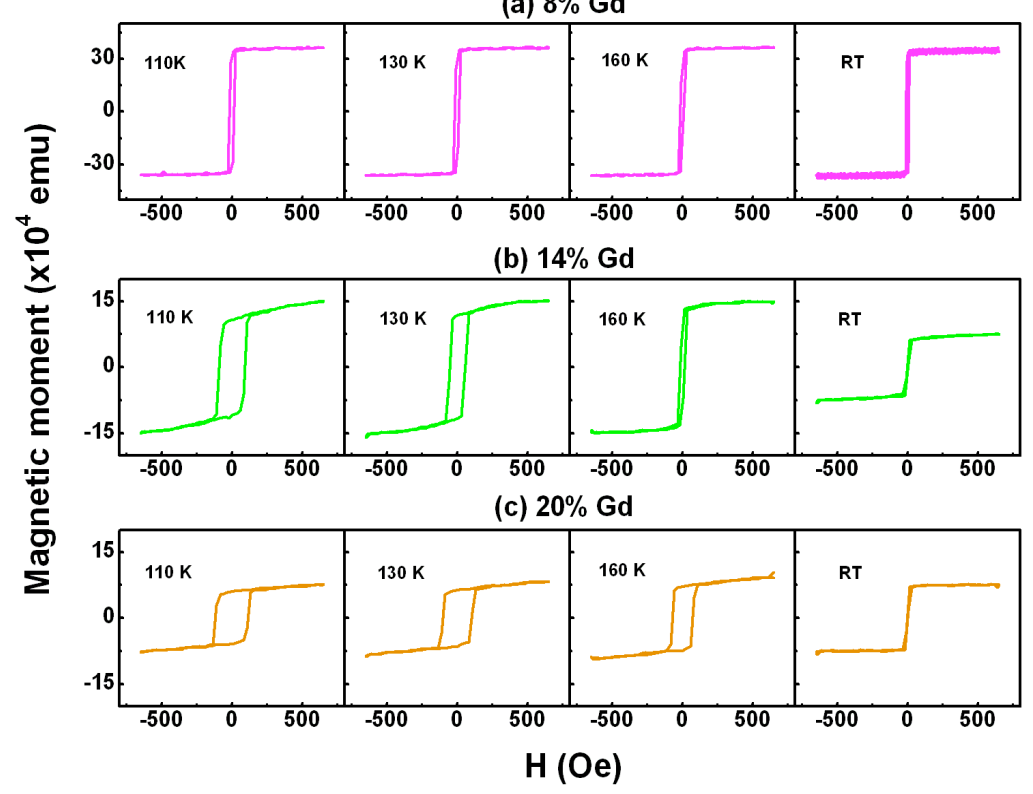

FIG. 6.2: Temperature-dependent magnetic hysteresis loops measured by SQUID. The applied maximum field is \pm 650 Oe.

This kind of coercivity enhancement above the compensation temperature (which represents the point where the magnetizations of the antiferromagnetically coupled TM and RE sublattices are equal 
and cancel each other) ${ }^{29}, T_{\text {comp }}$, has been explained due to the reduced net magnetization with decreasing temperature, where the Zeeman energy is reduced and thus the anisotropy energy wins out. ${ }^{27}$ However, this might not be the case in our samples, since we have shown in Fig. 6.3(b) that the net magnetic moment is not simply reduced upon including more $\mathrm{Gd}$, while it varies little with decreasing temperature. In order to investigate this, we performed temperaturedependent XMCD measurements, which is ideal to obtain microscopic magnetic moments for Fe and Gd and to separate their spin and orbital moments contribution, as discussed in the following sections.
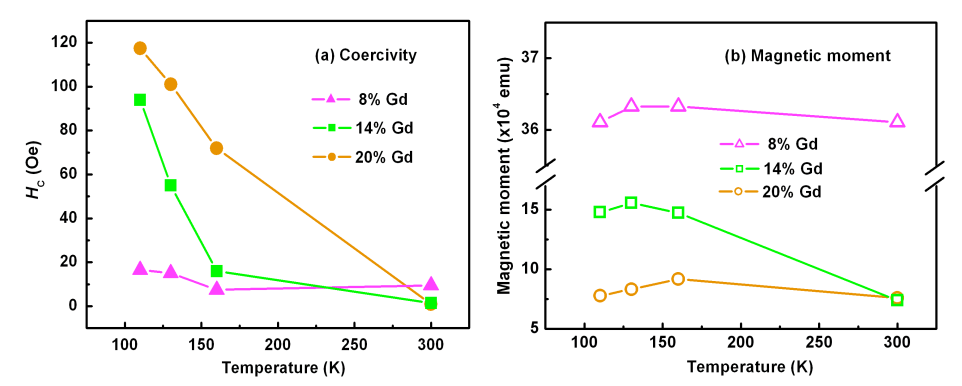

FIG. 6.3: Temperature-dependence of coercivity and saturation magnetization obtained from the SQUID hysteresis loops.

\subsection{XMCD results}

X-ray absorption spectroscopy (XAS) and XMCD spectra were taken at various temperatures in the total electron yield (TEY) mode at beam line I1011 of the MAX-Laboratory in Lund, Sweden. The angle of incidence of the X-ray beam, $\gamma$, was set to $60^{\circ}$ relative to the sample surface normal. XMCD spectra were recorded by reversing the helicity of the circularly polarized X-rays. Element-specific magnetic hysteresis loops were also taken by recording the XMCD signal at $\mathrm{Fe} L_{2,3}$ and $\mathrm{Gd} M_{4,5}$ absorption edges, respectively, as a function of the applied magnetic field, which is parallel to the X-ray beam direction. 


\subsubsection{Element-specific XMCD hysteresis loops}

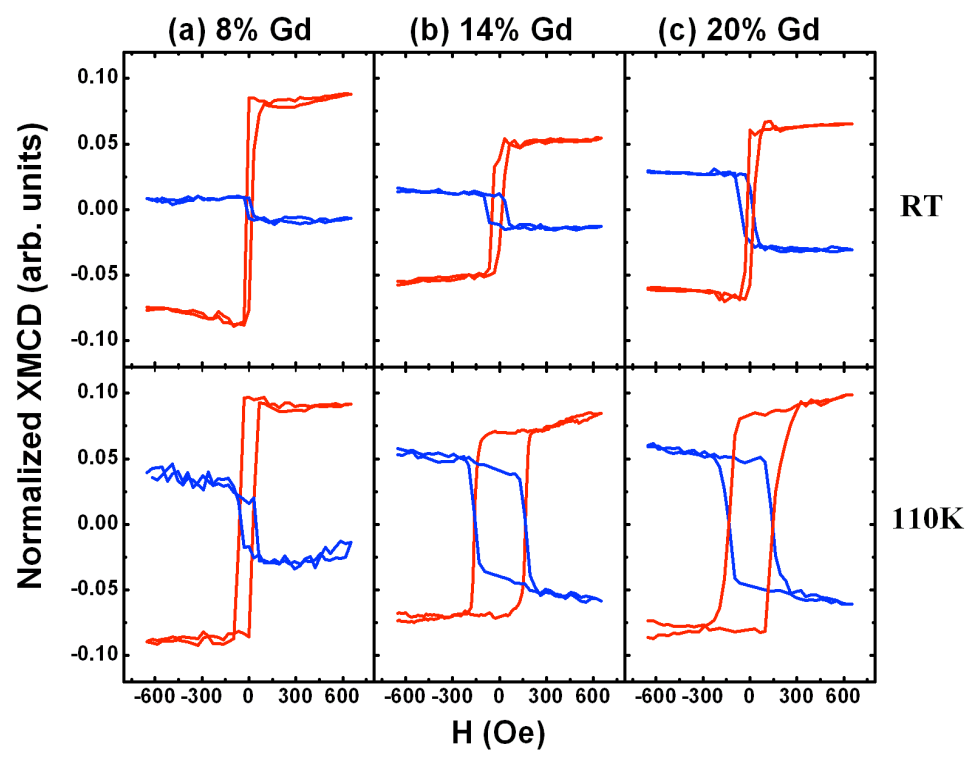

FIG. 6.4: Normalized XMCD hysteresis loops (major loops) taken at RT (top) and $110 \mathrm{~K}$ (bottom), respectively. The applied maximum field is \pm 650 Oe. The red and blue lines represent the $\mathrm{Fe}$ and $\mathrm{Gd}$ loops, respectively.

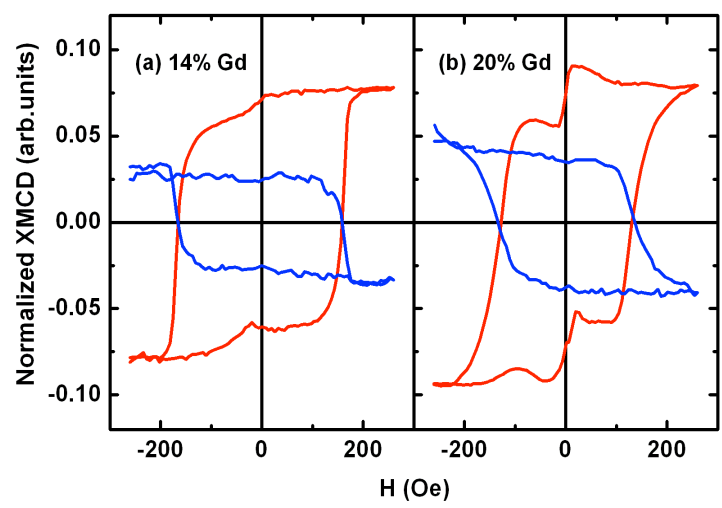

FIG. 6.5: Normalized XMCD hysteresis loops (minor loops) of (a) $\mathrm{Fe}_{86} \mathrm{Gd}_{14}$ and (b) $\mathrm{Fe}_{80} \mathrm{Gd}_{20}$, taken in the field range of $(-250 \mathrm{Oe},+250 \mathrm{Oe})$ at $110 \mathrm{~K}$. The red and blue lines represent the Fe and $\mathrm{Gd}$ loops, respectively. 
Figure 6.4 shows the Fe and Gd hysteresis loops taken in RT, $160 \mathrm{~K}$ and $110 \mathrm{~K}$, respectively, where an antiferromagnetic coupling of the Fe $3 d$ (red) and Gd $4 f$ (blue) magnetic moments is demonstrated. ${ }^{28,29}$ This is in line with the fact that the $4 f$ magnetic moments of the heavy $\mathrm{RE}$ atoms are coupled to the $3 d$ moments of TM via the intra-atomic $5 d$ orbitals, and the resulting effective $4 f-3 d$ exchange coupling is antiferromagnetic leading to an antiparallel alignment of RE $4 f$ moments and the TM $3 d$ moments. Consistent with the results shown in Fig. 6.2, the coercivity of both the Fe and Gd loops in Fig. 6.4 are greatly enlarged when the temperature is decreased to $110 \mathrm{~K}$. This enhancement is particularly significant for $x \approx 14 \%$ and $x \approx 20 \%$.

An interesting phenomenon is that a double-switching behavior appears in the Fe minor loops of the samples with relatively high $\mathrm{Gd}$ concentration, i.e., $\mathrm{Fe}_{86} \mathrm{Gd}_{14}$ and $\mathrm{Fe}_{80} \mathrm{Gd}_{20}$, as shown in Fig. 6.5, which has not been found in their major loops or at RT. It seems that in the minor loops, with small field sweep range, the Fe-system splits into two phases, which rotate with the field quasi-independently, leading to a double-switching behavior as reported on hard/soft magnet exchange-spring systems. ${ }^{30}$ Accordingly, in addition to the presence of $\mathrm{Fe}$ and Gd subnetworks, which have been widely accepted in amorphous FeGd samples, the XMCD Fe-loops suggest that a secondary phase containing $\mathrm{Fe}$ arises in these two samples, which becomes more apparent with higher Gd concentration. Moreover, the magnetic behavior of this secondary phase appears to be temperature dependent, namely, being absent at the RT while active at low temperature.

\subsubsection{Temperature-dependent Fe- and Gd orbital-to-spin moment ratios}

Figure 6.6 shows temperature-dependent XMCD spectra taken at the Fe $L_{2,3}$ edges (a) and $\operatorname{Gd} M_{4,5}$ edges (b), respectively, for the sample $\mathrm{Fe}_{80} \mathrm{Gd}_{20}$, where the most significant $H_{\mathrm{C}}$ enhancement takes place at low temperature. The Fe $L_{3}$ peak is clearly enhanced at $110 \mathrm{~K}$ while the $L_{2}$ peak remains almost the same, suggesting an enhanced orbitalto-spin moment ratio, $m_{L, \mathrm{Fe}} / m_{S, \mathrm{Fe}}$ at low temperature. In addition, by 
comparing the $M_{4,5}$ peaks of the Gd spectra, the Gd orbital-to-spin moment ratio, $m_{L, \mathrm{Gd}} / m_{S, \mathrm{Gd}}$, also shows a modification in $110 \mathrm{~K}$. The quantitative analysis for the Fe and Gd spectra will be shown in the following subsections.

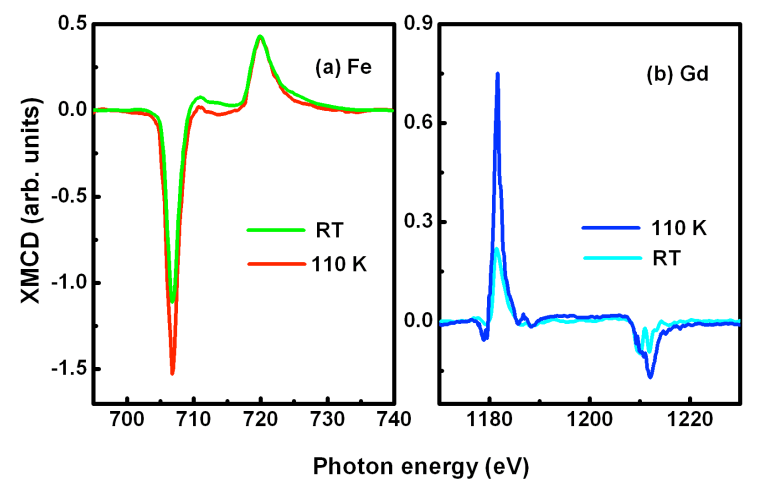

FIG. 6.6: XMCD spectra of $\mathrm{Fe}_{80} \mathrm{Gd}_{20}$ taken at (a) $\mathrm{Fe} L_{2,3}$ edges and (b) $\mathrm{Gd}$ $M_{4,5}$, respectively. The applied maximum field is \pm 650 Oe.

Table 6.2 lists the orbital and spin moments of $\mathrm{Fe}$ and their ratios, extracted from the temperature-dependent Fe XMCD spectra by sum rules when a magnetic field of 650 Oe was applied. The orbital- and spin moments for pure Fe obtained by others are also shown for comparison. From Table 6.2 we see that when the temperature decreases from RT to $160 \mathrm{~K}$, the value of $m_{L, \mathrm{Fe}}$ experiences a drastic increase by $\sim 7$ times, resulting in a strongly enhanced $m_{L, \mathrm{Fe}} / m_{S, \mathrm{Fe}}$ ratio. This suggests a greatly increased spin-orbit coupling and thus magnetic anisotropy, which explains the substantial enhancement in coercivity for $\mathrm{Fe}_{80} \mathrm{Gd}_{20}$ observed at $160 \mathrm{~K}$ in Fig. 6.2. In addition to the enhancement in the orbital moment and the $m_{L, \mathrm{Fe}} / m_{S, \mathrm{Fe}}$ ratio, the $\mathrm{Fe}$ spin moment $m_{S, \mathrm{Fe}}$ shows a pronounced increase by $\sim 58 \%$ at $160 \mathrm{~K}$ as well. Together with the increased $m_{L, \mathrm{Fe}}$, an increased total moment $m_{\mathrm{Fe}}=m_{S, \mathrm{Fe}}+m_{L, \mathrm{Fe}}$ results, which may be related to the arising of the secondary phase proposed in Sec. 6.4.1 and will be further discussed in Sec. 6.4.3. 
TABLE 6.2. Fe orbital and spin moments and their ratios in $\mathrm{Fe}_{80} \mathrm{Gd}_{20}$ thin films

\begin{tabular}{ccccc}
\hline \hline & Temperature & $\begin{array}{c}m_{L, \mathrm{Fe}} \\
\left(\mu_{\mathrm{B}} / \text { atom }\right)\end{array}$ & $\begin{array}{c}m_{S, \mathrm{Fe}} \\
\left(\mu_{\mathrm{B}} / \text { atom }\right)\end{array}$ & $m_{L, \mathrm{Fe}} / m_{S, \mathrm{Fe}}$ \\
\hline $\mathrm{Fe}_{80} \mathrm{Gd}_{20}$ & $110 \mathrm{~K}$ & 0.181 & 1.337 & 0.135 \\
& $160 \mathrm{~K}$ & 0.114 & 1.366 & 0.083 \\
& $\mathrm{RT}$ & 0.014 & 0.865 & 0.016 \\
${\text { pure } \mathrm{Fe}^{31}}^{\mathrm{R}}$ & $\mathrm{RT}$ & 0.086 & 1.98 & 0.043 \\
\hline \hline
\end{tabular}

TEY XMCD has been used previously to confirm the nominal orbital-to-spin moment ratios of $\mathrm{Tb}$ and $\mathrm{Gd}$ dopants using sum rules. $^{32}$ The corrected sum rules for the RE $M_{4,5}$ edges can be written as, $^{33}$

$$
\frac{m_{L, R E}}{m_{S, R E}}=\frac{2 C}{5 \frac{p}{q}-3}\left(1+\frac{6\left\langle T_{z}\right\rangle}{m_{S}}\right),
$$

where $p$ represents the integral over the $M_{5}$ edge and $q$ the integral over both edges. $q$ is directly proportional to $m_{L, \mathrm{RE}}$, whereas the branching ratio $p / q$ can be used to determine $m_{L, \mathrm{RE}} / m_{S, \mathrm{RE}} \cdot{ }^{34} C$ is the correction factor due to $j-j$ mixing, caused by the $3 d-4 f$ Coulomb interaction in the RE which is relatively large compared to the $3 d$ core-level spin-orbit interaction $^{35}$, and $T_{\mathrm{z}}$ is the magnetic dipole term.

Figure 6.7 shows the calculation for the XMCD spectrum of $\mathrm{Gd}$ $f 7$ with $C=0.949$ and $T_{\mathrm{z}}=0$ (in reality, however, the contribution of $T_{\mathrm{z}}$ in RE to the sum rule can be substantial) at absolute zero. The orange line is the integral of the spectrum, where $p$ and $q$ are marked. Assuming that the temperature dependence of the $m_{L, \mathrm{RE}} / m_{S, \mathrm{RE}}$ ratio is much stronger than that of $C$ and $<T_{\mathrm{Z}}>/ m_{S, R E}$ which is confirmed by theoretical calculations ${ }^{36}$, we simply compare the values of $2 C /(5 p / q$ 3 ) as the $m_{L, \mathrm{Gd}} / m_{S, \mathrm{Gd}}$ ratio at different temperatures, by assuming $C=$ 0.949, as shown in Fig. 6.8. The value obtained from the calculated Gd spectrum in Fig. 6.7 is also shown for comparison. The analysis in 
Fig. 6.8 suggests that the value of the $m_{L, \mathrm{Gd}} / m_{S, \mathrm{Gd}}$ ratio is different at different temperatures. Further investigation is required to map out the evolution of the Gd moments with temperature in more detail.

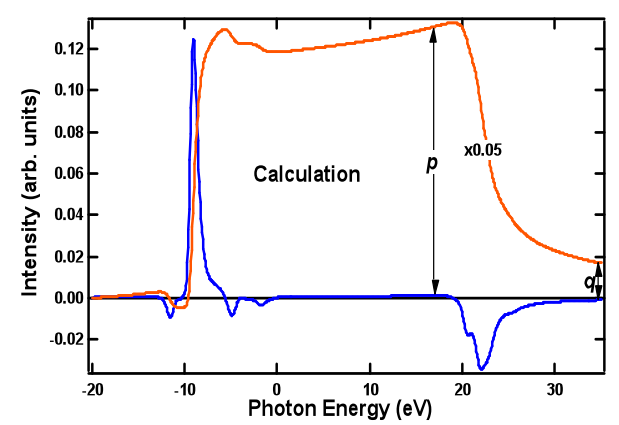

FIG. 6.7: Calculated Gd dichroism at absolute zero using $C=0.949$ and $T_{\mathrm{z}}=0$, and its integral.

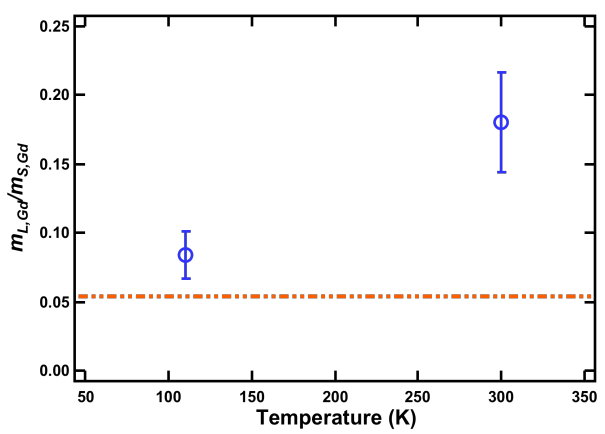

FIG. 6.8: $m_{L, \mathrm{Gd}} / m_{S, \mathrm{Gd}}$ ratio as a function of temperature for $\mathrm{Fe}_{80} \mathrm{Gd}_{20}$, by assuming $C=0.949$ and $T_{\mathrm{z}}=0$. The applied maximum field is \pm 650 Oe. The dashed line represent the value of $m_{L, \mathrm{Gd}} / m_{S, \mathrm{Gd}}$ ratio obtained from the Gd spectrum in Fig. 6.7.

\subsubsection{Fe- and Gd contribution to the macroscopic magnetization}

From the XMCD spectra we can also obtain the microscopic total moment of $\mathrm{Fe}$, which is the sum of the orbital- and spin moments, i.e., $m_{\mathrm{Fe}}=m_{\mathrm{L}, \mathrm{Fe}}+m_{\mathrm{S}, \mathrm{Fe}}$. Comparing them with the macroscopic magnetization obtained from SQUID measurement, we are able to evaluate the $\mathrm{Gd}$ magnetization $M_{\mathrm{Gd}}$ by 


$$
M_{\mathrm{Gd}}=\left[(1-x) M_{\mathrm{Fe}}-M_{\mathrm{tot}}\right] / x,
$$

where the magnetization contribution $M_{\mathrm{Fe}}$ is calculated from the value of $m_{\mathrm{Fe}}$ by assuming that the atomic volume of Fe is $7.1 \mathrm{~cm}^{3} / \mathrm{mol}$. The microscopic Gd magnetic moment $m_{\mathrm{Gd}}$ was then evaluated from $M_{\mathrm{Gd}}$ by assuming that the atomic volume of $\mathrm{Gd}$ is $19.9 \mathrm{~cm}^{3} / \mathrm{mol}$.

As shown in Fig. 6.9, we found that the Gd contribution to the macroscopic magnetization is increasing with decreasing temperature, the trend of which is similar to that of the Fe moment. At $110 \mathrm{~K}$, the $\mathrm{Gd}$ moment even reaches the value for single-ion, which is around $7.6 \mu_{\mathrm{B}}{ }^{36}$ (Note that there would be some error induced from comparing the macroscopic magnetization and the microscopic magnetic moments, which were obtained by two distinctly different methods.)
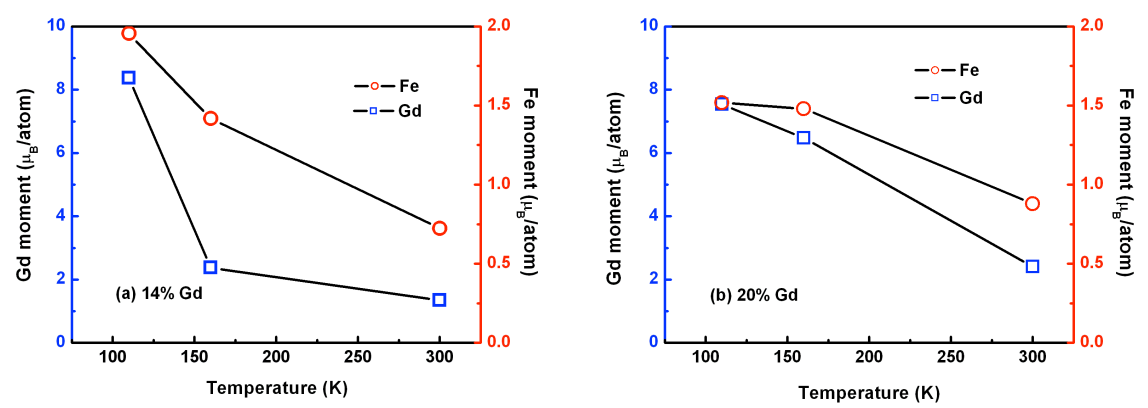

FIG. 6.9: Temperature dependence of microscopic magnetic moment for $\mathrm{Fe}$ and the evaluated Gd magnetic moment from Eq. (6.1), for (a) $\mathrm{Fe}_{86} \mathrm{Gd}_{14}$ and (b) $\mathrm{Fe}_{80} \mathrm{Gd}_{20}$.

Comparing the Fe total moment $m_{\mathrm{Fe}}$ at $\mathrm{RT}$ and $110 \mathrm{~K}$, we found that $m_{\mathrm{Fe}}$ is enhanced by $1.23 \mu_{\mathrm{B}} /$ atom for $\mathrm{Fe}_{86} \mathrm{Gd}_{14}$ and $0.71 \mu_{\mathrm{B}} /$ atom for $\mathrm{Fe}_{80} \mathrm{Gd}_{20}$, respectively, which may originate from the secondary phase suggested in Sec. 6.4.1. Considering that the net Fe moment and the magnetic behavior of the secondary phase are strongly temperature dependent, we propose two possibilities, namely, the appearance of (1) Fe and (2) Gd-Fe clusters (or both), which are expected to be superparamagnetic at the RT due to their small sizes. While when the temperature decreases to a certain value (let us call it 
the "frozen temperature", $T_{F}$ ), these clusters are activated which results in a large increase in both the Fe and the Gd moments, despite that the Gd moment has already been expected to be enhanced at low temperature.
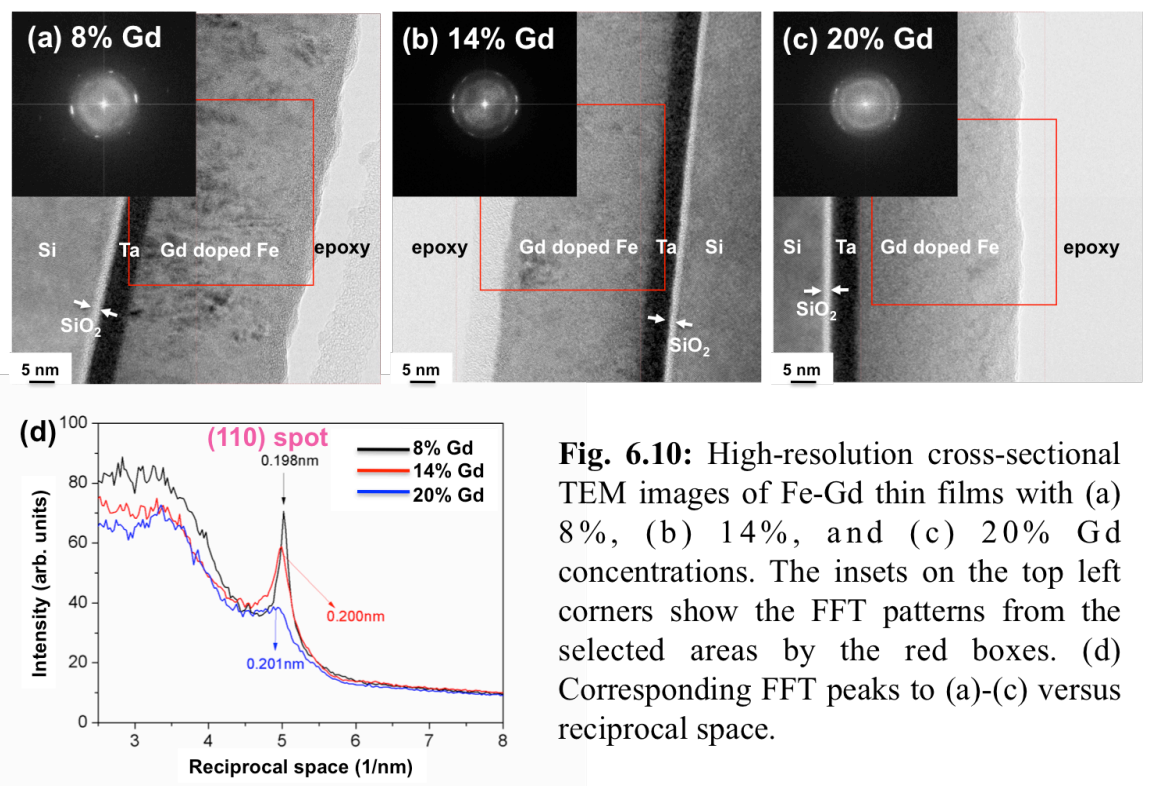

Fig. 6.10: High-resolution cross-sectional TEM images of Fe-Gd thin films with (a) $8 \%$, (b) $14 \%$, and (c) $20 \%$ Gd concentrations. The insets on the top left corners show the FFT patterns from the selected areas by the red boxes. (d) Corresponding FFT peaks to (a)-(c) versus reciprocal space.

The possible appearance of these two kinds of clusters could be rationalized as follows: When $x$ increases, a large amount of $\mathrm{Gd}$ atoms is dissolved into the Fe lattice and replaces the Fe atoms, forming Gd-Fe clusters. The big difference in the $\mathrm{Gd}$ and Fe atomic radius leads to a lattice expansion, subsequently causing a reduction of the pure Fe grain size. Direct evidence for such a lattice expansion is provided by our transmission electron microscopy (TEM) measurements.

High-resolution TEM images are shown in Fig. 6.10(a)-(c), where we see that the long-range ordering in $\mathrm{Fe}_{92} \mathrm{Gd}_{8}$ becomes less when $x$ increases. This is in line with the XRD results, i.e., the film becomes amorphous with increasing Gd concentration. We performed a fast Fourier transformation (FFT) for several randomly selected area indicated by red boxes, as shown in insets at the top left corners 
of Fig. 6.10(a)-(c). The diffraction peaks are shown in Fig. 6.10(d), and correspond to (110) spots of $\alpha$-Fe. It is clear that the diffraction peak is well resolved when $x=8 \%$, and its FWHM increases with increasing $x$, indicating a deterioration of the crystallinity of the thin film. Moreover, the spacing of the (110) plane increases from 0.198 $\mathrm{nm}$ to $0.201 \mathrm{~nm}$ when $x$ increases from $8 \%$ to $20 \%$, demonstrating a lattice expansion after dissolving Gd atoms into the Fe lattice. ${ }^{\dagger}$

It is noteworthy that at $160 \mathrm{~K}$, the $\mathrm{Fe}$ moment shows a great enhancement for both samples, while the Gd moment shows a much smaller increase for $\mathrm{Fe}_{86} \mathrm{Gd}_{14}$ than for $\mathrm{Fe}_{80} \mathrm{Gd}_{20}$. This is consistent with the drastic enhancement of the macroscopic magnetic moment at $160 \mathrm{~K}$ observed in Fig. 6.2(b), while the observation that the coercivity still remains low suggests that this enhancement is due to the activation of $\mathrm{Fe}$ clusters. The reason why this phenomenon appears in $\mathrm{Fe}_{86} \mathrm{Gd}_{14}$ instead of $\mathrm{Fe}_{80} \mathrm{Gd}_{20}$ may be that the Fe clusters have a larger size in $\mathrm{Fe}_{86} \mathrm{Gd}_{14}$ than in the $\mathrm{Fe}_{80} \mathrm{Gd}_{20}$, which is expected to result in a higher $T_{F}$. This evidence gives some support for our proposition about the possibility of the two clusters.

\subsection{Conclusion}

In summary, a secondary phase which is Fe-rich is suggested from our XMCD study combined with SQUID magnetometry measurements, which results in an enhancement in the magnetic anisotropy of the FeGd thin films with in-plane easy magnetization at low temperature for a $\mathrm{Gd}$ doping concentration of no more than $20 \%$. Further supported by the TEM analysis, we have ascribed this strongly temperature-dependent secondary phase - namely, absent at RT while activated at low temperature - to two possible sources: (1) Fe clusters embedded in a Fe-Gd matrix, where the coercivity of the Fe-Gd matrix is enhanced due to its decreased net magnetization while the appearance of superparamagnetic Fe clusters increases the Fe moment and thus the total magnetization at low temperature; (2)

\footnotetext{
${ }^{\dagger}$ Note that the (110) spacing of $\alpha$-Fe is usually $0.203 \mathrm{~nm}^{37}$, and the error here is no more than $2.5 \%$, which is acceptable.
} 
Gd-Fe clusters embedded in the Fe matrix, where the coercivity is enhanced at low temperature due to the highly anisotropic Gd-Fe clusters with the antiferromagnetic coupling between Fe and Gd, and also a larger magnetization than that at RT. 


\section{References}

${ }^{1}$ P. Chaudhari, J. J. Cuomo, R. J. Gambino, Appl. Phys. Lett. 22, 337 (1973).

${ }^{2}$ Y. Mimura, N. Imamura, T. Kobayashi, A. Okada, Y. Kushiro, J. Appl. Phys. 49, 1208 (1978).

${ }^{3}$ T. Chen, D. Cheng, G. B. Charlan, IEEE Trans. Mugn. MAG-16, 1194 (1980).

${ }^{4}$ Y. Togami, IEEE Trans. Magn. MAG-18, 1233 (1982).

${ }^{5}$ G. A. N. Connell, R. Allen, M. Mansuripur, J. Appl. Phys. 53, 7759 (1982).

${ }^{6}$ M. Urner-Wille, P. Hansen, K. Witter, IEEE Trans. Magn. MAG-16, 1188 (1980).

${ }^{7}$ J. M. D. Coey, J. Appl. Phys. 49, 1646 (1978).

${ }^{8}$ C. Chappert, A. Fert, F. N. Van Dau, Nature Mater. 6, 813 (2007).

${ }^{9}$ X. Jiang, R. Wang, et al., Phys. Rev. Lett. 94, 056601 (2005).

${ }^{10}$ G. Meier, et al., Phys. Rev. Lett. 98, 187202 (2007); L. Thomas, et al., Science 315, 1553 (2007).

11 E. G. Spencer, R. C. Le Craw, and A. M. Clogsten, Phys. Rev. Lett. 3, 32 (1959).

${ }^{12}$ M. H. Sirvetz and J. E. Zneimer, J. Appl. Phys. 29, 431 (1958).

${ }^{13}$ A. Rebei and J. Hohlfeld, Phys. Lett. A. 372, 1915 (2008).

${ }^{14}$ D. K. Hairston and M. H. Kryder, J. Appl. Phys. 63, 3621 (1988).

15 T. Yang, T. Matsumoto, H. Yamane, M. Kamiko, and R. Yamamoto, J. Magn. Magn. Mater. 198, 357 (1999).

${ }^{16}$ C. Kaiser, A. F. Panchula, S. S. P. Parkin, Phys. Rev. Lett. 95, 047202 (2005).

${ }^{17}$ Y. Guan, Z. Dios, D. A. Arena, L. Cheng, and W. E. Bailey, J. Appl. Phys. 97, 10A719 (2005).

${ }^{18}$ P. Hansen, C. Clausen, G. Much, M. Rosenkranz, and K. Witter, J. Appl. Phys. 66, 756 (1989).

${ }^{19}$ R. L. Thomas, M. Zhu, C. L. Dennis, V. Misra, and R. D. McMichael, J. Appl. Phys. 110, 033902 (2011). 
${ }^{20}$ S. Lepadatu, et al., Appl. Phys. Express 3, 083002 (2010).

${ }^{21}$ Y. Fu, L. Sun, J. S. Wang, et al., IEEE Trans.Magn. 45, 4004 (2009).

22 S. S. P. Parkin, M. Hayashi, and L. Thomas, Science 320, 190 (2008).

${ }^{23}$ R. Manaila, G. Filoti, et al., J. Magn. Magn. Mater. 86, 280 (1990).

${ }^{24}$ L. Sun, Y. K. Wang, et al., J. Appl. Phys. 111, 07A328 (2012).

${ }^{25}$ P. Scherrer, Göttinger Nachrichten Math. Phys. 2, 98 (1918); U. Holzwarth, N. Gibson, Nature Nanotech. 6, 534 (2011).

${ }^{26}$ Y. Mimura, N. Imamura, T. Kobayashi, et al., J. Appl. Phys. 49, 1208 (1978).

27 S. Demirtas, R. E. Camley, and A. R. Koymen, Appl. Phys. Lett. 87, 202111 (2005).

${ }^{28}$ H. S. Li, and J. M. D. Coey, J. Phys. Condens. Matter. 3, 7277 (1991).

${ }^{29}$ I. Radu, K. Vahaplar, et al., Nature 472, 205 (2011).

${ }^{30}$ A. N. Dobrynin, et al., New J. Phys. 9, 258 (2007); K. Mibu, et al., Phys. Rev. B. 58, 6442 (1998).

${ }^{31}$ C. T. Chen, et al., Phys. Rev. Lett. 75, 152 (1995).

${ }^{32}$ W. Bailey, H. Song, L. Cheng, cond-mat 0403627 (2004).

${ }^{33}$ G. van der Laan and B. T. Thole, Phys. Rev. B. 53, 14458 (1996).

${ }^{34}$ B. T. Thole, P. Carra, F. Sette, and G. van der Laan, Phys. Rev. Lett. 68, 1943 (1992).

${ }^{35}$ G. van der Laan and B. T. Thole, Phys. Rev. Lett. 60, 1977 (1988).

${ }^{36}$ S. S. Dhesi, et al., Phys. Rev. B. 82, 180402 (2010); S. Qiao et al., Phys. Rev. B 70, 134418 (2004).

37 S. Sasaki, K. Nakamura, Y. Hamabe, E. Kurahashi, and T. Hiroi, Nature 410, 555 (2001). 



\section{Summary}

This thesis aims to provide insights into a few challenging problems related to both conventional magnetic materials and new-generation magnetoelectronic devices intended for data storage and processing. The approach taken is mainly experimental, by utilizing the advantages of synchrotron radiation based techniques, which are extremely powerful tools for studying magnetism at the nanoscale. It is expected that these studies, performed predominantly in the area of X-ray magnetic circular dichroism (XMCD) and XMCD in photoemission electron microscopy (XPEEM), will help the further development of materials and devices for data storage and advanced spintronic technologies.

A well-known dilemma in composite CoPt:oxide perpendicular magnetic recording thin films is that, while the desirable inter-grain magnetic decoupling is improved with increasing oxide volume fraction (or decreasing grain size), the magnetic anisotropy is adversely reduced. Revealing the underlying physical mechanism of this quandary is not only of great scientific importance, but could also provide technological benefits, in deciding the optimum oxide percentage (or grain size) in the manufacturing process. In Chapter 3 , we use angle-dependent XMCD to quantify the spin- and orbital moments of $\mathrm{Co}$, which represent the main source of magnetization in $\mathrm{Co}_{80} \mathrm{Pt}_{20}: \mathrm{WO}_{3}$ perpendicular magnetic recording thin films, where the 
magnetocrystalline anisotropy significantly drops as the magnetic grain size decreases. The XMCD analysis shows that the isotropic orbital moment increases with decreasing grain size. This is due to the increasing surface-to-volume ratio of the magnetic grains, resulting in a reduced orbital anisotropy. It is concluded that this is the main cause of the reduced magnetocrystalline anisotropy. This chapter therefore clarifies the microscopic origin of the magnetic anisotropy drop in $\mathrm{Co}_{80} \mathrm{Pt}_{20}$ :oxide thin films, which is instructive for optimizing the size and, more importantly, the surface-to-volume ratio of the magnetic grains.

Since the emergence of spintronics in 1988, novel device functionalities, which were impossible in the past, have become reality. Representative examples are magnetic nano-devices based on the control and manipulation of domain walls (DWs), both magnetically and electrically, utilizing the spin torque effect.

The performance of such DW-based devices depends on a high velocity of the wall motion. However, most observations show that the DW velocity is far below the values predicted by theory. This has been explained by the so-called "Walker breakdown", above which a drastic reduction in the average DW velocity occurs. The underlying cause is a series of cyclic structural transformations of the DW, and consequent oscillations of its instantaneous velocity. In Chapter 4, we report a direct observation by XPEEM of the current-driven oscillatory DW motion above the Walker breakdown in $\mathrm{Ni}_{80} \mathrm{Fe}_{20} / \mathrm{Co}$ nanowires. Such studies have been lacking so far, and important characteristics, such as the oscillation period and amplitude, have remained unclear. Two key factors have been identified that enhance the oscillatory motion: $(i)$ an increase of the hard-axis magnetic anisotropy field value $\left|H_{\downarrow}\right|$; and (ii) an increase of the non-adiabatic spin-transfer parameter $\beta$. The latter is included in the Gilbert damping factor ratio, $\beta / \alpha$, which is required to be larger than 1 . By observing an oscillation period of several tens of nanoseconds and an amplitude of no less than $1 \mu \mathrm{m}$, the present study conveys a perspective of paramount importance for developing new functional DW-based operational devices.

The realization of high performance DW-based devices relies on a small critical current to drive the DW motion. To accomplish this, a material with high spin-polarization at the Fermi energy is preferred. 
$\mathrm{Fe}_{3} \mathrm{O}_{4}$ is one of such promising materials due to its high Curie temperature, strong spin polarization, film stability at ambient conditions, and growth compatibility with semiconductors. In Chapter 5, we have studied single crystal $\mathrm{Fe}_{3} \mathrm{O}_{4}$ thin films grown on $\mathrm{GaAs}(100)$ and $\mathrm{MgO} / \mathrm{GaAs}$, where an intrinsic uniaxial magnetic anisotropy is demonstrated in the film plane, which was not reported by others. By means of ferromagnetic resonance, we have studied quantitatively the evolution of the in-plane magnetic anisotropies in these two kinds of thin films. We found that interfacial chemical bonding plays a dominant role in causing the in-plane uniaxial anisotropy in the $\mathrm{Fe}_{3} \mathrm{O}_{4} / \mathrm{GaAs}$ system, while strain relaxation is most probably the main origin of uniaxial anisotropy in $\mathrm{Fe}_{3} \mathrm{O}_{4} / \mathrm{MgO} / \mathrm{GaAs}$ stacks. A thin film $(6 \mathrm{~nm})$ of $\mathrm{Fe}_{3} \mathrm{O}_{4}$ grown on GaAs, which exhibits only an intrinsic uniaxial magnetic anisotropy, has been patterned into nanowires by focused ion beam milling. In contrast to existing DW-based devices, which employ polycrystalline tracks, our single crystal $\mathrm{Fe}_{3} \mathrm{O}_{4}$ nanowires may supply an additional degree of freedom. The DWs play the role of information bits, while the magnetic domains are formed under the joint effects of shape- and intrinsic magnetocrystalline uniaxial anisotropy of the film. At the same time, a lower critical current density is achievable, due to the high degree of spin polarization in the magnetite-based nanostructures.

The interaction between spin-polarized current and DWs is strongly dependent on material properties such as the damping parameter $\alpha$, the non-adiabatic parameter $\beta$, and current polarization $P$. Rare-earth (RE) doping in transition-metal (TM) ferromagnets is an effective way to enhance $\alpha$. Recently, RE dopants have also been used to alter the spin-transfer velocity and the critical current in permalloy nanowires, due to their effects on $P$ and $\beta$. However, it is noteworthy that a high RE content in RE-TM alloys usually produces strong perpendicular magnetic anisotropy, or makes the alloys magnetically hard with high anisotropy. This is not desirable in DWbased devices, which require in-plane easy magnetization and relatively soft magnetism, to allow for tailoring via shape anisotropy. As a result, the study of appropriate RE dosages that preserve the soft magnetic properties of TMs deserves to be paid attention to. In Chapter 6, we describe a study of the magnetic anisotropy and magnetic moments of a series of binary Fe-Gd thin films with $\mathrm{Gd}$ concentrations of no more than $20 \%$. These films exhibit an in-plane 
uniaxial magnetic anisotropy. Using element-specific XMCD combined with superconducting quantum interference magnetometry measurements, we found that the magnetic anisotropy of these films is strongly enhanced at low temperature. This may have two possible origins as evidenced by transmission electron microscopy. The first is the presence of $\mathrm{Fe}$ clusters embedded in a Fe-Gd matrix. The enhanced coercivity may then be explained by the decreased net magnetization of the Fe-Gd matrix, while the appearance of superparamagnetic Fe clusters increases the Fe moment and thus the total magnetization at low temperature. The second possible origin is Gd-Fe clusters embedded in a Fe matrix, where the coercivity is enhanced at low temperature due to the highly anisotropic Gd-Fe clusters featuring antiferromagnetic coupling between $\mathrm{Fe}$ and $\mathrm{Gd}$. These findings demonstrate the possibilities for engineering magnetic properties by dissolving RE atoms into TM lattices even when the RE doping $\leq 20 \%$. Reports on films with such low RE concentrations are rare, in particular for RE-TM thin films with in-plane anisotropy. 


\section{Samenvatting}

Dit proefschrift heeft tot doel inzicht te geven in een aantal uitdagende problemen gerelateerd aan zowel conventionele magnetische materialen als nieuwe generatie magnetoelektronische devices bedoeld voor dataopslag en -verwerking. Er wordt gebruik gemaakt van een voornamelijk experimentele benadering, waarbij de voordelen van op synchrotronstraling gebaseerde technieken worden benut, die buitengewoon geschikt zijn voor het bestuderen van magnetisme op nanoschaal. Verwacht wordt dat deze studies, met name verricht door middel van X-ray magnetic circular dichroism (XMCD) en photoemission electron microscopy (XPEEM), de verdere ontwikkeling zullen ondersteunen van materialen en devices voor dataopslag en geavanceerde spintronica technologieën.

Een bekend dilemma met betrekking tot dunne film CoPt:oxide composieten voor loodrechte magnetische dataopslag is dat, terwijl de magnetische ontkoppeling tussen korrels wordt verbeterd door toevoeging van een grotere hoeveelheid oxide (wat de korrels kleiner maakt), de magnetische anisotropie hierdoor nadelig wordt beïnvloed. Het onthullen van het fysische mechanisme dat ten grondslag licht aan dit probleem is niet alleen van groot wetenschappelijk belang, maar kan ook technologische voordelen opleveren, door bepaling van het optimale percentage oxide (of 
grootte van de korrels) in het fabricageproces. In Hoofdstuk 3, gebruiken we XMCD om de magnetische spin- en baanmomenten van Co te kwantificeren, die de voornaamste bron van de magnetisatie vormen in $\mathrm{Co}_{80} \mathrm{Pt}_{20}: \mathrm{WO}_{3}$ dunne films voor loodrechte magnetische dataopslag. De magnetokristallijne anisotropie daalt significant wanneer de magnetische korrels kleiner worden. De XMCD analyse laat zien dat het isotrope karakter van het magnetische baanmoment toeneemt met afnemende korrelgrootte. Dit wordt veroorzaakt door de toegenomen oppervlakte tot volume verhouding van de magnetische korrels, hetgeen resulteert in een afname van de anisotropie van het baanmoment. Het kan worden geconcludeerd dat dit de belangrijkste oorzaak is van de afname van de magnetokristallijne anisotropie. Dit hoofdstuk verduidelijkt dus de microscopische oorsprong van de afname van de magnetische anisotropie in CoPt:oxide dunne films, hetgeen nuttig is voor het optimaliseren van de korrelgroote en, belangrijker nog, de oppervlakte tot volume verhouding van de magnetische korrels

Sinds de opkomst van spintronica in 1988 zijn nieuwe functionaliteiten in devices gerealiseerd die voorheen onmogelijk waren. Representatieve voorbeelden zijn magnetische nano-devices gebaseerd op het zowel magnetisch als elektrisch controleren en manipuleren van domeinwanden (DWs), gebruikmakend van het spin torque effect. De prestaties van dergelijke op DWs gebaseerde devices hangen af van een hoge snelheid van de DW beweging. Echter, de meeste observaties laten zien dat de DW snelheid ver beneden de theoretisch voorspelde waarden ligt. Dit kan worden verklaard door de zogenaamde "Walker breakdown", waarboven een drastische afname van de DW snelheid optreedt. De onderliggende oorzaak is een serie van cyclische structurele transformaties van de DW, met oscillaties van de instantane DW snelheid tot gevolg. In Hoofdstuk 4 presenteren we een directe observatie door middel van XPEEM van stroomgedreven oscillerende DW beweging boven de Walker breakdown in $\mathrm{Ni}_{80} \mathrm{Fe}_{20} / \mathrm{Co}$ nanodraden. Zulke studies waren tot dusver niet verricht en belangrijke kenmerken als de oscillatieperiode en -amplitude zijn onderbelicht gebleven. Twee belangrijke factoren zijn geïdentificeerd die de oscillerende beweging versterken: $(i)$ een grotere waarde van het hard-axis magnetische anisotropieveld $\left|H_{\lrcorner}\right|$; en (ii) een toename van de niet-adiabatische 
spin-transfer parameter $\beta$. Deze laatste verschijnt in de Gilbert dempingsfactor $\beta / \alpha$, die groter moet zijn dan 1 . Door middel van de observaties van een oscillatieperiode van enkele tientallen nanoseconden en een amplitude van niet minder dan $1 \mu \mathrm{m}$ laat de huidige studie een zeer belangrijk perspectief zien voor de ontwikkeling van op DWs gebaseerde devices.

De realisatie van DW devices met hoge prestaties hangt af van het kunnen aandrijven van DW beweging met een lage kritische stroom. Om dit te bewerkstelligen, zijn materialen gewenst met een hoge spin polarisatie aan het Fermi niveau. $\mathrm{Fe}_{3} \mathrm{O}_{4}$ is een dergelijk veelbelovend materiaal vanwege de hoge Curie temperatuur, hoge spin polarisatie, stabiliteit van dunne films onder atmosferische omstandigheden en compatibiliteit met halfgeleiders. In Hoofdstuk 5, beschrijven we een studie aan monokristallijne $\mathrm{Fe}_{3} \mathrm{O}_{4}$ dunne films gegroeid op $\mathrm{GaAs}(100)$ en $\mathrm{MgO} / \mathrm{GaAs}$. We demonstreren een nog niet eerder gerapporteerde intrinsieke uniaxiale magnetische anisotropie. De ontwikkeling van de anisotropie in het vlak van deze twee soorten films is kwantitatief bestudeerd door middel van ferromagnetische resonantie. We vonden dat chemische bindingen aan het grensvlak in het $\mathrm{Fe}_{3} \mathrm{O}_{4} / \mathrm{GaAs}$ systeem een dominante rol spelen in de ontwikkeling van uniaxiale anisotropie, terwijl spanningsrelaxatie de meest waarschijnlijke oorzaak is van de uniaxilae anisotropie in $\mathrm{Fe}_{3} \mathrm{O}_{4} / \mathrm{MgO} / \mathrm{GaAs}$ structuren. Uit een dunne film $(6 \mathrm{~nm})$ van $\mathrm{Fe}_{3} \mathrm{O}_{4}$ gegroeid op GaAs, met alleen intrinsieke uniaxiale anisotropie, zijn nanodraden gefabriceerd met behulp van focussed ion beam milling. In tegenstelling tot bestaande op DWs gebaseerde devices, die gebruik maken van polykristallijne sporen, kunnen onze monokristallijne $\mathrm{Fe}_{3} \mathrm{O}_{4}$ nanodraden een extra vrijheidsgraad bieden. De DWs spelen de rol van informatie bits, terwijl de magnetische domeinen gevormd worden onder invloed van de gezamenlijke effecten van vorm- en intrinsieke magnetokristallijne uniaxiale anisotropie van de film. Tegelijkertijd kan een lagere kritische stroom worden bereikt, vanwege de hoge spin polarisatie in de op magnetiet gebaseerde nanostructuren.

De interactie tussen een spin-gepolariseerde stroom en DWs hangt sterk af van materiaaleigenschappen zoals de dempingsparameter $\alpha$, de niet-adiabatische parameter $\beta$, en de polarisatie van de stroom $P$. Het toevoegen van zeldzame 
aardmetalen (rare earth, RE) aan ferromagnetische transitiemetalen (TM) is een effectieve manier om $\alpha$ te vergroten. RE dotering is recentelijk ook gebruikt om de spin transfer snelheid en de kritische stroom in permalloy nanodraden te beïnvloeden, door middel van het effect van REs op $P$ en $\beta$. Echter, het moet worden benadrukt dat een hoge RE concentratie in RE-TM legeringen meestal leidt tot een sterke loodrechte magnetische anisotropie, of de legering magnetisch hard maakt met een hoge anisotropie. Dit is niet wenselijk in op DWs gebaseerde devices, waarvoor anisotropie in het vlak van de film en relatief zacht magnetisch gedrag vereist is om de magnetische eigenschappen te kunnen bepalen via vorm anisotropie. Studies naar geschikte RE concentraties waarvoor de zachtmagnetische eigenschappen behouden blijven verdienen dus aandacht. In Hoofdstuk 6 wordt een studie beschreven naar de magnetische anisotropie en magnetische momenten van een serie binaire Fe-Gd dunne films met Gd concentraties niet hoger dan 20\%. Deze films worden gekenmerkt door uniaxiale anisotropie in het vlak van de film. Door middel van XMCD in combinatie met superconducting quantum interference magnetometry metingen is aangetoond dat de magnetische anisotropie sterk toeneemt bij lage temperatuur. Ondersteund door transmisison electron microscopy metingen wijzen we hiervoor twee mogelijke oorzaken aan. De eerste is de aanwezigheid van Fe clusters in een Fe-Gd matrix. De verhoogde coërciviteit kan dan worden verklaard door de verlaagde netto magnetisatie van de Fe-Gd matrix, terwijl de superparamagnetische Fe clusters bij lage temperatuur bijdragen aan het Fe-moment en dus de totale magnetisatie. De tweede mogelijke oorzaak is Gd-Fe clusters in een Fe matrix, waarbij de coërciviteit bij lage temperatuur wordt verhoogt door de sterk anisotrope Gd-Fe clusters waarin Fe en Gd antiferromagnetische gekoppeld zijn. Deze bevindingen demonstreren de mogelijkheden voor het beïnvloeden van magnetische eigenschappen door het oplossen van RE atomen in TM roosters zelfs bij RE concentraties $\leq 20 \%$. Rapportages omtrent films met dergelijk lage RE concentraties zijn zeldzaam, in het bijzonder voor RE-TM dunne films met anisotropie in het vlak van de film. 


\section{Appendix}

\section{Some detailed sample fabrication recipes}

\section{Wafer Cleaning}

(1) Scribe the substrate into the desired size, e.g. $1.0 \mathrm{~cm} \times 1.0$ $\mathrm{cm}$.

(2) Clean in Acetone for 15 min combined with an ultrasonic buzz.

(3) Rinse in Isopropyl Propan-2-ol (IPA) for 15 min with ultrasonic agitation, and blow dry with $\mathrm{N}_{2}$.

(4) Check the sample surface by optical microscope.

(5) Repeat Step 2-3 if necessary. Note that sometimes cotton tip wiping rinsed by solvents on top of samples can remove large blocks of organic materials (e.g. photoresist) efficiently.

* Solvent treatment with ultrasonic buzz only applies for samples with good layer adhesion or blank wafers. Otherwise films on top of the substrate tend to peel off.

\section{Optical Lithography}

(1) Spin photoresist (S1813) on the sample at $3500 \mathrm{rpm}$ for $40 \mathrm{~s}$.

(2) Bake for $1 \mathrm{~min}$ at $105^{\circ} \mathrm{C}$.

(3) Expose the sample under UV light for $7 \mathrm{~s}$.

(4) Develop in optical developer (MF319) for $1 \mathrm{~min}$.

(5) Rinse in DI water and blow dry with $\mathrm{N}_{2}$.

(6) Optical microscopy to confirm the proper pattern transfer. 



\section{Acknowledgements}

While I was writing this acknowledgement, I found it more difficult than writing the thesis itself. There is always a risk of forgetting someone. During the past few years of my $\mathrm{PhD}, \mathrm{I}$ had the opportunity to meet a lot of wonderful persons to whom I am truly grateful.

First, I would like to thank my promotors, Prof. Wilfred van der Wiel, and Prof. Yongbing $\mathrm{Xu}$, for offering me such a great opportunity to perform the joint research work presented in this thesis. I am very thankful for this offer, and learned a lot from it by looking into the nanomagnetism using synchrotron radiation techniques.

In particular I greatly appreciate my daily supervisor and assistant promotor, Dr. Michel de Jong, for careful check and critical comments, which have helped to improve a lot the quality of this thesis. Thank you very much for your interest in my ideas and strong support in the beamtimes. I wish you a big success in your new project - ORANOS!

I would also like to thank the members of my doctoral graduation committee, Prof. Gerrit van der Laan for numerous valuable discussions (via the quickest response in the world!), Dr. Leon Abelmann and Prof. Henk Swagten for their careful reading and kind suggestions on this thesis, and Prof. Guus Rijnders for making time to evaluate this work

For their help in the experiments at the Advanced Light Source and MAX-lab, I would like to thank Dr. Simon Morton, Dr. Andreas Scholl, Dr. Tony Young, Dr. Elke Arenholz, Dr. Gunnar Öhrwall, 
and Dr. Alexei Preobrajenski.

For their experimental support in Twente, York, and China, I would like to thank Johnny W for Magnetite growth, Lan Anh and Johnny S for assistance in UT clean-room, Kai for help in MAX beamtime, Rico for contributing very nice TEM images, Jialin and Zhaocong for MOKE measurement, Jonathon, Malcolm and Iain for assistance in York clean-room, and Jian Tao for SQUID characterization. Particular thank goes to Prof. Ya Zhai for great support in FMR measurement, and for offering the FeGd samples.

For the opportunity to work in many areas beyond the scope of my $\mathrm{PhD}$, I would like to thank Dr. Bin Lu in Seagate Technologies, Dr. Chris Bonet and Dr. Jing Wu in York Physics, Prof. Ed Boyes in York Nanocenter, Dr. Igor Barsukov and Prof. Michael Farle in Universität Duisburg-Essen.

I would also like to express my deepest gratitude to Prof. Hongru Zhai in Nanjing University, Prof. Xiangrong Wang in Hong Kong University of Science and Technology, Dr. Zhiyang Yu in Lehigh University, Dr. Peng Yan in TU Delft, Yi Liu and Dr. Zhe Yuan in Twente CMS group for numerous valuable discussions.

My time with the NE group at Twente has been very delightful. Within the environment I was involved in some other research areas, and learned many things during the scientific discussions at group meetings and even beyond the research. Thank you all group members for making of the group a friendly and productive work environment, and I wish you all the best.

I want to thank all of my office-mates for the nice atmosphere: Ksenia (I love your color candies), Derya (thank you for your plenty of stationery which I 'stole' sometimes without permission), Saurabh (I know you hate someone who doesn't drink Alcohol), and Serkan (my new office-mate). Also, I would like to thank Robin for thesis proofreading, Zhihua for thesis proofprinting, Tian for kindly providing thesis-related information, Michel $\mathrm{Z}$ and Floris for driving me to/back the FOM meeting, Martin and Filipp for sharing ideas about party places. I also appreciate Bernardus for his interest in my 
work, and am impressed by the friendly smiles of Janine and Jelle whenever I met them.

Two ladies deserve a special mention here: Carolien, our beloved secretary, for taking care of my registration and degree related issues, and for organizing my business trips; Ellen, the Office Foreign Employee of UT, for always timely solving all the problems relevant to my visa issues.

Thanks to my friend Pak Hang Wong for sharing the experience on the thesis writing and processing. Thanks also go to Xuefeng $\mathrm{Hu}$, Xiaoping Zha, Xiao Zou, for their friendship, their encouragement, and their help in York.

My warmest thank goes to my friends of many years: Sherry, Qun, Xiaoxia, Yaqi, Renxue, etc., and in particular Ruoge. We met each other at Southeast University when I was 17 years old. Ten years have passed after the graduation, but I still remember clearly those fresh faces 10 years ago, some of which are really genius. I will treasure our friendship forever the way you treasure it, and wish you all sisters and brothers in our Class 100981 have a good time on June 2,2012 , the $110^{\text {th }}$ anniversary for our university!

This special paragraph is reserved for my 'big' family - my grandparents, my aunties and uncles, my parents-in-law, etc. - for all the support and understanding for me wherever you are in the world. Especially I am greatly indebted to my parents for their unconditional support and endless love (I owe you a 'Happy Silver Wedding', Dad and Mom!), and my brother for his quick responses whenever I need his help during this $\mathrm{PhD}$ (I do appreciate your wedding gift for me, Feiran!). I miss the tender moments when we sat round the table, enjoyed the food, and had a free talk about everything interesting. Thank you for offering me such a relaxing atmosphere, which makes me always feel at ease.

Last but not least, I owe my husband, Johnny Wong, a HUGE thank. As you have mentioned in your thesis, I also 'appreciate you sharing with me the most crucial period in my last year of $\mathrm{PhD}$ and the late nights in the labs'. Yes, our efforts have paid off, and we both 
survived from the $\mathrm{PhD}$ finally! At last and the most importantly, I must show my highly gratitude and respect to your fantastic cooking every day, and I hope I can still keep fit anyway.

\section{Wen Zhang}

Enschede, May 2012 


\section{Author biography}

\section{Wen Zhang}

May 10, 1981 Born in Rugao, Jiangsu, China

Ph.D. Candidate

NanoElectronics Group, MESA+ Institute for Nanotechnology, University of Twente, The Netherlands

Thesis Title: "Synchrotron radiation studies of magnetic materials and devices" Promotors: Prof. dr. ir. Wilfred van der Wiel, Co-promotor: Prof. Yongbing Xu (University of York, UK),

Assistant Promotor: dr. ir. Michel de Jong

2006

Customer Service Engineer

Electronic Products and Solutions Group

Agilent Technologies Co., Ltd.

Shanghai Branch, China

2005

Master of Science in Condensed Matter Physics

Department of Physics, Southeast University, Nanjing, China

Thesis Title: "Study on the mechanism of interfacial exchange coupling in NiFe/FeMn bilayers"

Supervisors: Prof. Ya Zhai and Prof. Hongru Zhai (Nanjing University, China)

2002

Bachelor of Science in Applied Physics

Department of Physics, Southeast University, Nanjing, China

Thesis Title: "Magnetic properties and magnetoresistance of NiFe/FeMn bilayers"

Supervisors: Prof. Ya Zhai and Prof. Hongru Zhai (Nanjing University, China) 



\section{Publications}

Enhanced magnetic anisotropy of FeGd thin films in low temperature

W. Zhang, P.K.J. Wong, K. Wang, Y.K. Wang, Y. Zhai, Y.B. Xu, G. van der Laan, W.G. van der Wiel, and M.P. de Jong

In preparation.

Crystalline CoFeB/graphite interfaces for carbon spintronics fabricated by solid phase epitaxy

P.K.J. Wong, W. Zhang, T.L.A. Tran, A.A. Starikov, J.G.M. Sanderink, M.H. Siekman, G. Brocks, P.J. Kelly, W.G. van der Wiel and M.P. de Jong Submitted.

The relation between the Co orbital moment and magnetocrystalline anisotropy in $\mathrm{Co}_{80} P \mathrm{Pt}_{20}$ :oxide thin films

W. Zhang, S.A. Morton, P.K.J. Wong, B. Lu, Y.B. Xu, M.P. de Jong, W.G. van der Wiel and G. van der Laan

Submitted.

Observation of current-driven oscillatory domain wall motion in $\mathrm{Ni}_{80} \mathrm{Fe}_{20} / \mathrm{Co}$ bilayer nanowire

W. Zhang, P.K.J. Wong, P. Yan, S.A. Morton, X.R. Wang, A. Scholl, A. Young, J. Wu, Y.B. Xu, I. Barsukov, M. Farle, and G. van der Laan Submitted.

Effect of oxygen deficiency on room temperature ferromagnetism in Co doped $\mathrm{ZnO}$ H. Gu, W. Zhang, Y. Jiang, Y. B. Xu, M. Yan Applied Physics Letters, accepted (2012)..

Uniaxial magnetic anisotropy in epitaxial $\mathrm{Fe}_{3} \mathrm{O}_{4}$-based hybrid structures on GaAs(100) W. Zhang, J.Z. Zhang, P.K.J. Wong, Z.C. Huang, L. Sun, J.L. Liao, Y. Zhai, Y.B. Xu and G. van der Laan

Physical Review B 84, 104451 (2011).

Superparamagnetic behavior in ultrathin $\mathrm{Fe} / \mathrm{GaN}(0001)$

P.K.J. Wong, W. Zhang, X.G. Cui, I.G. Will, Y.B. Xu, Z.K. Tao, X. Li, Z.L. Xie and R. Zhang 
Physica Status Solidi A 208, 2348 (2011).

Fabrication and interface electrical properties of $\mathrm{Fe}_{3} \mathrm{O}_{4} / \mathrm{MgO} / \mathrm{GaAs}(100)$ spin contacts P.K.J. Wong, W. Zhang and Y.B. Xu

Physica Status Solidi A 208, 2344 (2011).

Influence of rare earth $\mathrm{Ho}^{3+}$ doping on the structural, microstructure and magnetic properties of $\mathrm{ZnO}$ bulk and thin film systems

G. Murtaza Rai, M. Azhar Iqbal, Y.B. Xu, I.G. Will and W. Zhang

Chinese Journal of Chemical Physics 24 (3), 1 (2011).

Magnetocrystalline anisotropy of magnetic grains in $\mathrm{Co}_{80} P t_{20}$ : oxide thin films probed by $X$-ray magnetic circular dichroism

W. Zhang, S.A. Morton, P.K.J. Wong, X.F. Hu, E. Arenholz, B. Lu, T.Y. Cheng, Y.B. $\mathrm{Xu}$ and $\mathrm{G}$. van der Laan

Journal of Applied Physics 109, 052111 (2011).

Influence of Au capping layer on the magnetic properties of ultrathin epitaxial $\mathrm{Fe}_{3} \mathrm{O}_{4} / \mathrm{GaAs}(001)$ film

E. Liu, J.Z. Zhang, W. Zhang, P.K.J. Wong, L.Y. Lv, Y. Zhai, Y.B. Xu and H.R. Zhai

Journal of Applied Physics 109. 07C121 (2011).

The effect of inter-element dipole coupling in the patterned ultrathin single crystal Fe square arrays

L. Sun, P.K.J. Wong, W. Zhang, X. Zou, L.Q. Luo, Y. Zhai, J. Wu, Y.B. Xu and H.R. Zhai

Journal of Applied Physics 109, 033913 (2011).

Ultrathin $\mathrm{Fe}_{3} \mathrm{O}_{4}$ epitaxial films on wide bandgap GaN(0001)

P.K.J. Wong, W. Zhang, X.G. Cui, J. Wu, Y.B. Xu, Z.K. Tao, X. Li, Z.L. Xie, R. Zhang and G. van der Laan

Physical Review B 81, 035419 (2010).

Magnetic and structural properties of fully epitaxial $\mathrm{Fe}_{3} \mathrm{O}_{4} / \mathrm{MgO} / \mathrm{GaAs}(100)$ for spin injection

P.K.J. Wong, W. Zhang, Y.B. Xu, S. Hassan and S.M. Thompson

IEEE Transactions on Magnetics 44, 2640 (2008).

Influence of capping layers on magnetic anisotropy in Fe/MgO/GaAs(100) ultrathin films

P.K.J. Wong, Y. Fu, W. Zhang, Y. Zhai, Y.B. Xu, Z.C. Huang, Y.X. Xu and H.R. Zhai IEEE Transactions on Magnetics 44, 2907 (2008).

A model of hybrid interfacial domain wall structure in $F / A F$ bilayers

W. Zhang, C. Ni, Y. Zhai, B. You, Y.X. Wang, J. Du, A. Hu, M. Lu and H.R. Zhai

Physica Status Solidi C. 1, 3271 (2004).

The shape anisotropy and non-uniform magnetization excitations in patterned NiFe 
films with submicron sizes

J. Li, Y. Zhai, L. Shi, W. Zhang, D. Zhang, Y. Xu, M. Lu, H.R. Zhai

Journal of Magnetism and Magnetic Materials 272, e1655 (2004).

Evolution of magnetic anisotropy in epitaxial Fe films by ferromagnetic resonance Y. Zhai, L. Shi, W. Zhang, W. Zhang, Y. X. Xu, M. Lu, H.R. Zhai, W.X. Tang, X.F. Jin, Y.B. Xu and J.A.C. Bland

Journal of Applied Physics 93, 7622 (2003).

A study on anisotropy in ultrathin single crystal Fe films in a few monolayer region Y. Zhai, L. Shi, W. Zhang, Y. X. Xu, M. Lu, H.R. Zhai, W.X. Tang, Y.B. Xu and J.A.C. Bland

Modern Physics Letters B 17, 1095 (2003). 
